\title{
GROUP FUNCTIONING IN CHILD CARE CENTERS
}

Mireille Aarts 
This study was in part supported financially by KION Child Care, Nijmegen, The Netherlands, and by Child Care Cooperative Association KINDwijzer, Breda, The Netherlands. Both organizations were not involved in the study design, data collection, analysis, interpretation of the data, or in the writing of this thesis.

ISBN : : 978-94-6233-546-2

Cover design : OptimaForma

(C) 2017 M.C. Aarts

All rights are reserved. No part of this book may be reproduced, distributed, stored in a retrieval system, or transmitted in any form or any means, without prior permission of the author 


\title{
GROUP FUNCTIONING IN CHILD CARE CENTERS
}

\author{
Proefschrift
}

ter verkrijging van de graad van doctor aan de Radboud Universiteit Nijmegen

op gezag van de rector magnificus prof. dr. J.H.J.M. van Krieken, volgens besluit van het college van decanen in het openbaar te verdedigen op maandag 20 maart 2017 om 14.30 uur precies

door

Mireille Caroline Aarts

geboren op 10 maart 1961

te Nijmegen 
Promotor: Prof. dr. J.M.A. Riksen-Walraven

Copromotor: Dr. W.J. Burk

Manuscriptcommissie:

Prof. dr. A.H.N. Cillessen

Prof. dr. R.G. Fukkink (Universiteit van Amsterdam)

Prof. dr. P.P.M. Leseman (Universiteit Utrecht)

Dr. H.J. Vermeer (Universiteit Leiden)

Dr. K.O.W. Helmerhorst (Universiteit van Amsterdam) 


\section{Contents}

$\begin{array}{lll}\text { Chapter } 1 & \text { General introduction } & 7\end{array}$

Chapter 2 Group functioning in child care centers: Conceptualization, measurement, and relation with structural characteristics

Chapter 3 Short-term stability of group functioning in child care centers

Chapter 4 Caregiver and environmental characteristics as predictors of group functioning in child care

Chapter 5 The accuracy of caregivers' identification of peer affiliations in child care groups

Chapter 6 Summary, conclusions, and general discussion

Nederlandse samenvatting (Dutch summary)

References

Dankwoord

Sponsors 

CHAPTER 1

General introduction 

Nowadays, in Western countries, many children attend group based care in a child care center from the first year of life until the time they start formal education. For many of these young children, child care is the first opportunity for interactions with a group of age-mates. While dyadic interactions between young children in child care groups have been studied by many researchers, it is somewhat surprising that research on group functioning in child care centers is lacking until now. This is striking, because at least in the Netherlands where I have been working in child care for the last 25 years, caregivers and pedagogues regard group functioning as a self-evident characteristic of any child care group. Dutch caregivers notice that some child care groups are lively and enthusiastic, while other groups are quiet and reserved. There are groups in which children have many quarrels, requiring frequent monitoring by caregivers. Other groups run smoothly, children enjoy themselves, alone or together with peers. In some groups children pay a lot of attention to each other, and there are groups that feel like 'loose sand'. According to the caregivers, no group is the same; each group has its own 'group functioning'.

I also noticed that caregivers associate 'group functioning' with children's wellbeing and behavior. They report, for instance, that a child who withdraws from peers when there are frequent quarrels in the group, may have more peer interactions when the group is less turbulent. In sum, my experiences with Dutch caregivers and pedagogues indicate that the functioning of a child care group is not only observable, but also relevant. They assume it influences children's experiences, behavior and wellbeing in the group and discuss possibilities to affect group functioning in a positive way.

Triggered by the experiences of caregivers and pedagogues in child care, I decided to learn more about group functioning in child care centers. The major questions in the present thesis were (1) do early child care groups indeed differ on 'group functioning', and (2) is 'group functioning' shaped by characteristics of the child care environment?

\section{Search for Literature on Group Functioning}

The first step was to search for literature on this topic. In Dutch publications, based on qualitative research among expert caregivers and child care pedagogues, group functioning in child care has been described as the group's character (Inhoudelijk begeleidersoverleg Den Haag, 1999), culture (Reijntjes, 2000), atmosphere (Meij \& Schreuder, 2007), the extent to which children experience togetherness (Meij \& Schreuder, 2007; Reijntjes, 2000), the ties between children in the group (Reijntjes, 2000), and the extent to which both children and the caregiver feel comfortable in the group (Balledux, 2001; Hoex \& Schreuder, 1997). Collectively, these publications 
yield a broad, but not a sharp and unequivocal definition of group functioning in child care centers. In international scientific journals, research on preschool classrooms has been reported (e.g. Johnson et al., 1997; La Freniere \& Charlesworth, 1983; La Paro, Pianta, \& Stuhlman, 2004; Martin, Fabes, Hanish, \& Hollenstein, 2005), but these studies concern older children in formal education. In conclusion, no quantitative research on group functioning in child care centers was found. Given the lack of empirical research, I had to start from scratch.

In the remainder of this introductory chapter, I begin with defining the 'child care group' and 'group functioning', referring to the theoretical perspective of Hinde's model of social complexity (1997). Next, I briefly portray the child care context in the Netherlands. Finally, at the end of the introduction, the outline of the empirical studies included in this thesis is presented.

\section{Definition of a Child Care Group in this Thesis}

The first question to be answered was how a child care group is defined. Is the caregiver part of the child care group or not? Given that this thesis was based on the caregiver's perceptions and questions about differences in the functioning between different child care groups, it was self-evident that the child care group should be defined as the peer group, including the children in the group, and not the caregivers. The caregivers' notion that the functioning of child care groups differs from each other indicates that caregivers do not consider themselves as part of the group. In addition, inclusion of the caregiver in the child care group would have complicated the examination of the relation between group functioning and caregiver behavior. As we wanted to provide recommendations for improvement of group functioning, in this thesis the caregiver is not considered part of the group, but part of the direct environment of the group. In conclusion, a child care group is defined here as all children who attend child care together in the same classroom.

\section{Definition of Group Functioning based on Hinde's Theoretical Model}

Our definition of group functioning of a child care group is based on Hinde's well-known model concerning personal relationships (1997). In this model a group is seen as the fifth level of social complexity (see Figure 1). All levels within this model are posited to influence each other in continuous time, so the third, fourth, and sixth levels of social complexity are also elaborated in this thesis. The individual-level processes and behaviors (the first two levels), while important, are not empirically investigated in this thesis. The application of the four upper levels of this theoretical framework to child care groups is elaborated below. 


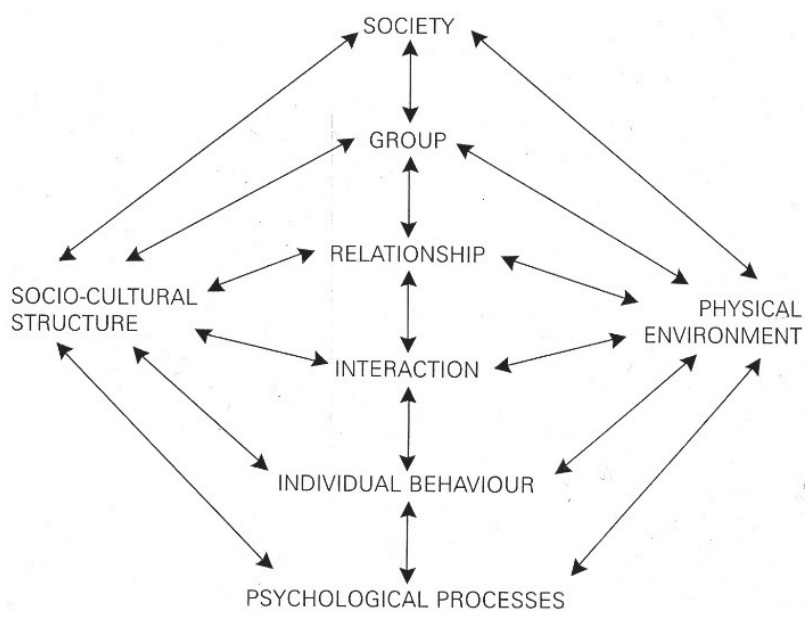

Fig 1. Levels of Social Complexity, Hinde (1997, p.xv).

Interactions between children in the group. The third level in the model concerns the first and most basic interpersonal level, namely relatively shortterm behavioral exchanges between two or more children. From their first year of life on, children are interested in each other (Brooks \& Lewis, 1976; Sanefuji, Ohgami, \& Hashiya, 2006; Zmyj, Daum, Prinz, \& Aschersleben, 2007), and interact with each other. Infants look, laugh, vocalize and touch other children (Markova, 2010; Rayna, 2001; Vandell, Wilson, \& Buchanan, 1980). By the time children are preschoolers, they show (pro)social behaviors (Eisenberg \& Strayer, 1987; Ramsey, 1995; Slomkowski \& Dunn, 1996), like helping and comforting each other, and more complex coordinated behavior, such as joint pretend play (Brenner \& Mueller, 1982; Camaioni, Baumgartner, \& Perucchini, 1991; Eckerman, Davis, \& Didow, 1989; Endedijk et al., 2015; Schaefer, Light, Fabes, Hanish, \& Martin, 2010; Singer $\&$ de Haan, 2007). The content and nature of the interaction is influenced by the individual characteristics of the children concerned, such as their temperament, cognitions, and emotions. An example: two 2-year old boys, Mark and Quincy, who both like rough and tumble play, fight about who can sit on the largest bicycle of the group. They push, pull and hit each other, until eventually Marks wins. The interaction, in turn, affects the emotions and behavior of the children. After the fight of Mark and Quincy, Mark feels triumphant: he has won and is sitting on the large bicycle; Quincy feels frustrated, and may turn to another activity, object or child.

Dyadic peer relationships in the child care group. By interacting regularly with each other, children develop dyadic relationships. This concerns the fourth 
level of Hinde's model. Through regular interactions between two children, these children develop expectations (cognitions) about their interactions and about each other. Mark knows that Quincy, like him, likes rough and tumble play. These expectations are accompanied by emotions and affect behavioral tendencies of the children. Marks feels that he can have fun with Quincy, and he wants to play with him. Quincy feels the same about Mark. Over time, the cognitions, emotions, and behavior of both children become more and more predictable to their interaction partner. A relatively stable pattern develops, typical for the interaction between these two children. Mark and Quincy often seek each other's company for rough and tumble play. Such a pattern of cognitions, emotions, and behavioral tendencies, distinctive for the interactions between two specific individuals, is called a relationship. In turn, the relationship affects the interactions and emotions of the two children. In the child care group, Mark and Quincy are happy, because they have a playmate to have fun with.

Group functioning of a child care group. The next level of social complexity is the group. Dyadic relationships are embedded in a group. Relationships between different group members relate to each other and affect one another. Continuing with the example: Mark not only often plays with Quincy, but also with Anna and Eva, two older girls. In Hinde's terms: Mark has relationships with Quincy, Anna, and Eva. When Anna and Eva include Mark in their play, Mark does not take much notice of Quincy anymore. When Quincy's endeavors to play together are rejected by Mark a couple of times, Quincy adjusts his expectations and emotions about the interaction with Mark ("Sometimes it is fun to play with Mark, but when he is playing with Anna and Eva, he ignores me, which makes me feel sad"). The behavior of Quincy changes accordingly. When Mark does not want to play with Quincy, instead of trying to persuade Mark to play with him, Quincy turns to Steven, another child in the group. Although Steven is 4 months younger than Quincy and is a less challenging play mate as Mark is, Steven turns out to be fun to play with. Consequently, Quincy's relationships with Mark and Steven have changed. Quincy plays with Mark when Mark allows it, but when Mark plays with Anna and Eva, Steven is Quincy's preferred companion. So, analogous to the development of dyadic relationships, in a group of children a relatively stable pattern of interactions, cognitions and emotions develops, organizing the group as a whole. This pattern is - compared to other groups - unique. In the present study we regard this unique pattern as the 'functioning' of this specific group, which affects the dyadic interactions and relationships within the group and the emotional and cognitive processes of individual children. So, group functioning is defined here as a relatively stable pattern of cognitions, emotions, and behavior of the children in 
the group, which develops as a result of interactions and relationships between the children in the group.

Child care groups in the Dutch context. According to Hinde's model (1997), groups and group functioning are influenced not only by internal processes, but also by the broad context of the group, by the society with its socio-cultural structure. Therefore, before giving an outline of the research presented in this thesis, we first provide a brief sketch of the Dutch child care context, as the studies described in this thesis were conducted in child care centers in the Netherlands and the child care situation in the Netherlands differs from the situation in most other western countries. Nowadays $61 \%$ of the Dutch 0 - to 4 -year-old children attend formal child care (OECD 2014). Children can attend child care from the age of 3 months until the age of 4 . The parents' working hours define how many, and on which day(s) their children attend child care. As most mothers (73\%) work on a part-time basis, on average 26 hours per week (Merens, Hartgers et al. 2012), and many parents combine formal care with informal care, for instance by grandparents, most Dutch children attend formal child care one to three days a week. The average formal child care attendance is 19 hours per week, which is among the lowest weekly attendance in western Europe (OECD 2014). As a result, the composition of child care groups varies over the days of the week, and is less stable over time than in most other countries. Consequently, the peer relationships in Dutch child care groups can be expected to be relatively volatile. On the other hand, the large number of potential play-mates offers more opportunities for developing peer relationships. Another characteristic of Dutch child care that might affect the development of peer relationships is the relatively large number of child care groups with a mixed age composition (0-4 year). This decreases the chance that children meet age-mates in a child care group, and potentially restricts the opportunities for children to develop rewarding relationships.

Consequently, with regard to group functioning, the question arises whether Dutch child care groups provide children with enough opportunities for frequent interactions with the same children so that dyadic relationships can develop and a relatively stable pattern of group functioning can emerge. Hay and Ross (1982) and Ross and Lollis (1989) showed that children of almost two years old who play together for only four or eighteen times respectively, still develop a unique and relatively stable interaction pattern, i.e., a relationship. So, although most children in Dutch child care groups see each other only once or twice a week, this low frequency is not expected to be an obstacle to the development of relationships and group functioning. 


\section{Thesis Outline}

The aims of the present thesis were to operationalize and measure group functioning in early child care groups, and to identify contextual factors associated with differences in group functioning. This thesis includes four empirical studies, based on data collected in a sample of one child care group in 46 Dutch child care centers (521 children). In some of these studies a subsample was used. Four types of data were collected: (1) video recordings of the behavior of the children in each group which were used to operationalize group functioning, (2) separate recordings of interactive behavior of caregivers toward the children in the group, (3) in vivo observations of the quality of the child care environment using standardized instruments, and (4) caregiver reports of their own background information, as well as the characteristics and relationships of each child in the group.

The necessary first step in this research project was to develop an instrument to measure group functioning in child care groups. This required a conceptual model of group functioning in groups of children of this young age. The model and the measurement instrument (GFI-CC) that we developed based on the model are described in chapter 2 . This chapter also presents the results of a first empirical study with the GFI-CC in 46 Dutch child care groups in which the reliability and validity of the instrument were tested. This first study also investigated associations between group functioning and structural characteristics of the child care groups, such as group size and constancy.

Group functioning is defined as a relatively stable pattern of a group. The second empirical study, described in chapter 3, therefore tested the stability of group functioning. Group functioning was observed twice, with an intermediate period of two or three weeks, in 36 child care groups.

The third study, presented in chapter 4, addresses the second main aim of the thesis, namely the association of group functioning with characteristics of the direct environment of the child care group, especially caregiver interactive skills, characteristics of the physical environment and the program structure of the child care group.

In the fourth and last study, described in chapter 5, we return to one of the impetuses of the present research, namely the caregivers' perceptions of the relationships between children in their group. It explores the extent to which caregivers have an eye for peer relationships in their own group.

Finally, in the sixth chapter, a summary of the results of the four studies is presented, followed by the main conclusions and general points of discussion of this thesis. 


\section{CHAPTER 2}

\section{Group functioning in child care centers: Conceptualization, measurement, and relation with structural characteristics ${ }^{1}$}




\begin{abstract}
This paper introduces and conceptually underpins an instrument to measure group functioning in child care groups, the Group Functioning Instrument for Child Care (GFI-CC). This instrument was applied in 44 Dutch child care groups (0- to 4-year-olds). The results of this first explorative investigation with the GFI-CC provided initial support for an underlying conceptual model of group functioning in child care centers based on cohesion (network structure, action coordination, and involvement) and emotional climate. The relation between group functioning and structural group characteristics was also examined. Mean age and group continuity (i.e., how long the children have already been attending the group) predicted group functioning, with higher group functioning in groups with older children and in groups with greater continuity. Group size and group constancy (i.e., how many days a week children attend the child care group together) did not independently contribute to the prediction of the group functioning variables.
\end{abstract}




\section{Introduction}

Group functioning is often mentioned as an important characteristic of child care groups by caregivers in child care practice, but empirical research underpinning this is lacking. Until now the functioning of child care groups has mainly been described and examined at the level of dyadic interactions and relationships between individual children (e.g., Fabes, Hanish, \& Martin 2003; Selby \& Bradly, 2003; for an overview see Hay, Caplan, \& Nash, 2009). Yet dyadic interactions and relationships are also embedded in a group context, and the child care group as a whole may have characteristics and effects beyond those at the dyadic level. Given that little is known about the functioning of groups of very young children, more research on this topic is needed.

Starting research on this topic first of all requires a theoretically based instrument to assess group functioning. Until now however, instruments for measuring group functioning in early child care groups are lacking, just as a sharp definition of the concept which should underlie such an instrument. The present paper addresses this gap by introducing and conceptually underpinning an instrument, the Group Functioning Instrument for Child Care (GFI-CC). The conceptual model underlying the GFI-CC will be elaborated in a separate section of this introduction.

This paper also presents the results of a first explorative study applying the instrument to groups of young children in Dutch child care centers. This study provides an initial description of group functioning in child care centers and examines the relation between group functioning and other, more structural characteristics of the child care group, namely age composition, group size, group continuity, and group constancy.

In this study a child care group is defined as all the children who attend child care together in the same classroom. Based on Hinde's seminal model (Hinde, 1997), we define group functioning as a relatively stable pattern of relationships, emotions, and cognitions, which develop as a result of repeated interactions among children in the group. To measure group functioning in early child care groups, we developed an instrument that is based on the two-dimensional conceptual model outlined below.

\section{Two-Dimensional Model of Group Functioning in Child Care Groups}

After reviewing the relevant literature on small group research with adults and school classrooms (Brown, 2000; Levine \& Moreland, 1998; Poole \& Hollingshead, 2005; Tobin, Ritchie, Oakley, Mergard, \& Hudson, 2013), two main dimensions of group functioning seem applicable to characterize the pattern of relationships and 
emotions in groups of very young children: cohesion and emotional climate. In the next paragraphs these dimensions and accompanying constructs, summarized in Table 1, are further elaborated.

Cohesion, the first main dimension of group functioning, has been defined and measured in numerous ways. In small group research with adults and in research with classrooms, cohesion refers to the group members' perceptions, for instance to their sense of belonging to a particular group (e.g., Bollen \& Hoyle, 1990), to their perception of the group as a whole (e.g., Carron et al., 2003; McMahon \& Wernsman, 2009), or to their perception of 'kids in the class who hang together a lot' (e.g., Cairns, Leung, Buchanan, \& Cairns, 1995; Kindermann, 1993). In child care groups, however, cohesion cannot be assessed in terms of these concepts given the young age of the children, which confines measurement possibilities to observations at the behavioral level. We therefore defined cohesion in child care groups as the mutual connection between children in the group, as reflected in their behavior. To do justice to the complex and multidimensional nature of cohesion, we described cohesion in terms of three complementary constructs, namely network structure, action coordination, and involvement (see Table 1).

The first cohesion construct, network structure, refers to the pattern of dyadic relationships between group members. As further elaborated in the method section, dyadic peer relationships are defined here in terms of observed interaction preferences between children, as usual in other studies with very young children (e.g., Howes, 1983; Strayer \& Santos, 1996; Whaley \& Rubenstein, 1994). In the present study the network structure is expressed in terms of three characteristics commonly used to describe social networks, namely density, inclusion, and strength (Wasserman \& Faust, 1994) (see Table 1). Network density describes the relative number of dyadic relationships among group members. Network strength reflects the degree of connectedness among children in the group and is defined as the average number of relationship paths (intermediaries) connecting any two group members. Inclusion refers to the number of children that have at least one relationship with another child in the group.

The two other cohesion constructs, i.e., action coordination and involvement, are analogous to the constructs task cohesion and social cohesion which are regularly distinguished in studies with older children in elementary school (Martin \& Carron, 2012; Rabaglietti, Vacirca, Zucchetti, \& Ciairano, 2012) and in the adult literature (Carless \& De Paola, 2000; Carron et al., 2003; Chang \& Bordia, 2001). Action coordination reflects the extent to which children in the group spontaneously coordinate their behavior with that of one or more other children, focus their behavior on the same theme or object, or show a shared goal or meaning in their behavior (Brenner 
\& Mueller, 1982; Verba, 1994). Examples of action coordination are imitating one another and showing parallel play or complementary behavior like give and take (Camaioni et al., 1991; Eckerman et al., 1989; Ross, 1982).

The degree of involvement among group members is the third cohesion construct. Examples of young children's behavioral expressions of involvement are showing positive interest in each other, seeking proximity with each other, looking and listening to each other (Ishikawa \& Hay, 2006), helping each other and showing affection (Singer \& de Haan, 2007). To summarize, cohesion - the first dimension of group functioning in our model - is described in terms of three constructs: network structure, action coordination, and involvement.

Table 1. Conceptual Model Underlying the Group Functioning Instrument for Child Care

\begin{tabular}{|c|c|c|}
\hline Dimension & Construct & Definition \\
\hline \multirow[t]{6}{*}{ A. Cohesion } & $\begin{array}{l}\text { 1. Network } \\
\text { Structure }\end{array}$ & $\begin{array}{l}\text { The pattern of relationships among children in the } \\
\text { group }\end{array}$ \\
\hline & a. Density & $\begin{array}{l}\text { The relative number of dyadic peer relationships in } \\
\text { the group }\end{array}$ \\
\hline & b. Strength & $\begin{array}{l}\text { The degree of connectedness among children in the } \\
\text { group, reflected in the number of relationship paths } \\
\text { (intermediaries) connecting any two children in the } \\
\text { group. }\end{array}$ \\
\hline & c. Inclusion & $\begin{array}{l}\text { The relative number of children that have at least } \\
\text { one peer relationship in the group }\end{array}$ \\
\hline & $\begin{array}{l}\text { 2. Action } \\
\text { Coordination }\end{array}$ & $\begin{array}{l}\text { The extent to which children in the group } \\
\text { spontaneously and simultaneously coordinate their } \\
\text { behavior with that of other children, or focus their } \\
\text { behavior on the same theme, goal, or object }\end{array}$ \\
\hline & 3. Involvement & $\begin{array}{l}\text { The extent to which children in the group show } \\
\text { positive attention, care, and affection toward each } \\
\text { other }\end{array}$ \\
\hline $\begin{array}{l}\text { B. Emotional } \\
\text { Climate }\end{array}$ & & $\begin{array}{l}\text { The most predominant affective tone and energy } \\
\text { level of children's behavior in the group }\end{array}$ \\
\hline
\end{tabular}

Emotional climate is the second broad dimension of group functioning in our model (see Table 1). Like cohesion, emotional climate has been defined in different ways, depending on the research field. In small group research, for instance, emotional climate refers to shared perceptions about collective emotions (e.g., Liu, Härtel, \& Sun, 2014) or about the feelings of most of the group members in the 
group (e.g., Yurtsever \& de Rivera, 2010). Within classrooms, emotional climate is often described in behavioral terms, namely the extent to which teachers are observed to provide emotionally supportive and responsive instructions (La Paro et al., 2004; Li Grining et al., 2010), and the affective tone of the interactions among teachers and students in the classroom (e.g., Avant, Gazelle, \& Faldowski, 2011; La Paro, Williamson, \& Hatfield, 2014; Roorbach Jamison, Cabell, LoCasale-Crouch, Hamre, \& Pianta, 2014). In the present study, where the teacher is not included in the definition of a child care group, emotional climate is defined as the affective atmosphere in the group as reflected in the predominant affective tone of the behavior of children in the group. In groups with a positive emotional climate, interactions are characterized by enthusiasm, playfulness, fun, and laughter (Gazelle, 2006; Rimm-Kaufman, La Paro, Downer, \& Pianta, 2005); and in groups with a negative climate the interactions are characterized by anger, hostility, aggression, and harshness (Gazelle, 2006; Pianta, La Paro, Payne, Cox, \& Bradley, 2002) or by tension, anxiety, and distress (DeRosier, Cillessen, Coie, \& Dodge, 1994).

\section{Aims and hypotheses}

Based on the two-dimensional model of group functioning described above, we developed the Group Functioning Instrument for Child Care (GFI-CC), which is described in the Method section. In the empirical study that is reported in the next part of this paper, we applied the GFI-CC to a sample of care groups in Dutch child care centers.

The study had two aims. The first aim was to examine the extent to which the observed data support the conceptual model. This was accomplished by inspecting the correlations among all group functioning measures. It was expected that the three cohesion measures, network structure (density, inclusion, and strength), action coordination, and involvement would be moderately intercorrelated (Wasserman \& Faust, 1994). It was also expected that these measures of cohesion would be positively associated with emotional climate (Barsade, 2002; George, 1990; Howes, 2000).

The second aim was to examine how group functioning is related to a number of theoretically relevant 'structural' characteristics of the child care groups. The first structural group characteristic examined was age composition. As older children have more sophisticated social skills, enabling them to develop more and more complex peer relationships, we expected groups with older children to score higher on measures of cohesion. Furthermore, we expected group size, group continuity (how long the children in the group have already been attending this group), and group constancy (how many days a week children attend the child care group 
together), to be related with group functioning. These three group characteristics affect the opportunities for children in the group to become familiar which each other and consequently the development of peer relationships in the group. We expected higher group functioning scores to be associated with smaller group size, greater group continuity, and greater group constancy.

\section{Method}

\section{Participating Groups}

A total of 160 Dutch child care centers were asked to cooperate in this study. In each center one group could participate. Participation criteria were the presence of at least eight children on the observation day and the written permission for the video recording of all the children's parents and the caregivers of the group. Fifty-three centers (33\%) agreed to cooperate, with high work pressure as the most commonly mentioned reason to refuse participation. Eight groups did not meet all participation criteria. Because the sample eventually contained only one toddler group (1-2 yr), we excluded this group from the statistical analyses. The final sample consisted of 44 groups: 30 mixed age (0-4 yr) and 14 preschool (2-4 yr) groups. In these groups a total of 521 children were observed (mean age 30.3 months, $47 \%$ girls), who attended their child care group on average 2.5 days a week.

\section{Procedure}

Each group was visited by the first author for an entire day (from 9:00 a.m. until 5:00 p.m.). The caregivers were asked to keep their usual daily schedule. At the beginning and halfway through the observation day, the visiting researcher recorded the number and names of children present. Caregivers were asked to fill in a form with characteristics of children present during the observation: name, age, and the period and days of the week the child attended the targeted child care group.

The children present in the classroom during at least 4 hours during the observation day were regarded as 'the group'. All scores on the group functioning variables were derived from video recordings of the group.

Below the filming procedure and the coding procedure and measures are elaborated. Decisions concerning these procedures were based on a pilot study involving observations in 20 child care groups, each lasting an entire child care day. In the first 8 groups the observations were written down on paper, in the remaining 12 groups video recordings were made. Based on these preliminary observations decisions were made regarding the duration and the number of video-episodes that could 
be filmed on a child care day. Because it was noticed that often part of the children in the child care group were not present in the classroom, for instance because they were taking a nap, we also decided on the minimal number of children that should be present for the filming to take place. Furthermore, the pilot-observations provided material for the description of the children's behavior in the rating scales for action coordination, involvement, and emotional climate (see below).

\section{Filming procedure.}

Criteria for where, when, and what to film. The children in the group were filmed inside, during free play and waiting situations. Free play is play during which children can choose what, where and with whom they play. Waiting situations are transitional situations, in which caregivers are busy with organizational tasks like setting the table. Both kinds of situations typically provoke spontaneous interaction among peers. Because we not only wanted to film who interacted with whom (the network structure), but also the content of these peer interactions (for rating action coordination and involvement), we used a handheld video camera that offers the possibility to respond to situations in the group in a flexible way and to film the children close-by.

The filming took place when at least five children were present in the classroom. An exception was made for situations after lunch, when three children present was the minimum. After lunch most children in the group take a nap, but often the babies are awake, which provided opportunities to film situations in which babies were visible and accessible to other children.

Every three minutes all children present in the classroom were filmed in random order. Each child was filmed long enough to get an impression of what he or she was doing and with whom. Depending on the number of children involved and the complexity of the situation this ranged from approximately 15 to $90 \mathrm{sec}$;; for example, a situation in which a child is playing alone in the corner of the room, or is sitting in a chair at the table looking at the caregiver, is less complex and takes less time to observe than three children doing a role-play. When the group of children was divided across several rooms (e.g., some children played for half an hour in the hall, while the other children stayed in the classroom), the two subgroups were filmed alternately. Situations in which (part of) the group played with children of other groups were not filmed.

Duration of filming. Each group of children was filmed as often and as long as possible, but in total at least during 72 minutes. This time span seemed sufficient to get an impression of daily group functioning and appeared attainable, based on the earlier described pilot study. 
Preparation for scoring. For observation of the group functioning, the video recordings were divided into 3-minute intervals. The pilot-observations showed that this interval was long enough to get an impression of group functioning, both during free play and waiting situations. For the description of group functioning in a child care group we aimed to obtain in total 24 intervals per observation day: 18 'free play' intervals and 6 'waiting' intervals. Per group we included at the most four intervals in which less than five children were filmed. For 21 groups we succeeded in obtaining the full 24 intervals. There were three groups where 23 intervals were obtained, twelve groups with 22 intervals, three with 21 intervals and six groups with 15 to 20 intervals. The missing intervals concerned both free play and waiting situations. The most common reason for not obtaining 24 intervals was that children were playing outside most of the time because of nice weather, while they should be filmed only inside. Groups where 24 intervals were filmed did not significantly differ from groups with fewer intervals on any of the study variables, except for the mean score on action coordination, which was significantly higher in groups with 24 intervals $(M=3.00, S D=.51)$ than in groups with fewer intervals $(M=2.67, S D=.52), t(42)=2.12, p=.04$.

\section{Coding procedure and measures.}

Two observational coding systems were created to code the videotapes. Time sampling was used to assess the network structure. Action coordination, involvement and emotional climate were measured using rating scales. Table 2 provides an overview of the coding systems and scoring of the group functioning measures.

Network structure. Measurement of the network structure was based on the total number of observed peer interactions between all possible dyads across all 3-minute intervals of each group (time sampling). An interaction was defined as an exchange of mutual or complementary verbal or non-verbal behavior of two children. For each dyad, we coded whether or not an interaction occurred during each interval; if an interaction continued into the next interval, it was coded as an occurrence in that interval too. Videos of the observed interactions for 10 groups (590 interactions) were initially scored by the first author and a trained research assistant. Inter-rater reliability was assessed with an intraclass correlation (ICC) which indicated almost perfect agreement (.97). The research assistant coded the interaction matrices for the remaining groups.

The time-sampling coding scheme resulted in the identification of a total of 3922 interactions observed between children during all intervals, ranging from 0 to 21 interactions per dyad. The number of interactions in each dyad was then converted into a dichotomous relationship measure $(0=$ absence of relationship 


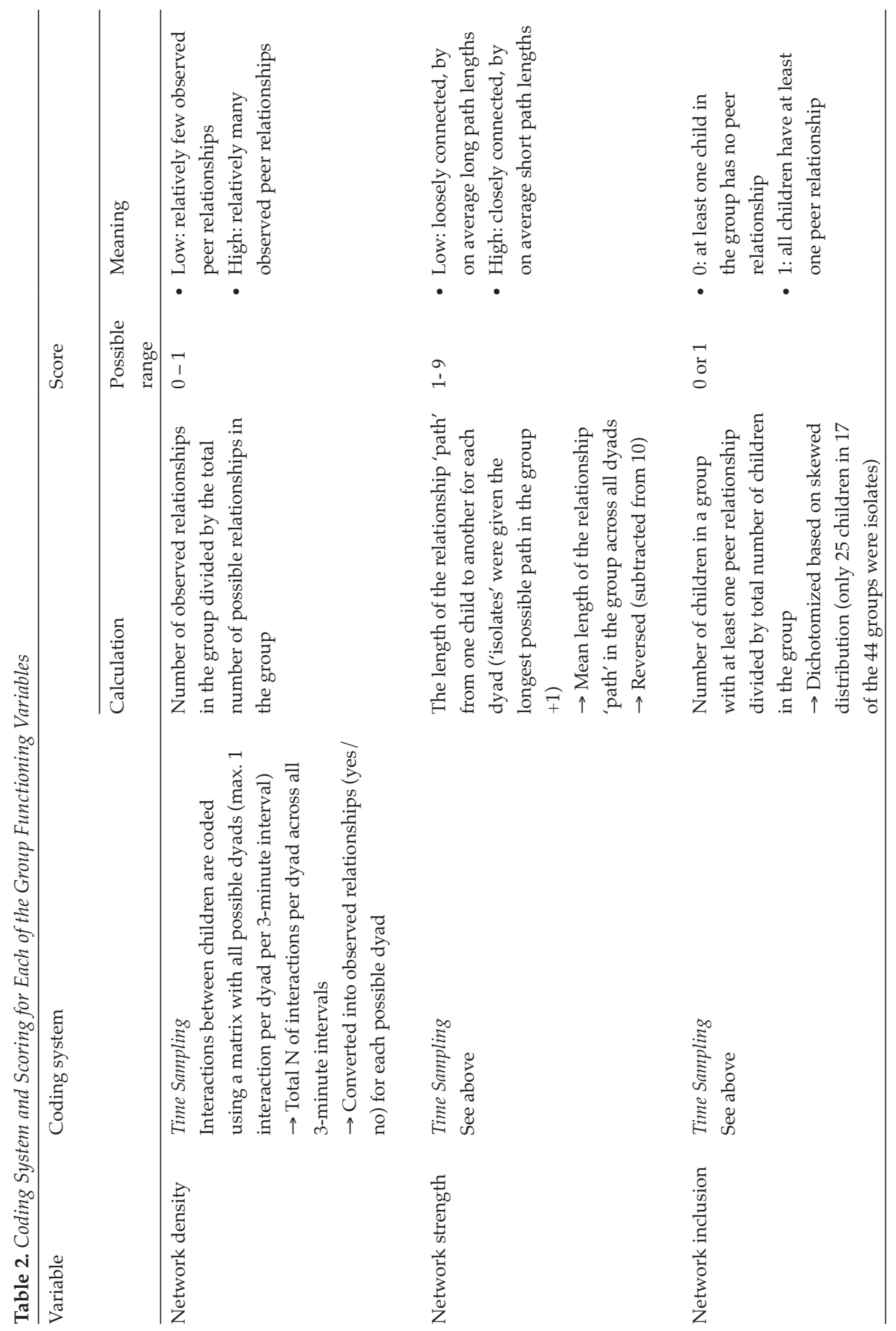




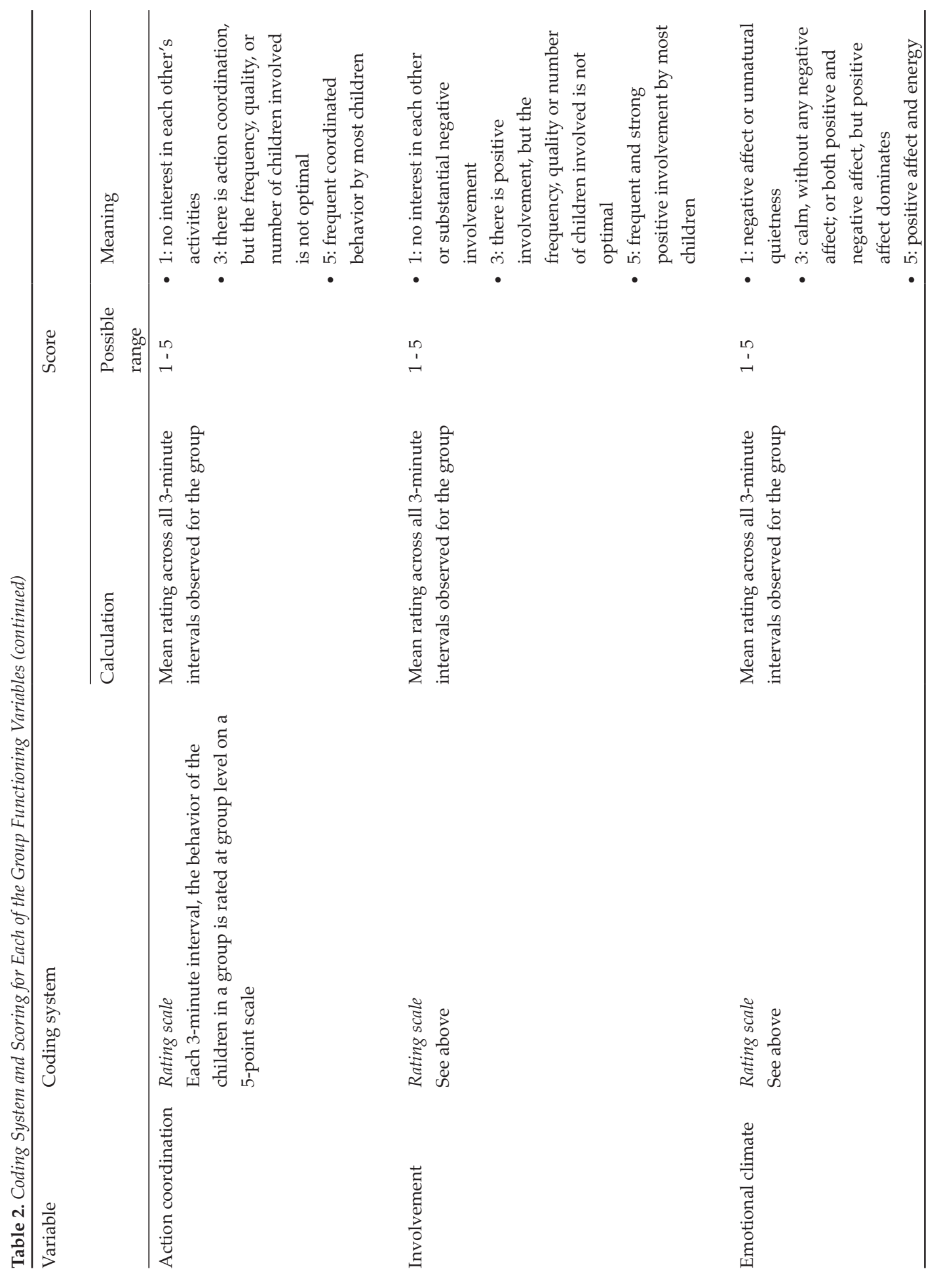


and 1 = relationship). In order to distinguish interactions between relationship partners and interactions that could be attributed to chance, a relationship was inferred when the number of observed interactions within a dyad was greater than expected by chance, in other words if the number of interactions child A had with child $\mathrm{B}$ divided by the total number of interactions of child A with group members was greater than one divided by the number of children in the group minus one (Schaefer et al., 2010). A total of 1111 relationships were identified, on average 25.3 relationships per group. These relationships form the basis for the calculation of the three network structure measures (density, strength, and inclusion; see Table 2). Together, these three measures reflect different patterns of relationships in a group. This is illustrated in Figure 1, which presents four sociograms of groups that differed in terms of network density and strength.

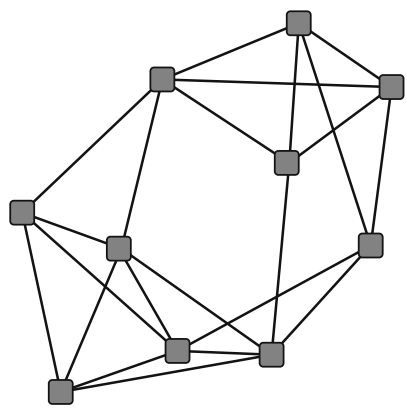

G21: Dense and Strong

Density .40; Strength 8.17

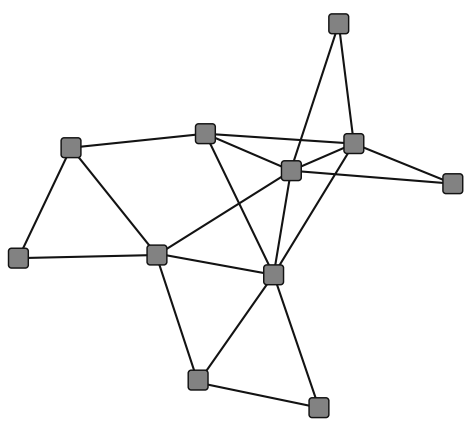

G27: Sparse and Strong

Density .27; Strength 6.87

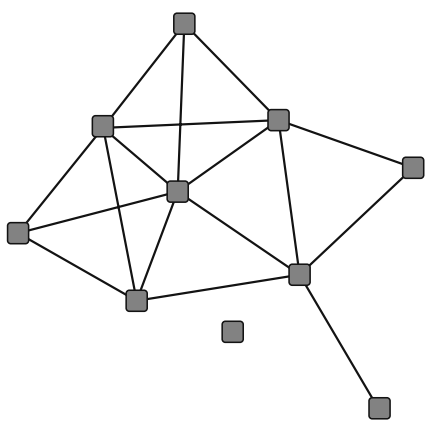

G34: Dense and Weak

Density .32; Strength 5.23

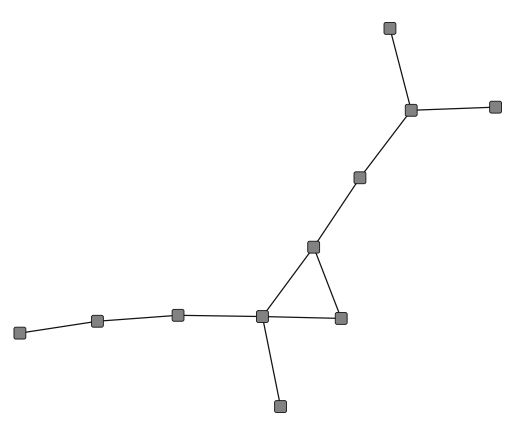

G37: Sparse and Weak

Density .14; Strength 1.09

Figure 1 Sociograms of Four Child Center Groups Differing as a Function of Network Density and Network Strength 
Action coordination, involvement and emotional climate. The second coding scheme involved ratings of action coordination, involvement and emotional climate in the group. Each of these constructs was rated on a 5-point Likert scale (see Table 2). Each rating scale included a definition of the construct and an extensive description of the relevant behavior. Detailed behavioral descriptions were given for each separate scale score, including examples. The scale descriptions were based on the pilot observations. The first author and a trained research assistant, who was blind to the network structure scores and other data, independently rated the children's behavior in each group on the three scales for each of the 3-minute intervals. The ICC (two way absolute agreement single measures) based on 214 3 -minute intervals (10 groups) was .63, .53, and .65, respectively, for action coordination, involvement, and emotional climate, which is regarded as a moderate degree of inter-rater reliability (Landis \& Koch, 1977). The internal consistency of the scales across the 24 3-minute intervals was good, namely .86 for action coordination, .90 for involvement, and .82 for emotional climate. When computed across 15 intervals, which was the lowest number of intervals observed in a group in the present study, the internal consistency was still sufficient, namely $.85, .78$, and .74, respectively.

Structural group characteristics. Age composition of a group was based on the caregiver's information and defined as the mean age of the children present in the group. Group size was defined as the largest number of children that was present in the group at the same time during the observation day, as recorded by the researcher who visited the group. Group continuity was defined as the proportion of children present in the group who had been attending the group for six months or longer, based on the caregiver's information. Group constancy was defined as the proportion of days per week on which children in the group attended the group together (see Pennings \& Meij, 2012).

\section{Results}

\section{Descriptive Statistics and Correlations Among Group Functioning Variables}

Table 3 presents the means and standard deviations for the six group functioning variables. All group functioning variables were normally distributed, except for inclusion (which was dichotomized). As also shown in Table 3, the three network structure variables density, strength, and inclusion were moderately and significantly interrelated ( $r$ s between .50 and .75). Action coordination and involvement were highly correlated $(r=.90)$. Both were significantly and moderately correlated 


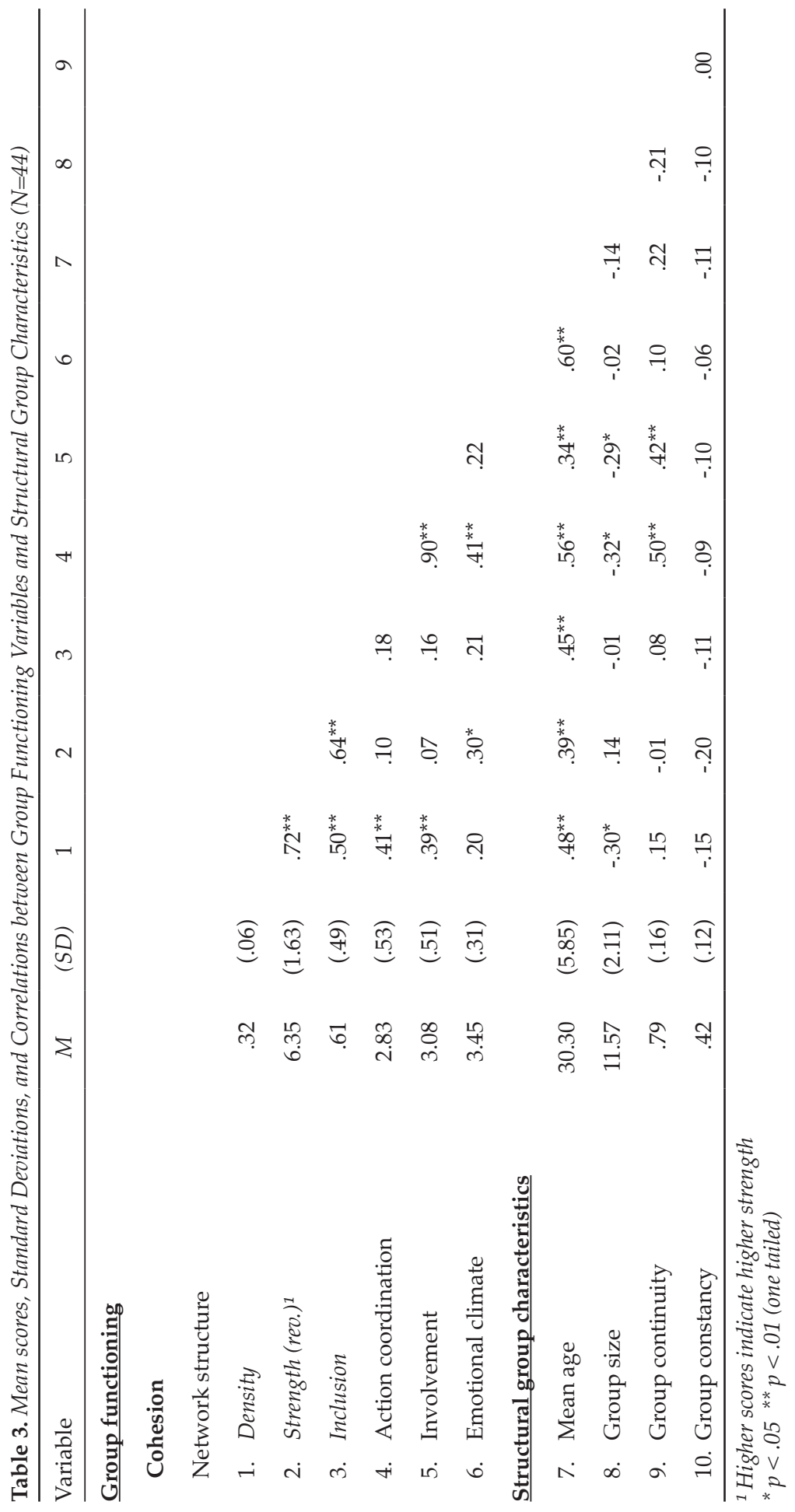


with network density ( $r=.41$ and .39 , respectively), but were uncorrelated with the network strength and inclusion ( $r$ s between .10 and .18). Emotional climate was moderately associated with all five cohesion measures, although the magnitude of these associations only reached statistical significance for network strength and action coordination ( $r=.30$ and .41 , respectively) and not for density, inclusion, and involvement ( $r=.20, .21$ and .22 , respectively). To summarize, returning to the first aim of this study: the correlations among the group functioning measures were generally consistent with our conceptual model (see Table 1). Exceptions to this pattern involved the lack of association between two of the network structure measures (strength and inclusion) on the one hand, and the very strong association between action coordination and involvement on the other.

\section{Group Functioning in Relation to Structural Group Characteristics}

The second aim of this study was to examine the relation between group functioning and structural group characteristics (age composition, size, constancy, and continuity). The means and standard deviations of these characteristics are presented in Table 3. The measures were normally distributed, except for group continuity, which was negatively skewed and positively kurtosed. As can be seen in Table 3, the bivariate associations between group functioning measures and structural group characteristics varied substantially. Compared to the other structural variables, mean age had the strongest association with group functioning. As expected, groups with older children were denser, stronger, more inclusive, and exhibited more action coordination, more involvement, and a more positive emotional climate than groups with a lower mean age. Group size was significantly and negatively related to density, action coordination, and involvement, with larger group sizes being related to lower density, less action coordination, and less involvement. Group continuity was significantly associated with action coordination and involvement, indicating that groups having a higher proportion of children attending the group for more than six months exhibiting more coordinated action and involvement. Group constancy was not associated with any of the group functioning measures.

To explore the relative contribution of the structural group characteristics to the prediction of group functioning, five multiple linear regression analyses were conducted, one for each of the separate group functioning measures, except for the dichotomous variable inclusion, for which a logistic regression was used. The regression results are summarized in Table 4. Collectively, the structural group characteristics predicted a statistically significant amount of variance on all of the group functioning variables. Mean age was a significant predictor of all group functioning measures except for involvement. Group continuity contributed sig- 
nificantly to the prediction of action coordination and involvement. Group size and group constancy did not independently contribute to the prediction of any of the group functioning variables.

Table 4. Multiple Regression Outcomes for the Prediction of Group Functioning Variables from Structural Group Characteristics $(N=44)$ and Logistic Regression Outcomes Used for the Prediction of the Dichotomous Variable Inclusion

\begin{tabular}{|c|c|c|c|c|c|c|c|}
\hline \multirow[t]{2}{*}{ Dependent variable } & \multirow[t]{2}{*}{ Predictor } & \multirow[t]{2}{*}{ B } & \multirow[t]{2}{*}{ se } & \multirow[t]{2}{*}{$\beta$} & \multirow[t]{2}{*}{$p$} & \multicolumn{2}{|c|}{ Model summary } \\
\hline & & & & & & $\mathrm{R}^{2}$ & $p$ \\
\hline \multirow[t]{4}{*}{ Density } & Mean age & .01 & .00 & .43 & .01 & .30 & .01 \\
\hline & Group size & -.01 & .00 & -.25 & .08 & & \\
\hline & Group continuity & .00 & .06 & .00 & .99 & & \\
\hline & Group constancy & -.00 & .00 & -.13 & .37 & & \\
\hline \multirow[t]{4}{*}{ Strength (rev.) ${ }^{1}$} & Mean age & .12 & .04 & .41 & .01 & .21 & .05 \\
\hline & Group size & .13 & .11 & .17 & .26 & & \\
\hline & Group continuity & -.67 & 1.56 & -.06 & .67 & & \\
\hline & Group constancy & -.02 & .02 & -.14 & .34 & & \\
\hline \multirow[t]{4}{*}{ Inclusion } & Mean age & .24 & .09 & 6.20 & .01 & .30 & .03 \\
\hline & Group size & .08 & .18 & .18 & .67 & & \\
\hline & Group continuity & -.90 & 2.44 & .14 & .71 & & \\
\hline & Group constancy & -.01 & .03 & .08 & .78 & & \\
\hline \multirow[t]{4}{*}{ Action coordination } & Mean age & .04 & .66 & .45 & .00 & .50 & .00 \\
\hline & Group size & -.05 & .01 & -.19 & .12 & & \\
\hline & Group continuity & 1.25 & .03 & .36 & .00 & & \\
\hline & Group constancy & -.00 & .01 & -.06 & .61 & & \\
\hline \multirow[t]{4}{*}{ Involvement } & Mean age & .02 & .01 & .23 & .11 & .28 & .01 \\
\hline & Group size & -.05 & .03 & -.19 & .18 & & \\
\hline & Group continuity & 1.07 & .47 & .33 & .03 & & \\
\hline & Group constancy & -.00 & .01 & -.09 & .50 & & \\
\hline \multirow[t]{4}{*}{ Emotional climate } & Mean age & .03 & .01 & .61 & .00 & .36 & .00 \\
\hline & Group size & .01 & .02 & .06 & .66 & & \\
\hline & Group continuity & -.04 & .27 & -.02 & .87 & & \\
\hline & Group constancy & .00 & .00 & .02 & .90 & & \\
\hline
\end{tabular}

${ }^{1}$ Higher scores indicate higher strength 


\section{Discussion}

In this paper we introduced the GFI-CC, an instrument to measure group functioning in child care groups, based on a conceptual model. We also presented the results of the first study applying the instrument in a sample of 44 child care groups. The results of this explorative investigation suggest that group functioning can be reliably assessed using the GFI-CC. The majority of the correlations among the group functioning measures represented in the GFI-CC were statistically significant and in the expected direction, which provides initial support for the underlying conceptual model. We also examined how group functioning was related to structural characteristics of the child care groups. Taken together, the structural characteristics predicted all group functioning variables. Mean age and group continuity were independent predictors of group functioning, with higher group functioning scores in groups with older children and in groups with greater continuity. Although group functioning scores were higher in smaller groups, group size did not independently contribute to the prediction of group functioning, and neither did group constancy.

\section{Group Functioning and the Conceptual Model}

Overall, the pattern of correlations among the dimensions and constructs supports the conceptual model (Table 1). The correlations between the two main dimensions cohesion (reflected in five measures), and emotional climate were in the expected direction, but three of the five correlations failed to reach conventional levels of statistical significance, which may be due to the small sample size in the present study. These results suggest that cohesion and emotional climate are related but distinct dimensions of group functioning, which is in accordance with the conceptual model.

With regard to the correlations among the five cohesion measures it can be concluded that the three network structure measures density, strength, and inclusion were moderately and significantly interrelated, and that action coordination and involvement (both measured with rating scales) were strongly interrelated. The correlations between the network structure measures and the ratings of action coordination and involvement were all in the predicted positive direction, but only two of the six correlations were statistically significant; network density was significantly correlated with action coordination and involvement, but network strength and network inclusion were not. So, of the three network structure measures, network density appears to be the measure that fits best in the conceptual model. An explanation for the relatively weak associations between network 
strength and inclusion and the ratings of action coordination and involvement is that the global ratings reflect the behavior of all children in the group; whereas the measures of inclusion and network strength are impacted by the relatively few isolated children (i.e., those who were observed to have no peer relationships) in the sample. Specifically, there were a total of 25 isolated children (5\% of individuals) identified in 17 (39\%) of the groups. As a result of the low prevalence of isolated children we elected to dichotomize the inclusion measure to indicate groups that did and did not include any isolates, and to include the isolated children when calculating network strength for each group. To address this issue in future studies, alternative measures of network strength and inclusion might be considered. For instance, network strength might be calculated so that isolates are not included in the calculation of this measure (Newman, 2003).

Another correlation among the group functioning measures that was not consistent with the conceptual model was the correlation between action coordination and involvement (.90), which was much higher than expected given that they were assumed to measure different aspects of cohesion. The high correlation suggests substantial overlap between the two measures, which is confirmed by the similarity of their associations with the other group functioning measures and structural group characteristics (see Tables 3 and 4). In this study, the constructs action coordination and involvement were based on the distinction between task cohesion and social cohesion, respectively, which is regularly made in small group studies with older age groups (Carless \& De Paola, 2000; Chang \& Bordia, 2001; Martin \& Carron, 2012; Rabaglietti et al., 2012). Knowing that children's peer relationships become more diverse and complex in the course of time (for an overview see Rubin, Bukowski \& Parker, 2006), it is likely that action coordination and involvement are not as clearly differentiated with very young children as compared to older age groups. Future studies utilizing this instrument might further examine the relation between action coordination and involvement in child care groups. In case the results of the present study are confirmed, researchers may elect to aggregate the action coordination and involvement scores. Another possibility is to simplify the conceptual model of group functioning in early child care groups by including only one of the two ratings. If a choice has to be made between these two measures, based on these data action coordination is the most likely candidate to be selected, because of its slightly stronger correlations with the other group functioning variables and the structural group characteristics.

In addition to the exclusion of one of the rating scales, could the conceptual model be further simplified based on the results of the present study? As indicated earlier, the results suggest that the two main dimensions cohesion and emotional 
climate should both be retained because they reflect somewhat related but distinct dimensions of group functioning. However, simplification could be realized by further reducing the number of variables to measure cohesion. As indicated above, of the three network structure variables that measure cohesion, network density appears to fit best in the conceptual model. Given that network density was also more consistently related with the structural group characteristics than the other two network structure variables (see Table 3), network density appears to be the best choice to be kept in the conceptual model in case of further simplification.

Taken together, if we had to simplify the conceptual model (see Table 1) based on the empirical evidence resulting from this very first study, our simplified model would still include the two dimensions of cohesion and emotional climate, but the cohesion dimension would be represented by only two of the original five measures, namely network density and action coordination. We would retain both of these cohesion measures because they represent theoretically different aspects of cohesion: network density is a quantitative measure focusing on the relative number of relations between children in the group, while action coordination is a more qualitative measure reflecting the 'how' of the interactions between the children. The resulting simplified model would be consistently supported by the correlations between the three remaining measures. The correlation between the two cohesion measures is moderate $(r=.41)$, while their correlations with emotional climate are the same or somewhat weaker ( $r s=.20$ and .41 for network density and action coordination, respectively), which can be expected given that they represent distinct dimensions.

Finally, we want to emphasize that the simplified model above is only tentative, and that decisions to simplify the model should be based on much more empirical evidence - not only replications of the present study in other - preferably larger - samples, but, more importantly, studies examining the predictive validity of the GFI-CC, to show how the various group functioning measures may contribute to the children's functioning and development.

\section{Reliability and Validity of the GFI-CC}

As argued above, the pattern of bivariate associations between the dimensions and constructs represented in the GFI-CC, provides initial support for the underlying conceptual model, which can be viewed as evidence regarding the construct validity of the GFI-CC. Furthermore, the correlations between the structural variables and group functioning measures provide initial evidence for the predictive validity, strengthened by the results of the multiple regression analyses. The internal consistency of the global rating scales action coordination, involvement, 
and emotional climate of the GFI-CC across the 24 3-minute intervals was good (between .80 and .90), which provides additional support for the reliability of these scales. To obtain information about how much observation time is necessary to acquire reliable results, we also computed the internal consistency of these three scales across 12 intervals (half the number of intervals we aimed to obtain in the present study). Over 12 intervals a reliable picture of the global ratings was still accomplished; the internal consistency was $.82, .75$, and .70 respectively. This result suggests that a total observation time of 36 minutes (12 33 minutes) suffices for a reliable impression of group functioning in a child care group. However, we have to keep in mind that the internal consistency of the network scores could not be calculated, because these scores were based on the total number of interactions observed across all 3-minute intervals of a group. As it is not possible to separate the interactions observed in the individual 3-minute intervals, we do not have an indication of whether half of the observation time would suffice to also obtain a comparably reliable picture of the network structure. This will be an interesting question for future research.

Another question about the observation time concerns the length of the 3-minute intervals we used to observe the interactions between children; as described in the Method, we coded whether or not an interaction occurred for each dyad during each interval. For feasability reasons, we chose to use the same 3-minute intervals that we also used for applying the the rating scales. For scoring a rating scale an observation period of 3 minutes is the minimum, as shown by the pilot-observations and in other studies using rating scales. However, for coding interactions between children, 3-minute intervals are relatively long and may have restricted the variation in interactions between dyads. The meaningful results with regard to the network structure scores in the present study, which were based on the observed interactions between dyads, support the validity of the interaction measures. Nevertheless, exploring the effect of using shorter intervals for observing the dyadic interactions remains an interesting topic for further study.

\section{What Distinguishes the GFI-CC From Other Early Peer Group Measures?}

The most distinctive characteristic of the GFI-CC is that it focusses on the group of children as a whole, in contrast to other measures for young children in the context of the peer group or classroom. For instance, studies examining early peer relationships within peer groups or classrooms mostly focus on subgroups or dyads, while the GFI-CC reflects the structure of the group as a whole. Peer acceptance studies also examine children in classrooms, but the sociometric measures they use are also not meant to characterize the peer group as a whole. Instead these measures, such 
as acceptance, rejection, and popularity, characterize individual children's position or reputation in their peer group, reflecting an individual focus and not a group focus like the GFI-CC. Studies measuring the emotional climate in classrooms do focus on the classroom as a whole. However, the most frequently used instruments to measure the emotional climate in early classrooms, such as the Classroom Assessment Scoring System (CLASS, e.g., La Paro et al. 2014), include the teacher as part of the classroom, while the GFI-CC characterizes the peer group by itself, without the teacher. So, compared to other measures for young children in early classrooms, the GFI-CC is unique in its focus on the peer group as a whole.

\section{Group Functioning and Structural Group Characteristics}

The second aim of this study was to examine how group functioning is related to the structural group characteristics age composition, group size, group continuity, and group constancy. Of these structural group characteristics, age composition or the mean age of children in the group was most clearly related to group functioning. Groups with older children had higher scores on every group functioning measure. This is in accordance with our expectation that older children with more sophisticated social skills would score higher on variables that reflect cohesion. Age composition was also moderately and positively correlated with emotional climate. We did not formulate a hypothesis for this relationship, but we think this positive correlation can be explained in two ways. First, a child care group is stressful for most children, especially for infants and toddlers (Watamura, Donzella, Alwin, \& Gunnar, 2003). Infants and toddlers utter their negative affect by fussing and crying, so groups with (more) infants and toddlers will have a greater chance to have a more negative emotional climate. The second explanation focuses on the older children in the group. The results indicate that older children, on average, are more positively connected with other children, they are less isolated, and show more coordinated and involved behavior in a child care group than younger children. These positive peer interactions may be related to higher well-being (Gevers Deynoot-Schaub \& Riksen-Walraven, 2006), which in turn might be reflected in a more positive emotional climate.

Group continuity or the proportion of children that have been attending the child care group for at least 6 months, was also related to group functioning. It reflects the opportunities children have had to interact with each other. Continuity uniquely predicted action coordination and involvement, but unexpectedly it was not associated with network structure or emotional climate. Apparently, in child care groups children develop dyadic relationships (reflected in the network structure) more or less independent of how long the children know each other. 
More advanced interactions and more complex triadic relationships, reflected in more and higher levels of action coordination and involvement in the group, take more time to develop (Schaefer et al., 2010) and are consequently associated with higher group continuity.

Like continuity, constancy (referring to the time children presently spend together in the child care group per week) is an indicator for the opportunities the children have had to interact with each other. Surprisingly, constancy was not associated with any of the group functioning measures. In the present study, constancy was relatively low, reflecting the typically Dutch situation of part-time child care attendance by young children. The constancy scores indicate that most children meet half of the other children in their group only during one day a week. Although this low frequency does not necessarily hinder the development of peer relationships (Ross \& Lollis, 1989), it is possible that the time children spend together is too confined to explain differences in the development of more advanced relationships, as reflected in higher levels of action coordination and involvement. Another possible explanation for the lack of an association between constancy and group functioning is the definition of constancy used in the present study. Our definition did not take into account interaction preferences for specific interaction partners that even young children show (Maccoby, 1990; Martin et al., 2005; Sanefuji et al., 2006). The development of more advanced relationships may require more frequent interaction possibilities, not between any dyad in the group (reflected in constancy as measured in this study), but between specific combinations of children. To test this hypothesis, future studies would have to measure group constancy while also taking into account interaction preferences of children in the group.

\section{Limitations and Directions for Future Research}

This study has several limitations. First, this initial study on group functioning in child care has a preliminary explorative character. Therefore, conclusions can only be drawn with caution and replication is needed.

Another limitation of this study is the selective sample. Possibly, groups that did not want to participate would have achieved different results, especially given that high work pressure was a common named reason not to participate. The response rate was relatively low (33\%), but is comparable to other recent Dutch child care studies (e.g., Helmerhorst, Riksen-Walraven, Vermeer, Fukkink, Tavecchio 2014). Furthermore, given the specific characteristics of the Dutch child care context with, for instance, mixed age groups as the most prevalent type of group, and an over-representation of children of higher educated parents in child care centers (Veen, Roeleveldt, \& Heurter, 2010) - the results of this study may not generalize to 
other countries. Replication of this study in a larger sample and in other countries is needed.

In this study we observed the groups during a whole day, to get an appropriate reflection of functioning of the group during the observation day. However, we have defined group functioning as a relatively stable pattern of relationships, emotions, and cognitions. An indication that group functioning is not a coincidental pattern is the association with several structural, and thus relatively stable, group characteristics. However, more definitive evidence concerning the stability of group functioning can only be obtained by repeated observations of group functioning in the same group.

Although this study provides preliminary support for the Group Functioning Instrument for Child Care, it is necessary to further examine the validity and usefulness of the GFI-CC. Therefore, it would be worthwhile to explore the relation between group functioning measured by the GFI-CC and other measurements at group level, such as perceptions of the caregivers about the child care group.

Another interesting issue to examine in future research is whether and how gender-composition and gender preferences in play behavior affect group functioning in child care, given that young girls' and boy's social behavior appears to differ (e.g., Hay, Caplan, et al. 2009) and same-sex play preference appears to arise from age 3 (Corsaro, 2005; Fabes et al., 2003; Maccoby, 1990).

In the present study we examined how group functioning is associated with the structural group characteristics, which are considered as global indicators of the quality of child care. A next interesting step could be to examine group functioning in relation to more proximal indicators of the quality of care, especially the quality of caregiver-child interactions and characteristics of the immediate physical environment of the group. Both are generally recognized to affect the quality of children's peer interactions (Kantrowitz \& Evans, 2004; NICHD Early Child Care Research Network, 2001), and might therefore also influence various measures of group functioning.

Finally, we want to emphasize that we realize this study represents a first step in obtaining more knowledge about group functioning in child care centers. Our interest in this topic was triggered by observations that caregivers in practice frequently refer to differences in group functioning between child care groups. Many experienced caregivers are convinced that group functioning affects children's behavior and development, and are eager to know how they might improve group functioning. In the present study we took the initial step in examining these questions by introducing a definition of group functioning and, based on this, an instrument to measure group functioning in groups of young children - the GFI- 
CC. Our first application of this instrument in a sample of 44 child care groups demonstrated that differences in group functioning could indeed be observed, and that these differences were associated with structural group characteristics. Many important questions concerning group functioning and its potential determinants and consequences for children's behavior and development remain unanswered. To answer these questions, further research is certainly needed. 


\section{CHAPTER 3}

\section{Short-term stability of group functioning in child care centers ${ }^{2}$}

2 This chapter has been submitted as: Aarts, M. C., Burk, W. J., \& Riksen-Walraven, J. M. (2016c). Short-time stability of group functioning in child care groups 


\begin{abstract}
Research findings: This study examined short-term stability of group functioning in 36 early child care groups twice across two or three weeks. Child care groups were defined as peer groups, including all children in the group, but not the caregivers. Group functioning was measured using the Group Functioning Instrument for Child Care (GFI-CC). Two dimensions of group functioning were assessed: cohesion (reflected in network structure, action coordination and involvement) and emotional climate. Based on the definition of group functioning in child care groups as a relatively stable pattern of relationships and emotions which develops as a result of repeated interactions between children, we expected group functioning to show short-time stability. Four indicators of stability (rank-order stability, meanlevel stability, and stability of the correlation patterns among group functioning variables) pointed to short-term stability in group functioning. This supports the reliability of the GFI-CC as a measure of group functioning.
\end{abstract}




\section{Introduction}

Frequently, experienced caregivers in child care centers mention the 'functioning' of a child care group as a typical group characteristic, which varies among child care groups and affects children's daily experiences and behavior in the group. Until now, however, child care researchers have paid little attention to this subject. Recently, a conceptually based instrument to measure group functioning in child care groups, the Group Functioning Instrument for Child Care (GFI-CC), was developed and applied to groups of 0- to 4-year-old children in child care centers (Aarts, Burk, \& Riksen-Walraven, 2016b). The outcomes provided initial evidence for the internal consistency and validity of the GFI-CC. This first study on group functioning in child care was based on observations in child care groups on a single day. A next important question is whether group functioning in child care groups is stable across time. As a first step, the present paper addresses the issue of short-term stability of group functioning, which can also be viewed as test-retest reliability of the GFI-CC. Group functioning was measured twice with an intermediate period of two or three weeks in 36 child care groups.

\section{Definition of Group Functioning in Child care Groups}

Child care groups are defined here as peer groups, including all children in the group, but not the caregivers. Group functioning in child care groups may be conceptualized as a relatively stable pattern of relationships and emotions, which develops as a result of repeated interactions between the children in the group (Aarts et al., 2016b). Group functioning is operationalized in terms of two broad dimensions: cohesion and emotional climate (see Table 1). Cohesion is the extent to which children's behavior reflects mutual connection, and is represented by three different constructs: network structure, action coordination, and involvement. Network structure refers to the number and pattern of relationships between children in the group and can be characterized by three network features: density (the relative number of relationships among children in the group), network strength (the average number of relationship 'paths' or intermediaries connecting any two children in the group) and inclusion (the relative number of children who have at least one relationship with other children in the group). Action coordination, the second cohesion construct, refers to the extent to which the children in the group spontaneously coordinate their behavior with each other and simultaneously focus their behavior on the same goal or meaning. The third cohesion construct, involvement, is the extent to which children show attention, care, and affection toward each other. The second broad dimension of group functioning is emotional climate. 
This is the affective atmosphere in the group, reflected in the predominant affective tone and energy level of children's behavior.

Table 1. Conceptual Model Underlying the Group Functioning Instrument for Child Care (Aarts et al. 2016b)

\begin{tabular}{|c|c|c|}
\hline Dimension & Construct & Definition \\
\hline \multirow[t]{6}{*}{ A. Cohesion } & $\begin{array}{l}\text { 1. Network } \\
\text { Structure }\end{array}$ & $\begin{array}{l}\text { The pattern of relationships among children in the } \\
\text { group }\end{array}$ \\
\hline & a. Density & $\begin{array}{l}\text { The relative number of dyadic peer relationships in } \\
\text { the group }\end{array}$ \\
\hline & b. Strength & $\begin{array}{l}\text { The degree of connectedness among children in the } \\
\text { group, reflected in the number of relationship paths } \\
\text { (intermediaries) connecting any two children in the } \\
\text { group. }\end{array}$ \\
\hline & c. Inclusion & $\begin{array}{l}\text { The relative number of children that have at least } \\
\text { one peer relationship in the group }\end{array}$ \\
\hline & $\begin{array}{l}\text { 2. Action } \\
\text { Coordination }\end{array}$ & $\begin{array}{l}\text { The extent to which children in the group } \\
\text { spontaneously and simultaneously coordinate their } \\
\text { behavior with that of other children, or focus their } \\
\text { behavior on the same theme, goal, or object }\end{array}$ \\
\hline & 3. Involvement & $\begin{array}{l}\text { The extent to which children in the group show } \\
\text { positive attention, care, and affection toward each } \\
\text { other }\end{array}$ \\
\hline $\begin{array}{l}\text { B. Emotional } \\
\text { Climate }\end{array}$ & & $\begin{array}{l}\text { The most predominant affective tone and energy } \\
\text { level of children's behavior in the group }\end{array}$ \\
\hline
\end{tabular}

\section{Previous Research on Stability of Group Functioning}

Given that group functioning is assumed to be the outcome of repeated interactions between the children in the group, the stability of group functioning can be expected to depend on the stability of group composition or the extent to which the group is composed of the same children. The more stable the group composition, the more stable group functioning will be. Until now, stability of group functioning in child care groups has not been empirically examined, but stability of group functioning has been studied with older children attending elementary school and preschool classrooms. The most relevant findings involving stability of group functioning are discussed below, with special attention to the two group functioning dimensions cohesion and emotional climate and their association with stability of group composition. 
The results of studies investigating the stability of cohesion in elementary school and preschool classrooms indicate that the stability of this aspect of group functioning is related to the consistency of the classroom composition and length of time between assessments. When stability of cohesion was measured within a school year and consequently group composition was consistent, cohesion tends to be moderately stable (Fish \& Dane, 2000; La Freniere \& Charlesworth, 1983; Vaugh \& Santos, 2006). In studies in which stability was determined over a year or longer, a less stable pattern has been reported (Estell, Cairns, Farmer, \& Cairns, 2002), and the degree of stability turned out to be a function of the consistency of the classroom composition (Neckerman, 1996).

Most investigations of the stability of emotional climate in school classrooms have focused on the role of teacher's behavior (e.g. Rivers, Brackett, Reyes, Elbertson, \& Salovey, 2013; Tobin et al., 2013). As a result, only indirect evidence of the stability of emotional climate is available. For instance, Kinderman (1993, 2007) reported that the peer group culture (defined as classroom norms regarding engagement and motivation in school) remained stable throughout the school year even when almost half of the students changed classroom membership from the fall to spring. Apparently group culture, which may be associated with a group's emotional climate (De Rivera, Kurrien, \& Olsen, 2007), is a group characteristic less dependent on group composition than cohesion. However, there is no direct evidence regarding the stability of emotional climate in elementary school or preschool classrooms, at least not from studies that define emotional climate as is done in the present study.

In sum, there are some elementary and preschool studies indicating that cohesion is stable over time, provided that the group composition is also relatively stable. Empirical evidence concerning the stability of emotional climate in groups with young children, the second group functioning dimension in the model depicted in Table 1 , is lacking.

\section{The Dutch Child Care Context}

Because this study was conducted in Dutch child care centers, and the outcome might reflect the child care situation in the Netherlands, we provide a brief sketch of the Dutch child care context. During the last decades, child care attendance in the Netherlands has increased enormously, caused by the growing number of employed mothers, which is now over 70\% (Merens, Hartgers, \& Van den Brakel, 2012). Although the employment hours of mothers have increased too, most mothers $(73 \%)$ work on a part-time basis, on average 26 hours per week (Merens et al., 2012). Nowadays $61 \%$ of the Dutch 0 - to 4-year-old children attend formal child 
care (OECD, 2014), in which children of parents with higher education and higher income are over-represented (Merens et al., 2012; OECD, 2011). Children can attend child care from the age of 3 months, when paid maternity leave ends, until the age of 4 when children enter kindergarten. Almost half of the children in Dutch child care centers attend child care for more than three years (Veen et al., 2010). The parents' working hours define how many and on which day(s) their children attend child care. Often child care centers offer flexible child care (e.g. care for half days, longer opening hours, switching days during the week) to conform to the parents' child care needs. Because child care is relatively expensive, many parents combine formal care with informal child care provided by grandparents, neighbours etc. Children attend formal child care on average for 19 hours per week, which is almost the lowest weekly attendance in western Europe (OECD, 2014). For the present study it is relevant to note that, as a result of the part-time and flexible child care attendance, which can also change over time depending on the parents' child care needs, the composition of child care groups varies over the days of the week, and is less stable over time than in most other countries.

\section{The Present Study}

In this study we examined the short-term stability of group functioning in child care groups. To compare the functioning of child care groups with as many of the same children as possible on the two observation times, the second observation took place on the same week day as the first observation, two or three weeks later.

Based on the definition of group functioning and previous studies investigating stability of cohesion in groups with older children, we expected group functioning to show short-time stability. Three measures were used as indicators of stability. First, we examined rank-order stability of group functioning over time; we expected that groups would retain their relative position to each other with regard to group functioning over the two or three week interval. Second, we examined mean-level stability of group functioning; we expected that the average group functioning scores across all observed groups would remain the same between Time 1 and Time 2. Third and finally, we examined the pattern of interrelations among the group functioning measures over time; we expected to find similar correlations among group functioning dimensions and constructs at Time 1 and at Time 2 . 


\section{Method}

\section{Participating Groups}

A total of 160 Dutch child care centers were asked if they were willing to cooperate with one of their child care groups in this study, first by letter, a few weeks later by phone. A group could participate if at least eight children were present on two observation days with an intermediate period of two or three weeks and if caregivers and parents of all children present on the observation days gave their written consent. Fifty-three centers (33\%) agreed to cooperate, of which eight groups did not meet the criteria. Given that there was only one toddler group (1-2 yr), we excluded this group from the sample. The sample at Time 1 consisted of 44 groups. After the observations on Time 2, eight of these 44 groups could not be included in the final sample for the present study. In two groups less than eight children were present on Time 2, in five groups the second observation provided too little video-material (because the groups played outside most of the time, while the video recordings were made inside), and one group did not participate in the second observation because of high work pressure for the caregivers. The eight groups that were excluded did not differ from the 36 groups in the analytic sample with regard to Time 1 group functioning measures, except for density and network strength. The excluded groups exhibited lower network density and network strength, reflecting somewhat lower group functioning than the groups that were included in the analytic sample, $t s(\mathrm{df})=2.63, p<0.05$ and $-2.09, p<0.05$ (excluded groups: density $M=.27, S D=.08$; strength $M=3.41, S D=1.43$; included groups: density $M=.33, S D=.05$ and strength $M=4.70, S D=2.14$ ). For the present study the analytic sample included the 36 groups that were observed twice, i.e., 23 mixed age groups (0-4 yr) and 13 preschool groups (2-4 yr). In these groups a total of 475 children were observed (424 during Time 1, 418 during Time 2) who attended their child care group on average 2.5 days a week.

\section{Procedure}

Each group was visited twice by the first author. In principle, the second observation took place exactly two weeks after the first observation, on the same day of the week. In case this day turned out to be a holiday or a day on which less than eight children were expected to be present, the second observation was postponed until exactly three weeks after the first observation day. In total 26 groups were observed with a two-week interval, 10 groups with a three-week interval. The procedure was identical at Time 1 and Time 2. Each visit lasted from 9.00 a.m. to 5 p.m. The caregivers were asked to keep their usual daily schedule. 
The children present in the classroom during at least four hours during the observation day were regarded as 'the group'. The group was filmed inside, during free play and waiting situations. During free play most children can choose what, where, and with whom they play. Waiting situations are transitional situations where most children are instructed to sit or stand together, waiting for an activity to begin (snack time, play outside, etc), while at the same time the caregiver is busy with organizational tasks. To observe group functioning, the video recordings were divided into 3-minute intervals. At Time 1, on average 22.35 intervals per group were obtained (range 15-24), at Time 2 we attained on average 22.33 intervals per group (range 14-24). For a detailed description of the filming procedure, see Aarts et al. (2016b).

\section{Instruments and Measures}

Two coding systems, summarized in Table 2, were used to code the video recordings. Network structure was based on time sampling of interactions between children in the group. Action coordination, involvement, and emotional climate were assessed at the group level, using global rating scales.

Network structure. Measurement of the three constructs reflecting the network structure (density, strength, inclusion) was based on the total number of observed interactions between children in each group (see Table 2). Videos of the observed interactions for 22 different groups (14 Time 1, 8 Time 2) were initially scored together by the first author and a research assistant. Next, 10 groups (590 interactions) were scored separately by the first author and the research assistant. Inter-rater reliability was assessed with an intraclass correlation (ICC) which indicated almost perfect agreement (.97). The research assistant coded the interaction matrices for the remaining groups.

The time-sampling coding scheme resulted in the identification of 2226 interactions observed between dyads at Time 1 and 2075 interactions at Time 2, the number of interactions per dyad ranged from 0 to 21 at Time 1 and from 0 to 19 at Time 2. Based on the observed interactions, dyadic relationships were identified (Schaefer et al., 2010). At Time 1 a total of 929 relationships were identified, at Time 2 a total of 893 dyadic relationships. The network structure measures (density, strength and inclusion) were based on these relationship measures at both Time 1 and Time 2 (see Table 2).

Action coordination, involvement and emotional climate. The second coding scheme in Table 2 includes three global group functioning measures, i.e., action coordination, involvement and emotional climate in the group, which were rated on 5-point Likert scales. These ratings represent a global assessment of the behav- 
ior of the children in the group during each 3-minute interval. A trained research assistant, blind to the network structure scores and other data, and the first author rated the behavior of the children in the group on the three global scales for each of the 3-minute intervals filmed in the group. Thirteen groups (297 intervals) were scored together. The ICC (assessing absolute agreement for single measures) based on 278 separately scored 3-minutes intervals (13 groups) was .63, .53, and .65, respectively, for action coordination, involvement, and emotional climate, which is regarded as a moderate degree of inter-rater reliability (Landis \& Koch, 1977). For each group, mean scores for action coordination, involvement and emotional climate were calculated separately for Time 1 and Time 2 .

\section{Results}

\section{Stability of Group Composition at Time 1 and Time 2}

Despite the relatively confined time interval of two or three weeks, the stability of group composition was expectedly not very high. The proportion of identical children present at both observation days, computed as the number of children present on both times divided by the total number of different children present in the group on Time 1 and Time 2 was $.76(S D=.14$, range $=.47-1.00)$. In only 4 of the 36 groups $(11 \%)$ the group composition at Time 1 and Time 2 was exactly the same.

\section{Descriptives}

Table 3 shows the means, standard deviations, and ranges of the six group functioning measures at Time 1 and Time 2. Almost all group functioning variables were normally distributed at both times, except for inclusion, which was dichotomized. Groups that were observed over a 2-week interval and groups that were observed over a 3-week interval did not differ with regard to group functioning scores at Time 1 . However, at Time 2, groups that were observed after three weeks had a significantly lower mean score on action coordination than groups observed over a 2-week interval, $t(\mathrm{df})=2.51 p=.02$ (3 week interval: $M=2.70, S D=.46 ; 2$ week interval: $M=3.10, S D=.42$ ).

\section{Rank-Order Stability}

As can be seen in Table 3, the correlations between the group functioning scores at Time 1 and Time 2 were all statistically significant and moderate, reflecting rank-order stability among the groups with regard to the six group functioning 


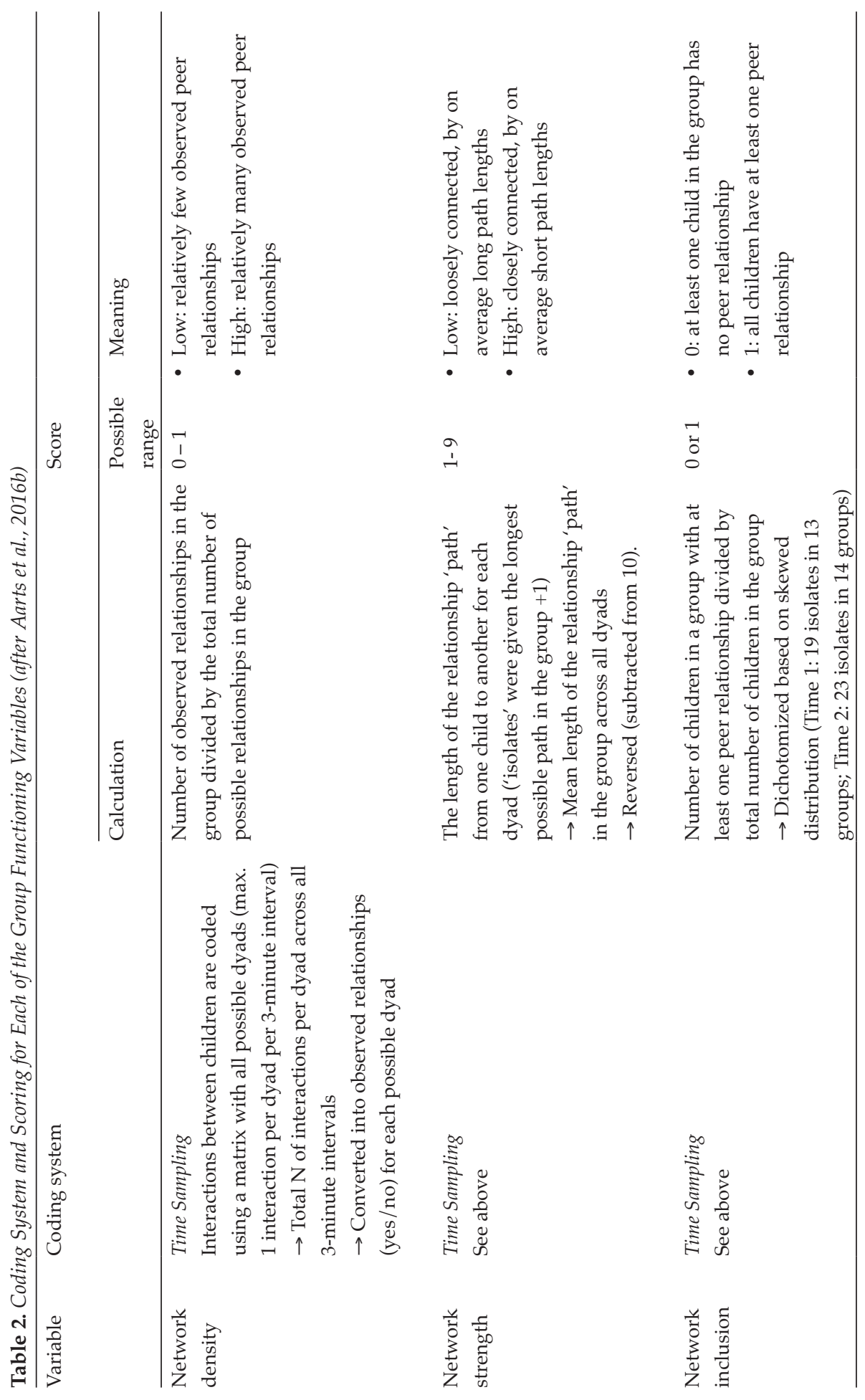




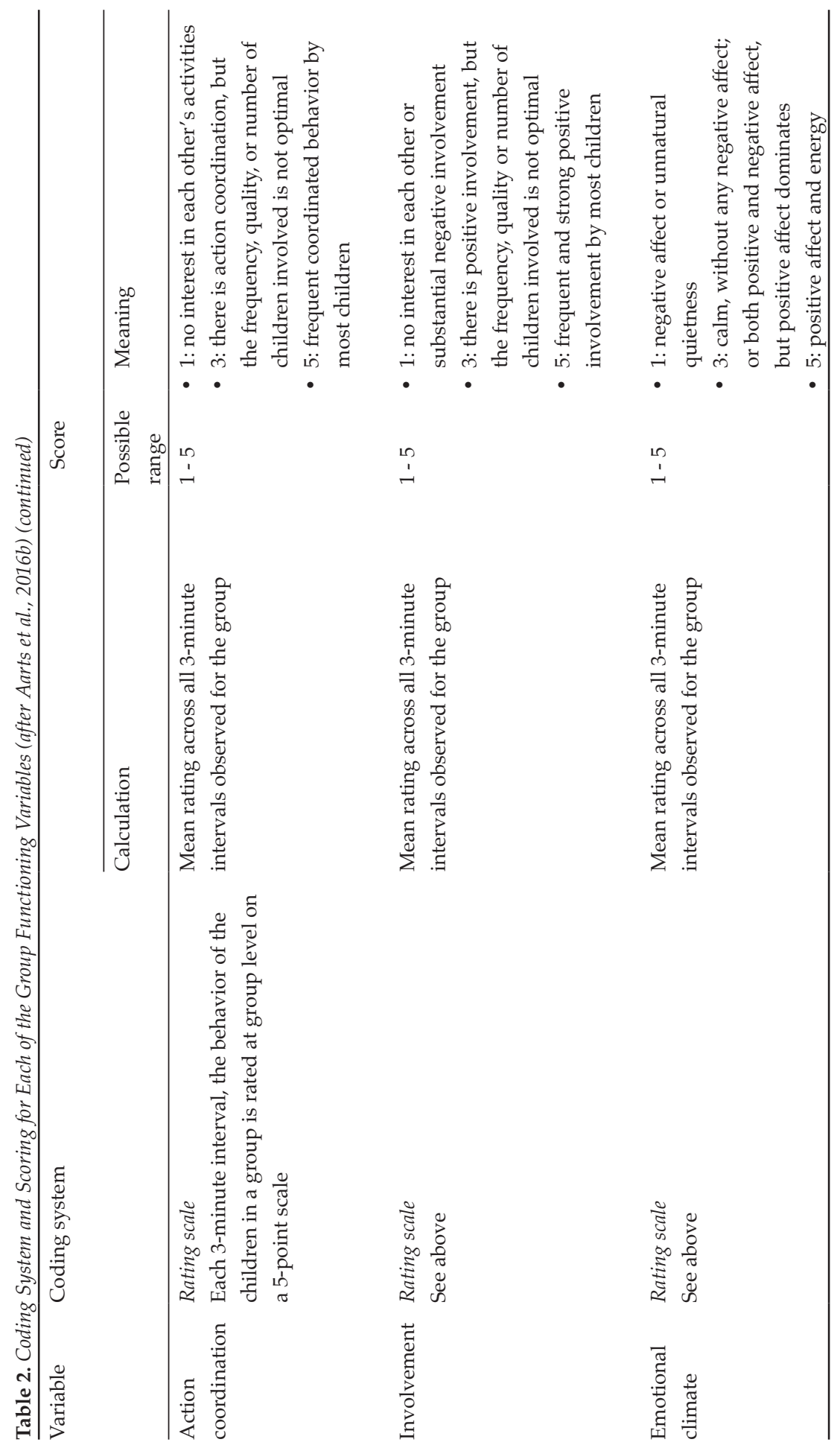




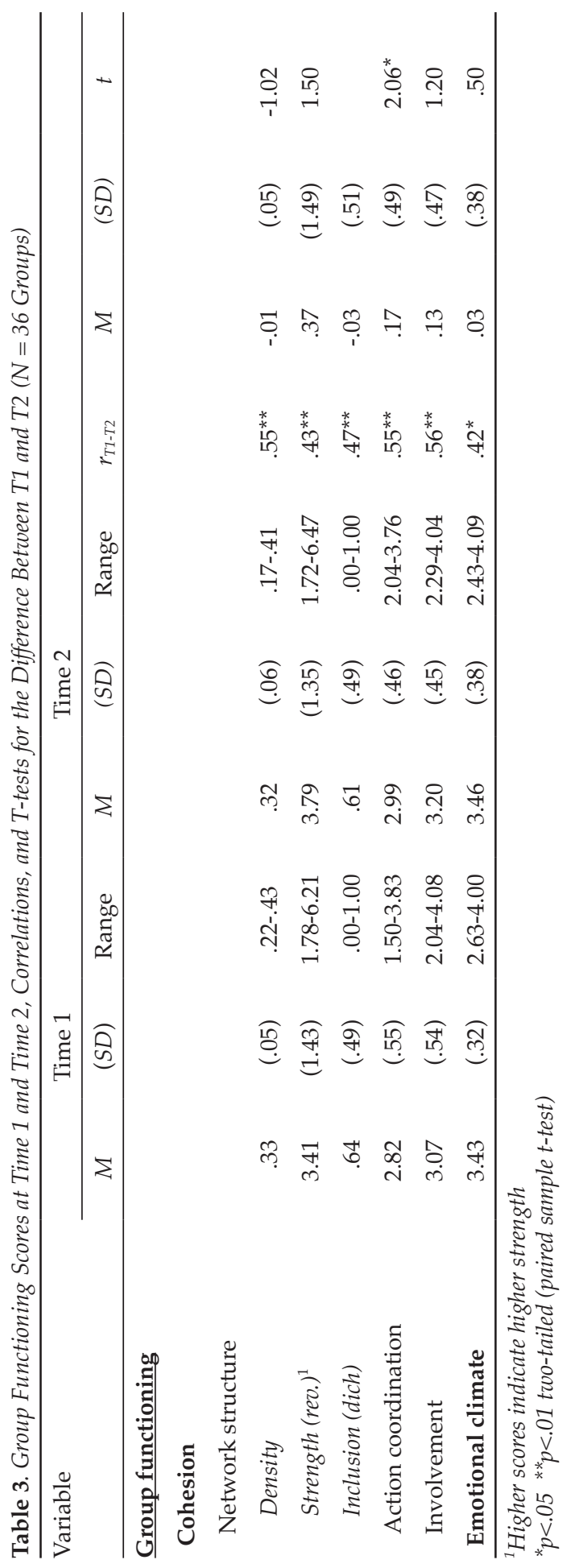


variables. This reflects that each group retained its relative position compared to the other groups in the sample over time, as expected. We also computed partial correlations which controlled for the instability of the group composition between the first and second observation (not in the table). The largest difference between the partial correlations and the Pearson correlations was .02, so group composition did not affect the relation between group functioning scores at Time 1 and Time 2 .

\section{Mean-level Stability}

Comparing the group functioning mean scores at Time 1 and Time 2 (see Table 3) revealed that, except for action coordination, on which the groups on average achieved a significantly higher mean score at Time 2 than on Time 1, the differences between the average scores of the group functioning variables at Time 1 and Time 2 were small and nonsignificant. This indicates stability in the mean-level of five out of six group functioning scores across all the groups over time. When adjusting for group composition, the significant difference between the mean scores on action coordination at Time 1 and Time 2 was no longer statistically significant (not in the table).

\section{Stability of Interrelations Among Group Functioning Variables}

Table 4 presents the intercorrelations among the group functioning variables at Time 1 (below diagonal) and at Time 2 (above diagonal). Contrasts of the 15 correlations among Time 1 and Time 2 measures (Steiger, 1980) revealed that concurrent associations did not differ at Time 1 and Time 2 ( $p$ is on average .49, range .06 - .89), indicating that the interrelations among group functioning measures demonstrated moderate stability. Although the interrelations among group functioning measures did not differ significantly from each other over time, some associations were more stable than others. The least stable relations among group functioning variables over time $(p<.15)$ were the correlations between strength and inclusion $(r \mathrm{~s}=.57$ and .78 respectively, $p=.09$ ), and between involvement and emotional climate ( $r \mathrm{~s}$ $=.61$ and $.28, p=.06$ ). The most stable relations over time were the associations between density and inclusion ( $r \mathrm{~s}=.58$ and .60 respectively for T1 and T2, $p=.89$ ), and between strength and emotional climate ( $r \mathrm{~s}=.28$ and $.30, p=.92)$.

In sum, the three stability indicators - rank-order stability, mean-level stability, and stability of the correlation patterns among group functioning variables - all point to short-time stability of group functioning in child care groups. 
Table 4. Intercorrelations among Group Functioning Variables at Time 1 (below diagonal) and Time 2 (above diagonal) $(N=36$ groups)

\begin{tabular}{lcrrrrr}
\hline Variable & 1 & 2 & 3 & 4 & 5 & 6 \\
\hline Group functioning & & & & & & \\
Cohesion & & & & & & \\
$\quad$ Network structure & & & & & & \\
$\quad$ 1. Density & & $.67^{* *}$ & $.58^{* *}$ & $.32^{*}$ & .22 & $.37^{*}$ \\
$\quad$ 2. Strength (rev.) & $.62^{* *}$ & & $.57^{* *}$ & .26 & .22 & $.28^{*}$ \\
$\quad$ 3. Inclusion (dich) & $.60^{* *}$ & $.78^{* *}$ & & .28 & .19 & .01 \\
4. Action coordination & $.45^{* *}$ & .10 & .18 & & $.87^{* *}$ & $.66^{* *}$ \\
5. Involvement & $.42^{* *}$ & .09 & .16 & $.91^{* *}$ & & $.61^{* *}$ \\
6. Emotional climate & .27 & $.30^{*}$ & .28 & $.45^{* *}$ & .28 & \\
\hline
\end{tabular}

${ }^{1}$ Higher scores indicate higher strength

${ }^{*} p<.05{ }^{* *} p<.01$ one-tailed

\section{Discussion}

In this study we examined short-time stability of group functioning in 36 child care groups, measured with the Group Functioning Instrument for Child Care (GFI-CC), over a period of two or three weeks. Stability was demonstrated both for rank-order and mean-level scores, and for the pattern of interrelations among group functioning variables. This supports our definition of group functioning as a relatively stable pattern of relationships and emotions. It is striking that this stability was demonstrated even in the relatively unstable and flexible Dutch child care context, as evident from the relatively low stability of the group composition over two or three weeks. Apparently, even in groups of very young children who meet each other only one or two days a week and in which regularly children leave or new children enter the group, a stable group functioning pattern can be observed.

The group functioning variables showed both moderate rank-order and meanlevel stability. This provides initial empirical evidence supporting our definition of group functioning as a relatively stable pattern and demonstrates the test-retest reliability of the GFI-CC, the instrument by which group functioning is measured. The present study showed that interrelations among group functioning measures, which were also in accordance with the model, demonstrated stability as well.

There was a remarkable finding that was not in accordance with expectations. The almost identical values of the Pearson correlations and of the partial correlations - which controlled for the instability of the group composition - between group functioning at the first and at the second observation, indicate that each 
group kept its relative position to the other groups, independently of changes in group composition. A possible explanation is that group functioning in child care groups is highly affected by external influences that are consistent over time, for instance the caregivers' behavior or the physical environment of the group, and therefore is less sensitive for changes in group composition. An alternative explanation is that some children affect group functioning in child care groups to a larger extent than other children in the group do. Perhaps most of these influential children were present in the groups at both observation times, which resulted in larger group functioning stability than expected based on the moderate stability of group composition.

\section{Limitations}

The most important limitation of the present study is the relatively small and non-representative sample, which prevents broad generalization of the results. Necessarily, the sample size was confined because of the time consuming and labor intensive observation and coding procedure. A second limitation is the relatively low response rate. The most common reason not to take part was high work pressure, so one might expect the results to be different in centers which refused participation. However, the response rate in this study was comparable to the response rate in other Dutch studies (de Kruif et al., 2007; Helmerhorst, Riksen-Walraven, Vermeer et al., 2014). A third limitation could lie in selective attrition between T1 and T2. The eight groups lost to attrition did exhibit somewhat lower group functioning scores than those in the analytic sample, but we have no reason to suspect that the loss of these groups had any impact on the associations presented in this study. Given the specific characteristics of the Dutch child care context, care should also be taken in generalizing the results of this study to child care groups in other countries. Indeed, the observed short-term stability of group functioning in child care groups might well be a conservative estimate, given the relatively unstable group composition that is typical for Dutch child care centers. Replication of this study in a larger sample and in other countries is recommended.

\section{Directions for Future Research}

The results of this study indicate that group functioning is relatively stable and that the GFI-CC provides a reliable and consistent assessment of this construct in child care groups. A next step is to examine how group functioning affects the wellbeing and development of the children in the group. If group functioning is stable over time, then children experience more or less the same interaction and relationship patterns every day they attend child care. It is likely they are influenced 
by these recurring experiences. Although direct empirical evidence for the possible association between group functioning in child care groups and the development of children is lacking up to now, studies in school classes and families indicate that group functioning can affect children's behavior and competences. For instance, in primary school classrooms or families the emotional climate appears to affect peer relationships (Avant et al., 2011; Gazelle, 2006), social competence (Sheffield Morris, 2007), aggressive behavior (Howes, 2000), and problem behavior (Modry-Mandell \& Gamble, 2007). Positive group functioning may not only stimulate wellbeing and social skills, but may also impact cognitive development. For instance, groups with many and qualitatively advanced interactions between children can be expected to provide numerous opportunities for cooperative learning. It is a challenging and important goal for future studies to investigate the relation between the functioning of child care groups and children's social-emotional and cognitive development.

Another direction for future research is to determine the factors responsible for differences in group functioning. Apart from the association of group functioning with structural group characteristics such as mean age of children in the group, group size, and the period the children have been attending the group (Aarts et al., 2016b), little is known about the precursors of group functioning. The present finding that stability of group functioning is relatively independent of the composition of the child care group suggests that stable external factors play an essential role in the shaping of group functioning. Factors such as the quality of caregiver behavior, the physical environment, and the daily schedule are generally recognized to affect the quality of children's peer interactions (Kantrowitz \& Evans, 2004; NICHD Early Child Care Research Network, 2001) and therefore are likely candidates to be predictors of group functioning. Examining their influence is an important issue for further research.

The present study demonstrates stability of group functioning in child care groups over a short time interval. Although demonstrating short-term stability is the most obvious initial step and the restricted period was necessary to ensure the stability of group composition of the observed groups, the present findings allow no conclusions about stability of group functioning over more than a few weeks. A next question is whether group functioning in child care groups is stable over longer periods of time. There are indications that group functioning is positively related to how long the children have been attending the group (Aarts et al., 2016b; Schaefer et al., 2010), so over longer periods of time, group functioning is expected to show some change, provided that group composition is stable. To grasp more insight in stability of group functioning over longer periods of time, studies with 
groups that vary in terms of compositional stability and across more elongated time intervals are needed.

This study convincingly shows that group functioning in child care groups is stable, at least over relatively short periods of time, which indicates that group functioning may affect the behavior and development of children in the long run, and may therefore be regarded as a relevant indicator of child care quality for individual children. At the same time, research on group functioning in child care has only begun. Many important questions about stability, determinants of group functioning and possible ways to improve it, and the relation between group functioning and children's development remain unanswered and further research is certainly needed. 



\section{CHAPTER 4}

\section{Caregiver and environmental characteristics as predictors of group functioning in child care ${ }^{3}$}

3 This chapter has been submitted as: Aarts, M. C., Burk, W. J., \& Riksen-Walraven, J. M. (2016a). Caregiver and Environmental Characteristics as Predictors of Group Functioning in Child Care 


\begin{abstract}
Research findings: This study showed that group functioning in 44 early child care groups, as reflected in emotional climate and cohesion, is related to various characteristics of the child care environment. Caregivers' interactive skills (such as sensitive responsiveness and fostering positive peer interactions) and the space and furnishings of the classroom (such as room arrangement for play and gross motor play equipment) were found to carry most of the weight in explaining differences in group functioning. The program structure and the crowdedness of the classroom appeared to be less important for group functioning.

Practice or policy: The results of this first study on the relation between group functioning in child care and environmental characteristics of the child care group offer tentative guidelines for caregivers to foster group functioning. The results suggest that the emotional climate of a child care group may be promoted by improving caregivers' interactive skills, especially their sensitive responsiveness. The cohesion of a child care group (i.e., the number and complexity of peer relations in the group) may be promoted by improving caregivers' skills in fostering positive peer interactions and by providing a classroom with well-defined and varied play areas.
\end{abstract}




\section{Introduction}

In child care practice, group functioning is often referred to as an important group characteristic. Caregivers in early child care centers notice that group functioning differs among child care groups and has an impact on children's behavior and experiences in the group. They want to know how to promote positive group functioning. This requires knowledge of what factors determine group functioning in early child care centers, but such knowledge is scarce. Therefore, we examined group functioning in child care centers in relation to various theoretically relevant characteristics of the group's immediate environment, namely the interactive skills of the caregivers, the program structure of the child care day, and the physical environment of the child care group.

\section{Definition of Group Functioning in Child Care Groups}

Child care groups are defined here as peer groups, including all children in the group, but not the caregivers. Group functioning is defined as a pattern of relationships and emotions, which develops as a result of repeated interactions between the children in the group (Aarts, Burk, \& Riksen-Walraven, 2016b). Based on this definition Aarts et al. (2016b) developed a conceptual model underlying an instrument to measure group functioning in child care groups. As shown in table 1 (Aarts et al., 2016b), group functioning is assumed to be reflected in two broad dimensions: cohesion and emotional climate. Cohesion is the extent to which children's behavior represents mutual connection. Cohesion is reflected in three different constructs: network structure, action coordination, and involvement. Network structure refers to the number and pattern of relationships between children in the group and can be characterized by three network features: density (the relative number of peer relationships in the group), network strength (the average number of relationship 'paths' or intermediaries connecting any two children in the group) and inclusion (the relative number of children who have at least one peer relationship in the group). Action coordination, the second cohesion construct, refers to the extent to which the children in the group spontaneously coordinate their behavior with each other and focus their behavior on the same goal or meaning. The third cohesion construct, involvement, is the extent to which children show attention, care, and affection toward each other. The second broad dimension of group functioning is emotional climate. This is the affective atmosphere in the group, reflected in the predominant affective tone and energy level of the children's behavior. The first studies on group functioning in child care, conducted in Dutch child care groups, provided initial evidence for this conceptual model (Aarts et al., 2016b), and demonstrated stability in group functioning over a short-time period (Aarts, Burk, \& Riksen-Walraven, 2016c). 
Table 1. Conceptual Model Underlying the Group Functioning Instrument for Child Care (Aarts et al. 2016b)

\begin{tabular}{|c|c|c|}
\hline Dimension & Construct & Definition \\
\hline \multirow[t]{6}{*}{ A. Cohesion } & $\begin{array}{l}\text { 1. Network } \\
\text { Structure }\end{array}$ & The pattern of relationships among children in the group \\
\hline & a. Density & $\begin{array}{l}\text { The relative number of dyadic peer relationships in the } \\
\text { group }\end{array}$ \\
\hline & b. Strength & $\begin{array}{l}\text { The degree of connectedness among children in the } \\
\text { group, reflected in the number of relationship paths } \\
\text { (intermediaries) connecting any two children in the group. }\end{array}$ \\
\hline & c. Inclusion & $\begin{array}{l}\text { The relative number of children that have at least one peer } \\
\text { relationship in the group }\end{array}$ \\
\hline & $\begin{array}{l}\text { 2. Action } \\
\text { Coordination }\end{array}$ & $\begin{array}{l}\text { The extent to which children in the group spontaneously } \\
\text { and simultaneously coordinate their behavior with that of } \\
\text { other children, or focus their behavior on the same theme, } \\
\text { goal, or object }\end{array}$ \\
\hline & 3. Involvement & $\begin{array}{l}\text { The extent to which children in the group show positive } \\
\text { attention, care, and affection toward each other }\end{array}$ \\
\hline $\begin{array}{l}\text { B. Emotional } \\
\text { Climate }\end{array}$ & & $\begin{array}{l}\text { The most predominant affective tone and energy level of } \\
\text { children's behavior in the group }\end{array}$ \\
\hline
\end{tabular}

\section{Caregiver Interactive Skills and Group Functioning}

Caregiver interactive behavior is the most obvious environmental characteristic to affect group functioning because it is generally acknowledged as the key factor determining the quality of individual children's everyday experiences in child care (for an extensive overview, see Vandell \& Wolfe, 2000), and has also been shown to influence interactions between children in the group (Holloway \& ReichhartErickson, 1988; Howes, Hamilton, \& Matheson, 1994; Howes, Phillips, \& Whitebook, 1992; Howes \& Stewart, 1987; NICHD Early Child Care Research Network, 2001; Wishard, Shivers, Howes, \& Ritchie, 2003). Based on the associations between caregiver interactive behavior and interactions among children found in previous research, we expected the following caregiver skills to be related to group functioning in child care groups: fostering positive peer interactions, sensitive responsiveness to the children signals and needs, respect for the children's autonomy, and the expression of positive affect and negative regard toward the children. These interactive skills are elaborated below.

Fostering positive peer interactions, the skill theoretically most directly related to peer interactions, refers to the promotion and guidance of interactions between children in the group, for instance by creating opportunities for positive peer interaction, drawing the attention of children to their peers and peer relations, 
and explaining other children's emotions and behavior. Fostering positive peer interactions has been linked to more complex peer play, less peer refusal, less peerdirected negative initiatives and de-escalation of conflicts (Howes \& Matheson, 1992; Howes et al., 1992; Singer \& Hännikäinen, 2002; Singer, Van Hoogdalem, De Haan, \& Bekkema, 2011; Tierney Williams, Mastergeorge, \& Ontai, 2010). Positive interactions among peers, in turn, have been found to be associated with higher levels of child well-being (Gevers Deynoot-Schaub \& Riksen-Walraven, 2006) and social competence (Howes, 2000; Howes \& Phillipsen, 1998; NICHD Early Child Care Research Network, 2001). Based on these results we expected fostering positive peer interactions to be positively related to group functioning.

Sensitive responsiveness, the second caregiver interactive skill examined in this study, is generally regarded as the most important and most basic aspect of caregiver interactive behavior. It is defined as the extent to which a caregiver recognizes individual needs of children and responds appropriately and promptly to their cues and signals (Ainsworth, Blehar, Waters, \& Wall, 1978). Sensitive responsiveness is seen as a prerequisite for the development of a secure attachment between caregivers and children (Ainsworth et al., 1978; Bowlby, 1969). Sensitive responsiveness toward children has been associated positively with the children's sense of emotional security (Ahnert, Pinquart, \& Lamb, 2006), their well-being (De Schipper, Riksen-Walraven, \& Geurts, 2006) and with a positive climate in child care groups (LoCasale-Crouch et al., 2007). Furthermore, sensitive responsiveness has been linked to positive interactions among children in child care groups, i.e. to empathy, prosocial behavior, and positive play (Lamb \& Zakhireh, 1997; Mashburn et al., 2008; NICHD Early Child Care Research Network, 2001). Hence, we expected a positive relation between caregiver sensitive responsiveness and group functioning.

The third caregiver interactive skill, respect for autonomy, refers to the extent to which a caregiver recognizes and respects the children's perspective and intentions. In child care groups, caregivers' respect for autonomy has been associated with children's wellbeing (De Schipper, Riksen-Walraven, \& Geurts, 2006) and a positive emotional climate (Pianta et al., 2002). Respect for autonomy has been found associated with group cohesion too, namely with less peer refusal (Tierney Williams et al., 2010) and higher levels of cooperation and complexity of peer play (Howes, 2000; Ramani, 2012). Therefore, we expected respect for autonomy to be positively associated with group functioning in child care groups.

The last two caregiver interactive skills that we examined in relation to group functioning, expression of positive affect and negative regard, concern the emotional tone of caregivers' verbal and non-verbal behavior toward the children. More positive affect expressed by a caregiver in interaction with children has been found re- 
lated to higher levels of child well-being, while more negative regard is associated with less well-being of children in the caregiver's child care group (De Schipper et al., 2006). Caregiver positive affect is also associated with more positive involvement between peers (Wishard et al., 2003) and higher social competence of children (Pianta et al., 2002). So we expected the affective tone of caregivers' expressions to be associated with group functioning in child care groups.

\section{Beyond Caregiver Interactive Skills: Program Structure and Physical Environment}

Beyond the caregivers' interactive behavior, we examined two characteristics of the child care environment that have proven to be associated with interactions among the children in the group, and therefore are expected to influence group functioning, namely the program structure and the physical environment of the child care group.

Program structure and group functioning. The structure of a child care day, such as the frequency at which routines and activities are carried out in the child care group as a whole, the proportion of structured time and the opportunities for free play, affects the quantity and quality of interactions among children. During situations that are not structured by the caregiver like free play, children's interactions with peers have been found to be more expressive, positive and complex than during caregiver directed situations (Booren, Downer, \& Vitiello, 2012; Kontos \& Keyes, 1999; Rimm-Kaufman et al., 2005). Another relevant feature of the program structure with regard to peer interactions in a child care group is the extent to which activities are carried out in the group as a whole versus activities in small subgroup settings of for instance three or four children. More than whole group settings, small subgroup settings promote conversation and cooperation with peers (Booren et al., 2012). Based on these results, we expected better group functioning if the structure of the program offers the children more opportunities to interact with one another during free play and in small group settings.

Physical environment and group functioning. Children's social interactions are also affected by characteristics of the physical environment. In classrooms with higher physical density (more children per square meter), preschool aged children show more non-play and more disruptive and aggressive behavior, and have fewer interactions with other children than in classrooms with lower physical density (for an extensive overview, see Kantrowitz \& Evans, 2004). Even more important than crowdedness appears to be the arrangement of the furnishings and materials in the classroom, especially the number and variety of well-defined play areas in the room. A play area is a section in a child care room with clear physical boundaries, with sufficient, varied and accessible play materials for the particular activity, and 
enough space to play (Kantrowitz \& Evans, 2004). Children in classrooms divided in more varied play areas with appropriate play materials, show more explorative behavior, more interaction and cooperation with other children (Moore, 1986), and less aggressive and disruptive behavior (Rohe \& Patterson, 1974). In rooms with more children per play area (with many children in the room, or with only a few play areas, or both), children play less. So, we expected the quality of the physical environment, namely the crowdedness (the square meters per child and the number of children per play area), and the number of well-defined play areas in the classroom to be related to group functioning.

\section{Summary and Research Aims}

In this study we examined how group functioning of child care groups, as reflected in the cohesion and emotional climate of the group, is related to characteristics of the group's direct environment, namely caregiver interactive skills, the program structure of the child care day, and the physical environment of the child care group. We expected the caregiver interactive skills of fostering positive peer interactions, sensitive responsiveness, respect for autonomy, and positive affect to be positively associated with group functioning. Caregiver negative regard was expected to show a negative relation with group functioning. With regard to the program structure of the child care day, we expected the number of free play opportunities and small group settings to be positively related to group functioning. The number of well-defined play areas in the classroom was also expected to be positively related to group functioning, while crowdedness was expected to show a negative relation with group functioning.

\section{Method}

\section{Participating Groups and Caregivers}

A total of 160 Dutch child care centers were asked if they were willing to cooperate with one of their child care groups in this study, first by letter, and a few weeks later by phone. A group could participate if the caregivers of the group and the parents of the children present on the observation day gave their written consent, and if at least eight children were present on the observation day. Fifty-three centers (33\%) agreed to cooperate, of which eight groups did not meet the participation criteria. The sample contained only one toddler group (1-2 yr), so this group was excluded from the statistical analysis. The final sample consisted of 44 groups, i.e., 30 mixed age groups (0-4 yr) and 14 preschool groups (2-4 yr). In these groups a total of 521 
children and 105 caregivers were observed. All caregivers but one were female. The vast majority (91\%) was born in the Netherlands. On average, the caregivers were 34.4 years old (range 23-62 years), had 7.0 years of working experience in child care (range 1-29 yrs) and worked 26.2 hours per week (range 8-37 hrs). Most of them $(87 \%)$ were educated at intermediate level, the mandatory vocational level for child care in The Netherlands, the other $13 \%$ had a more advanced degree.

\section{Procedure}

Each group was visited by the first author. A visit lasted from 9.00 a.m. to 5 p.m. The caregivers were asked to keep their usual daily schedule. During the visit, the group of children was filmed. The children present in the classroom for at least four hours during the day of the visit were regarded as 'the group'. The group was filmed inside, during free play and waiting situations. In free play situations most children can choose what, where, and with whom they play. Waiting situations are transitional situations in which caregivers are busy with organizational tasks like setting the table.

To observe group functioning, the video recordings were divided afterwards into 3-minute intervals. On average 22.4 intervals were obtained per group (range 15-24). For a detailed description of the filming procedure of the group of children, see Aarts et. al (2016b).

To assess caregiver interactive skills, caregivers present in the classroom for at least four hours were also filmed during the visit to the child care group, in separate filming episodes. Each caregiver was filmed in four different naturally occurring situations in which they interacted with children, namely diapering, guidance of a play activity, transition between different activities, and snack or lunch time. Per caregiver on average 3.5 situations were obtained (range 1-4). Thirteen caregivers $(12 \%)$, seven of which were only present for half a day, were filmed in one or two situations. On average a situation was filmed for 7.4 minutes (range 2-8 minutes).

Next to the filming, the researcher visiting the group completed two ITERS-R or ECERS-R subscales to assess program structure and space and furnishings, and recorded characteristics of the physical environment of the classroom.

\section{Instruments and Measures}

Group functioning. Group functioning was rated from the videotapes of the groups of children using the Group Functioning Instrument for Child Care (GFICC), developed by Aarts et al. (2016b). The GFI-CC includes two coding systems, summarized in Table 2 (Aarts et al., 2016b). Time sampling of interactions between individual children in the group is used to assess the network structure of the 
group, while rating scales at the level of the child care group are used to assess action coordination, involvement, and emotional climate.

Network structure. Measurement of the three constructs reflecting the network structure (density, strength, inclusion) was based on the observed interactions between children in each group (time sampling). The three-minute intervals of 10 groups were initially scored together by the first author and a trained research assistant. Next, 10 groups (590 interactions) were scored separately by the first author and the research assistant. Inter-rater reliability was assessed with an intraclass correlation (ICC), which indicated almost perfect agreement (.97). The research assistant coded the interaction matrices for the remaining groups.

The time-sampling coding scheme resulted in the identification of 3922 interactions observed between dyads, ranging from 0-21 interactions per dyad. Based on the observed interactions, dyadic relationships were identified. A relationship was defined as a behavioral preference child A has for child B, which was inferred when the number of observed interactions one child had with another child was greater than expected by chance (Schaefer et al., 2010). A total of 1111 relationships were identified. The network structure of a group was based on these relationship measures and represented in scores for density, strength and inclusion (see Table 2).

Action coordination, involvement, and emotional climate. The video recordings of the group of children were also observed to obtain three global group functioning measures; action coordination, involvement and emotional climate in the group, which were rated on 5-point Likert scales (see Table 2). A trained research assistant, blind to the network structure scores and other data, and the first author rated the behavior of the children in the group on the three 5-point scales for each of the three-minute intervals filmed in the group. The inter-rater reliability (two way absolute agreement single measure ICC) based on 214 separately scored 3-minute intervals (10 groups), was for action coordination, involvement, and emotional climate $.63, .53$, and .65 , respectively, which is viewed as moderate inter-rater reliability (Landis \& Koch, 1977).

Caregiver interactive skills. Most rating scales to assess caregiver interactive skills focus on caregivers' interactions with individual children (Ainsworth et al., 1978; Erickson, Sroufe, \& Egeland, 1985; NICHD, 1996). In the present study we wanted to rate caregiver interactive skills not only in interactions with individual children in the group, but also at the group level. Therefore, we used rating scales that were designed especially for that purpose, namely the Caregiver Interaction Profile scales (CIP; Helmerhorst, Riksen-Walraven, Vermeer et al., 2014) and the caregiver-child interaction scales developed by De Schipper et al., (2006). In both sets of scales, the highest scores for the different interactive skills is only obtained 


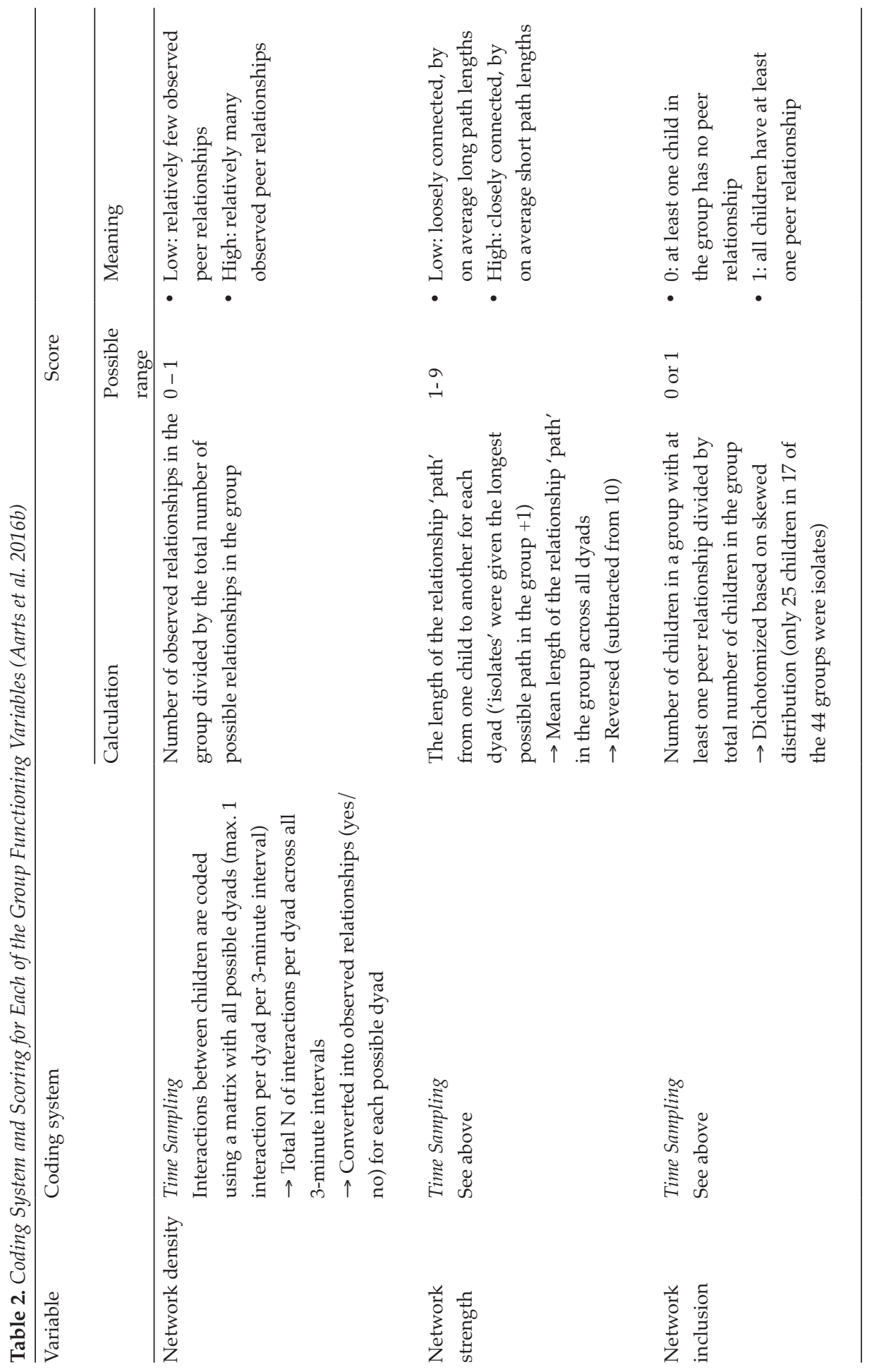




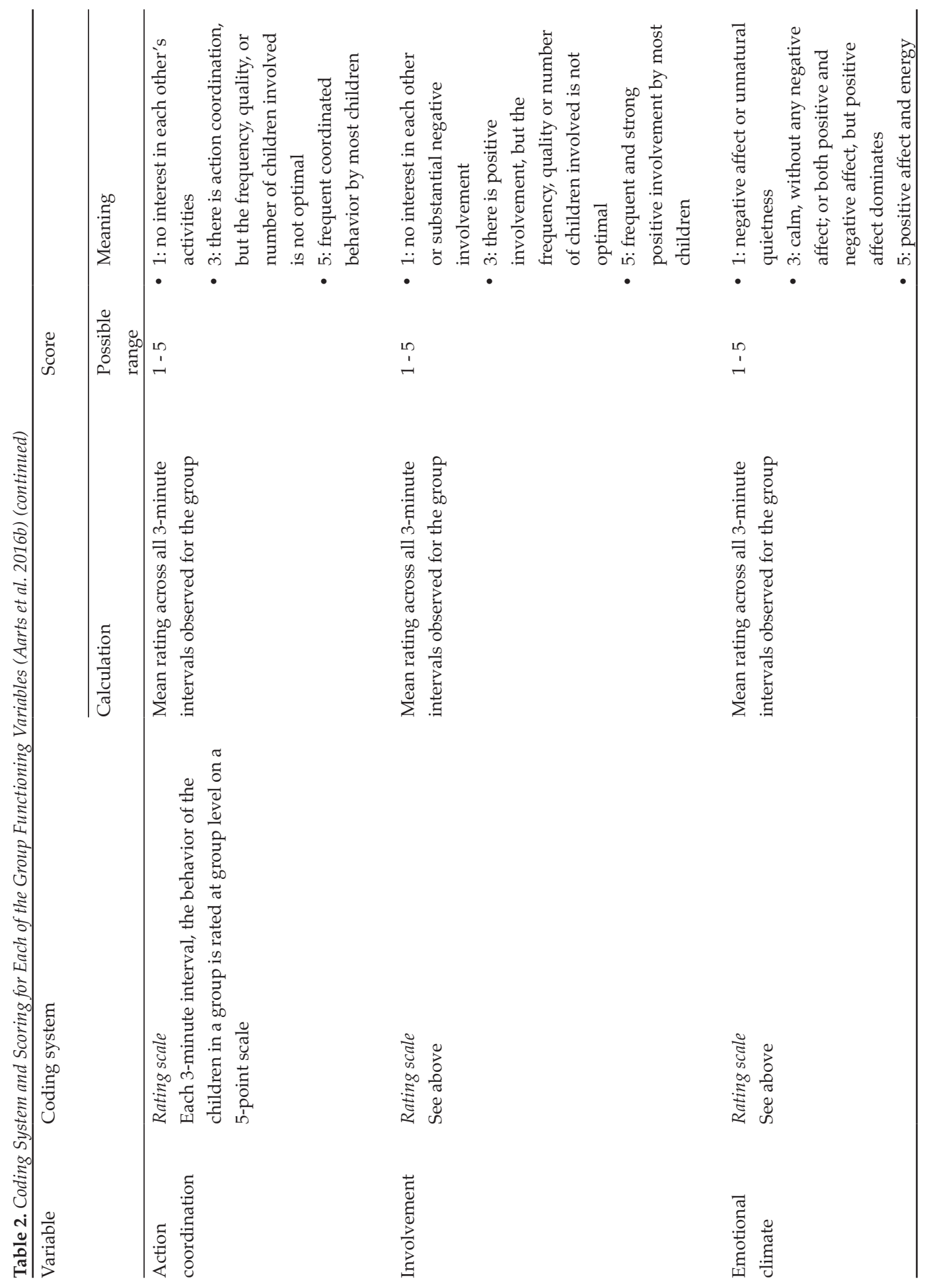


when the caregiver divides her attention across children and shows high quality interactive behavior consistently toward all children in the group. Each of the six interactive skills was rated from the videotapes on a single 7-point rating scale $(7=$ very high, 6 = high, $5=$ moderate $/$ high, $4=$ moderate, $3=$ moderate $/$ low, $2=$ low, $1=$ very low). Each rating scale entails a definition of the corresponding construct, a broad description of the relevant behaviors, and a detailed behavioral description for each separate scale point.

The first three rating scales were taken from the Caregiver Interaction Profile scales (Helmerhorst, Riksen-Walraven, Vermeer, et al., 2014). The scale fostering positive peer interactions rates the extent to which the caregiver gives positive attention to spontaneous positive peer interactions and actively stimulates positive interactions between children, for instance by creating situations that promote positive interactions or by directing the children's attention to each other in a positive way. A high score on this scale reflects a situation in which the caregiver both reacts positively on positive interactions and actively promotes them. Caregivers with a low score on this scale seem not to notice positive interactions between children or misinterpret them.

Sensitive responsiveness reflects the degree to which a caregiver reacts promptly and adequately on children's signals for emotional support. A high score is given to a caregiver who shows warm attention and emotional support when needed and therefore serves as a 'safe haven' for all the children. A caregiver with a low score on this scale hardly gives any emotional support at all. She fails to recognize the children's signals and cues, or reacts too late or inadequately.

The scale respect for autonomy measures the extent to which the caregiver acknowledges the children as individuals with motives and perspectives of their own. A caregiver with a high score on this scale explicitly acknowledges the children's individuality by stimulating them to perform activities and tasks autonomously and make their own choices. She does not enforce her own ideas or perspectives in an intrusive way or without giving attention to the children's perspective. A low score indicates that a caregiver ignores the children's perspectives or treats the children without respect.

The final two rating scales were taken from the caregiver-child interaction scales, developed by de Schipper et al (2006). The scale positive regard assesses the extent to which a caregiver expresses positive feelings toward the children, for instance by speaking in a warm tone of voice, hugging or other expressions of physical affection, facial expressions, smiling, laughing with the children, enthusiasm, and general enjoyment of the children. Caregivers with a high score on this scale frequently show strong positive affect toward most of the children. A low score 
represents the absence of positive affect toward the children; the caregiver's affect is neutral, flat or negative.

Negative regard represents the caregiver's expression of impatience, irritation, frustration, anger, dislike, or rejection of the children. A caregiver with a high score on this scale is overtly, facially, and vocally negative toward the children. The nature of the interaction is threatening or frightening for the children. A caregiver scoring low on this scale shows no signs of negative behavior.

For each of the four situations in which the caregiver was filmed (diapering, guidance of play activity, transition, and lunch or snack time) the five interactive behaviors were rated. A mean score across the four situations was calculated for each of the five rating scales for each caregiver. For each scale, group level scores were calculated by averaging the mean scores across the caregivers observed in the group. An overall score for the caregiver interactive skills at the level of the child care group was computed by averaging the standardized group mean scores across the five caregiver skills. For this calculation, the mean score on negative regard was reversed, so a high score on negative regard would reflect high qualitative interactive behavior, like the other caregiver skills. The episodes were independently rated by two trained observers. Inter-rater reliability (ICC), computed on $20 \%$ of the episodes ( 24 caregivers) was . 85 , namely .78 for fostering positive peer interactions, .64 for sensitive responsiveness, .63 for respect for autonomy, .64 for positive affect, and .60 for negative regard.

Program structure. To determine the structure of the child care day and opportunities for free play and play in small groups, we used one of the seven subscales of the ITERS-R (Harms, Cryer, \& Clifford, 2003) and ECERS-R (Harms, Clifford, \& Cryer, 2005), namely 'Program Structure'. The ITERS-R and ECERS-R are widely used instruments to measure the quality of the child care environment in child care centers; the ITERS-R is used in groups in which more than half of the children are younger than 30 months, whereas the ECERS-R is used in groups in which more than half of the children are between 30 and 48 months of age. The items of the ITERS-R and ECERS-R are rated on a 7-point scale with descriptions for the scores 1 (inadequate), 3 (minimal), 5 (good), and 7 (excellent). In this study, the ITERS-R was used in the 16 groups in which at least half of the children present on the observation day were younger than 30 months. In the other 28 groups the ECERS-R was used. The ITERS-R and ECERS-R subscale program structure contains three items: schedule, free play, and group time. The item schedule assesses the extent to which the daily structure meets the needs of individual children, the opportunities for play during the child care day, the balance between in- and outside play, and between active and quiet activities, and the smoothness of transitional 
situations. The item free play refers to the children's opportunities for free play, the quality of the play material and caregivers' surveillance and support during children's play. The third and last item in the subscale program structure group time assesses whether group activities match with the developmental level and needs of individual children, the extent to which caregivers are positive, accepting and supportive during group activities, and children's possibilities to play in small subgroups or individually during the child care day (this last feature is only assessed in the ECERS-R). With the ITERS-R, if no whole group activities are observed, this item is not scored. This was the case in 9 of the 16 groups where the ITERS-R was used. The program structure mean score of a child care group was calculated by averaging the item scores across the scored items. In the statistical analysis both the item scores and mean scores of the program structure subscale were used. The researcher who applied the ITERS-R and ECERS-R subscales during her visit to the group was trained by one of the translators of the Dutch version of the ITERS-R and ECERS-R. Cronbach's alpha for the three items of the subscale could be computed for 35 groups, and was 62 .

Space and furnishings. To measure the quality of the physical environment of the group we used the ITERS-R or ECERS-R subscale space and furnishings. In the ITERS- $R$, this subscale entails seven items, the ECERS- $R$ includes an additional two items. The item indoor space concerns the physical quality of the classroom, the footage, temperature, cleanliness, ventilation, day light regulation, and the accessibility for disabled children. Furniture for routine care, play, and learning refers to the availability of solid and comfortable furniture that promotes the independence of the children, such as open storage space for play material, and tables and chairs of children's size. The item furniture for relaxation and comfort assesses the softness in the classroom, such as rugs, pillows, and soft play materials and an accessible cozy corner, protected from active play. Room arrangement for play concerns the number of different play areas, the extent to which areas for quiet and active play and walking routes are separated from each other, the accessibility of the play material for the children, and the extent to which the classroom can be overviewed by and is convenient for the caregiver. The item space for privacy is only found in the ECERS$\mathrm{R}$, and refers to the number of spaces for privacy in the classroom where one or two children can play undisturbed. Child related display of materials assesses the number and quality of pictures, photographs, hanging objects, children's art products, or other materials for children to look at, at children's eye level. Gross motor play (ITERS-R) concerns space for gross motor activities, the quality of the outer space, the amount and appropriateness of the material for gross motor activities, and the frequency by which this is used. In the ECERS-R, these features are assessed 
with two items: Space for gross motor play and Gross motor play equipment. The mean score of a child care group on the subscale space and furnishing was calculated by averaging the item scores. In the statistical analysis both the item scores and mean scores of the space and furnishing subscale were used. Cronbach's alpha for the eight items of the subscale, calculated for 28 groups, was .61. The application of the subscale space and furnishings was identical to the application of the subscale program structure described above.

Crowdedness. Two measures for crowdedness were used. First, the number of square meters per child was defined as the square footage of the classroom, as measured by the observer, divided by the maximum number of children present on the observation day. The second crowdedness variable, the number of children per play area was defined as the maximum number of children present on the observation day, divided by the total number of play areas in the classroom. A play area was described as a clearly defined section in a child care room with functionally related materials assembled and exhibited, and space to play. Temporary play areas were also considered as play area, for instance a carpet with wooden blocks, or a table with craft supplies, on the condition children could play here for at least one hour during the observation day.

\section{Results}

The results are presented in three sections. The first section reports the results of preliminary analyses, i.e., the distributions of all study variables and the correlations among the group functioning variables and among the contextual variables. The second section presents the correlations between the contextual variables on the one hand and the group functioning variables on the other. The third and final section reports the results of multiple regression analyses examining the independent contribution of the different groups of contextual characteristics (caregiver interactive skills, program structure, and space and furnishings) in the prediction of the different group functioning variables.

\section{Preliminary Analyses}

Table 3 presents the means and standard deviations for the study variables. The average network structure scores indicate that nearly one third of all possible relationships in the groups were observed (density), that children were connected to each other on average through three or four relationship paths (strength) and that in most groups (61\%) all children had one or more observed relationships (inclu- 
Table 3. Mean Scores, Standard Deviations, and Correlations with Group Functioning for Caregiver Interactive Skills, Program Structure, Space and Furnishings, Crowdedness ( $N=44$ groups)

\begin{tabular}{|c|c|c|c|c|c|c|c|c|}
\hline Variable & $\sum$ & $\begin{array}{l}\widehat{\hat{D}} \\
\text { ज्ञ }\end{array}$ & 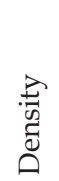 & $\begin{array}{l}\text { 吉 } \\
\text { Dै } \\
\text { के }\end{array}$ & 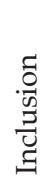 & 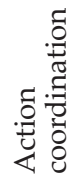 & 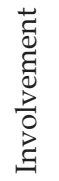 & 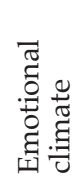 \\
\hline
\end{tabular}

\section{Group functioning}

\section{Cohesion}

Network structure

Density

Strength (rev. $)^{1}$

Inclusion (dich)

Action coordination

Involvement

Emotional climate

\section{Caregiver interactive skills (group level)}

Caregiver interactive skills mean

(standardized)

Fostering positive peer interactions (CIP)

Sensitive responsiveness (CIP)

Respect for autonomy (CIP)

Positive affect (De Schipper)

Negative regard (De Schipper)

Program structure (ITERS-R, ECERS-R)

Program structure mean

Schedule

Free play

Group time ( $N=35)$

Space and Furnishings (ITERS-R, ECERS-R)

Space and Furnishings mean

Indoor Space

Furniture routine care, play and learning

Furnishings for relaxation and comfort

Room arrangement for play

Space for privacy $(N=28)$

Child-related display

Gross motor play $(N=16)$

Space for gross motor play $(N=28)$

Gross motor play equipment $(N=28)$

\section{Crowdedness}

M2 per child

Number of children per play area

${ }^{1}$ Higher scores indicate higher strength

${ }^{* *} p<.01,{ }^{*} p<.05$, one tailed
$.32 \quad(.06)$

$6.35(1.63) \quad .72^{* *}$

$.61(.49) .50^{* *} .64^{* *}$

$\begin{array}{lllll}2.83 & (.53) & .41^{* *} & .10 & .18\end{array}$

$\begin{array}{llllll}3.08 & (.51) & .39^{* *} & .07 & .16 & .90^{* *}\end{array}$

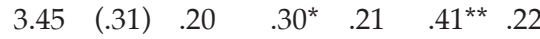

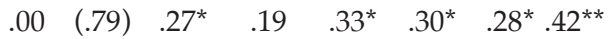

$2.00 \quad(.58) \quad .31^{*} \quad \begin{array}{lllll}.12 & .25 & .33^{*} & .31^{*} .24\end{array}$

$\begin{array}{lllllll}4.92 & (.57) & .23 & .16 & .32^{*} & .31^{*} & .26^{*} .44^{* *}\end{array}$

$\begin{array}{llllllll}4.73 & (.45) & .09 & .10 & .23 & .19 & .16 & .34^{*}\end{array}$

$3.40(1.00) \quad .26^{*} \quad .20 \quad .27^{*} \quad .30^{*} \quad .29^{*} .31^{*}$

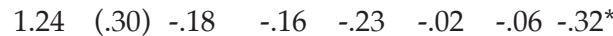

$\begin{array}{lllllll}3.70(1.15) & .04 & .01 & .05 & .23 & .15 & .45^{* *}\end{array}$

$\begin{array}{lllllll}4.34(1.63) & .02 & .10 & .08 & .24 & .10 & .49^{\text {** }}\end{array}$

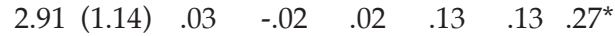

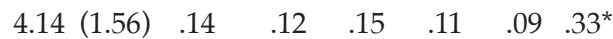

$3.70(1.01) \quad .31^{*} \quad .22 \quad .26 \quad .42^{* *} .32^{*} .38^{* *}$

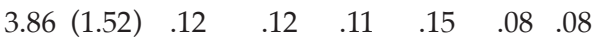

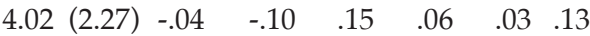

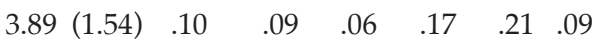

$2.86(1.36) \quad .49^{* *} \quad \begin{array}{llllll}.40^{* *} & .20 & .38^{* *} & .23 & .35^{*}\end{array}$

3.25 (1.69) $\quad .04 \quad-.23 \quad-.17 \quad .38^{*} \quad .35^{*} .10$

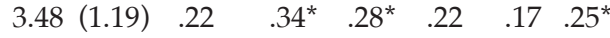

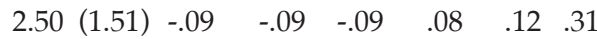

$\begin{array}{llllllll}4.93 & (1.76) & .25 & .24 & .24 & .08 & .12 & .07\end{array}$

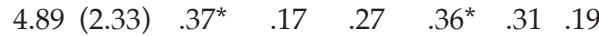

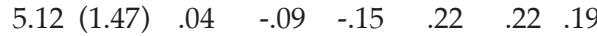

$\begin{array}{llllll}2.73(1.23) & -.09 & .20 & .16 & -.25 & -.30 *-.12\end{array}$ 
sion). On average, the groups showed moderate levels of action coordination and involvement, and a mainly positive and calm emotional climate. The average scores on the caregiver interactive skills sensitive responsiveness, respect for autonomy, and positive affect were moderate. The average scores on negative regard were low, representing few signs of negative behavior of the caregivers. The low average score on fostering positive peer interactions indicates that in most groups the caregivers hardly gave any attention to positive interactions among the children, nor did they promote them. The average scores on the ITERS-R and ECERS-R items and subscales program structure and space and furnishing were moderate. Table 3 also shows that the group functioning variables were moderately interrelated, in line with the conceptual model presented in Table 1.

Table 4 presents the correlations among the caregiver interactive skills, the ITERS-R / ECERS-R program structure and space and furnishings variables, and the additional measures of the physical environment. The caregiver interactive skills were moderately and significantly interrelated, indicating they reflect different aspects of the same construct, namely caregiver interactive competence. The same holds for the three items of the program structure subscale. Among the space and furnishings items the picture is less consistent. The crowdedness variables show a negative (non-significant) relation with each other, reflecting relatively few children per play area in large classrooms. The sum scores of the three contextual domains caregiver skills, program structure, and space and furnishings were significantly and moderately interrelated.

\section{Correlations Between Contextual Characteristics and Group Functioning}

Caregiver Interactive Skills in Relation to Group Functioning. The correlations between group functioning variables and the measures characterizing the child care environment are shown in Table 3. The five caregiver interactive skills were related to the group functioning variables, although the strength of the associations varied and network strength was not significantly related to any of the caregiver measures. The caregiver interactive skills mean score and all scores for the distinct caregiver skills, except for fostering positive peer interactions, were related stronger to the emotional climate than to the cohesion of the child care group. Indeed, caregiver respect for autonomy and negative regard were only significantly related to emotional climate, and not to cohesion measures. Sensitive responsiveness, positive affect, and the caregiver interactive skills mean score were significantly associated both with emotional climate and with one or more cohesion variables. Fostering positive peer interactions was the only caregiver skill not related to emotional climate. 


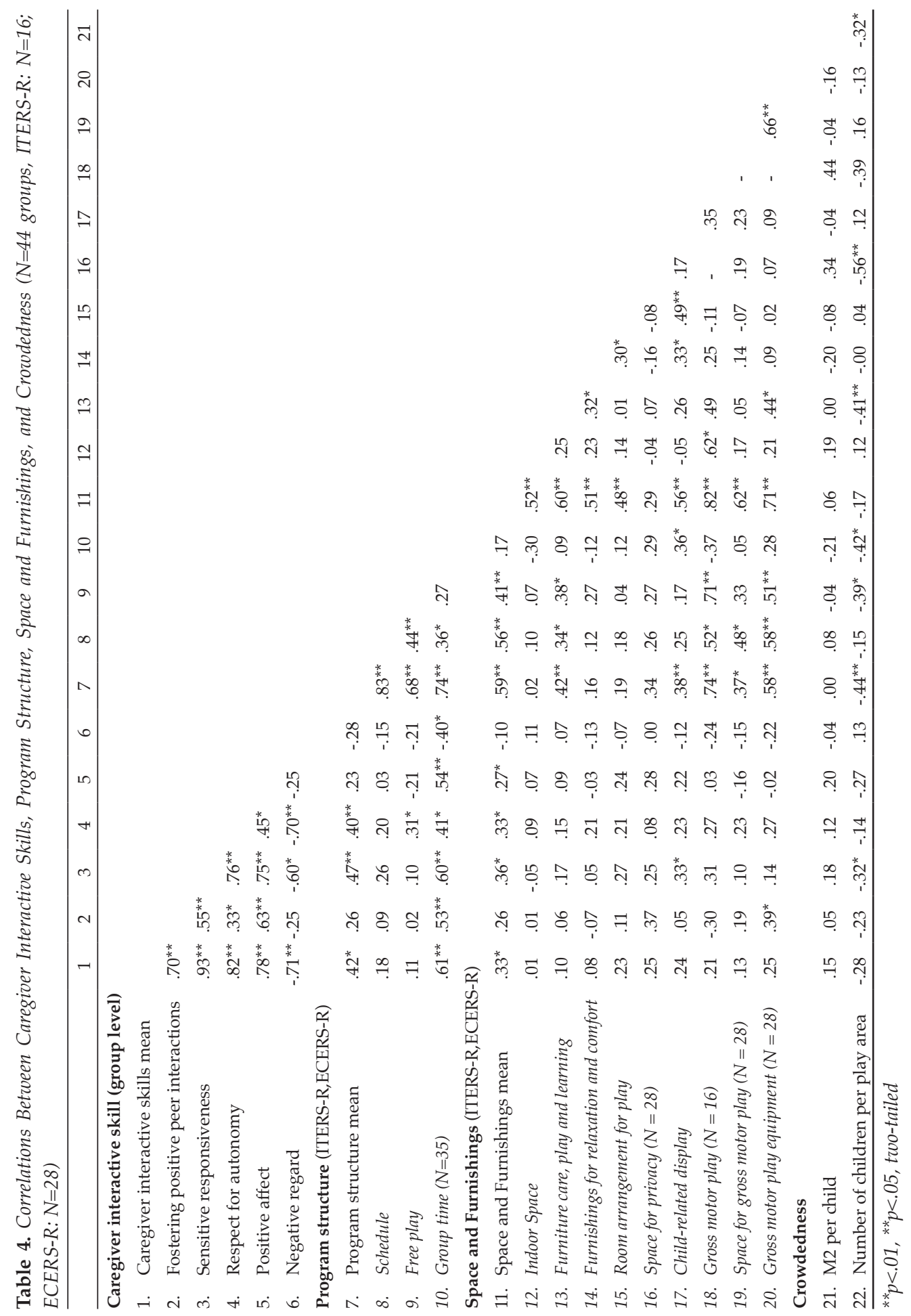


Program Structure in Relation to Group Functioning. As can be seen in Table 3 , the mean score on the ITERS-R/ ECERS-R subscale program structure was positively related to group functioning, but only to emotional climate. The same was true for the individual items of this subscale. So our expectation that group functioning would be better in groups where the program structure offers children opportunities for free play and play in small subgroups, was only met with regard to one dimension of group functioning, namely emotional climate.

Space and Furnishing in Relation to Group Functioning. The ITERS-R/ECERS$\mathrm{R}$ subscale space and furnishings showed a more consistent association with group functioning than the subscale program structure (see Table 3 ). The space and furnishing mean score was significantly related to the two group functioning dimensions cohesion and emotional climate, in the expected direction. At the level of the distinct items, a relation with both group functioning dimensions was found for the items room arrangement for play and child related display; these items were significantly and moderately correlated with both cohesion and emotional climate. The items space for privacy and gross motor play equipment, only assessed in groups in which more than half of the children were older than 30 months, showed a significant association with cohesion but not with emotional climate.

Crowdedness in Relation to Group Functioning. Contrary to our expectation, the number of square meters per child was not related to group functioning. The number of children per play area was significantly and negatively related to involvement, indicating that, as expected, children show more mutual involvement in classrooms with fewer children per play area.

\section{Multiple Regressions Predicting Group Functioning}

Five multiple regression analyses were conducted to examine the relative contribution of the three types of contextual variables (caregiver skills, program structure, and space and furnishing) in the prediction of group functioning. Separate analyses were performed for each group functioning measure (see Table 5). The contextual predictors explained a statistically significant amount of variance for four of six group functioning variables, namely emotional climate and three of the five cohesion measures, (i.e., density, inclusion, and action coordination). In general, the relative contributions of the contextual variables to the prediction of these group functioning measures are in line with their correlations, with caregiver skills and space and furnishing explaining more variance in group functioning than program structure. For emotional climate and inclusion, the three contextual variables collectively predicted $29 \%$ and $28 \%$ of the variance respectively, with the caregiver skills as the only significant predictor. For density $23 \%$ of the variance was ex- 
plained, with significant contributions of caregiver skills and space and furniture, while for action coordination the three predictors explained $21 \%$ of the variance, with space and furnishing emerging as the only statistically signficiant predictor.

Table 5. Multiple Regression Outcomes for the Prediction of Group Functioning Variables from Caregiver Interactive Skills, Program Structure, and Space and Furnishing $(N=44)$ and Logistic Regression Outcomes Used for the Prediction of the Dichotomous variable Inclusion

\begin{tabular}{|c|c|c|c|c|c|c|c|}
\hline \multirow{2}{*}{$\begin{array}{l}\text { Dependent } \\
\text { variable }\end{array}$} & \multirow[t]{2}{*}{ Predictor } & \multirow[t]{2}{*}{ B } & \multirow[t]{2}{*}{ se } & \multirow{2}{*}{$\begin{array}{l}\beta / \\
\text { OR }\end{array}$} & \multirow[t]{2}{*}{$p$} & \multicolumn{2}{|c|}{ Model summary } \\
\hline & & & & & & $\mathrm{R}^{2}$ & $p$ \\
\hline \multirow[t]{3}{*}{ Density } & Caregiver interactive skills & .03 & .01 & .36 & .016 & .23 & .016 \\
\hline & Program structure & -.02 & .01 & -.34 & .056 & & \\
\hline & Space and furnishing & .02 & .01 & .38 & .013 & & \\
\hline \multirow[t]{3}{*}{ Strength (rev.) ${ }^{1}$} & Caregiver interactive skills & .54 & .26 & .30 & .039 & .14 & .114 \\
\hline & Program structure & -.34 & .21 & -.27 & .106 & & \\
\hline & Space and furnishing & .38 & .21 & .27 & .077 & & \\
\hline \multirow[t]{3}{*}{ Inclusion } & Caregiver interactive skills & .56 & .28 & 1.75 & .047 & .28 & .040 \\
\hline & Program structure & -.36 & .27 & .70 & .186 & & \\
\hline & Space and furnishing & .51 & .33 & 1.67 & .123 & & \\
\hline \multirow{3}{*}{$\begin{array}{l}\text { Action } \\
\text { coordination }\end{array}$} & Caregiver interactive skills & .13 & .10 & .19 & .194 & .21 & .025 \\
\hline & Program structure & -.04 & .09 & -.10 & .615 & & \\
\hline & Space and furnishing & .22 & .08 & .41 & .004 & & \\
\hline \multirow[t]{3}{*}{ Involvement } & Caregiver interactive skills & .14 & .10 & .22 & .138 & .15 & .093 \\
\hline & Program structure & -.07 & .08 & -.15 & .441 & & \\
\hline & Space and furnishing & .17 & .07 & .34 & .008 & & \\
\hline \multirow{3}{*}{$\begin{array}{l}\text { Emotional } \\
\text { climate }\end{array}$} & Caregiver interactive skills & .12 & .05 & .29 & .011 & .29 & .004 \\
\hline & Program structure & .07 & .04 & .26 & .090 & & \\
\hline & Space and furnishing & .04 & .05 & .12 & .447 & & \\
\hline
\end{tabular}

${ }^{1}$ Higher scores indicate higher strength

Note: Beta weights $(\beta)$ are reported, with one exception: Odds ratios (OR) are reported for the logistic regression analysis involving inclusion.

\section{Discussion}

In the present study we examined the relation between group functioning and characteristics of the immediate environment of the child care group that were expected to affect group functioning, namely caregiver interactive skills, the program structure of the child care day, space and furnishings, and crowdedness. In general, 
caregiver skills and space and furnishing showed the expected association with group functioning, while program structure was only related to one of the two dimensions of group functioning, namely emotional climate, and crowdedness was only significantly associated with involvement. Multiple regression analyses confirmed that caregiver interactive skills and space and furnishings carry most of the weight in explaining differences in group functioning among child care groups. These results are discussed in more detail below.

\section{Caregiver Interactive Skills and Group Functioning}

As caregiver interactive skills are known to affect peer interactions in child care groups, we expected these skills to be associated to group functioning as well. This appeared to be the case: all of the six caregiver skills we observed were related to one or more aspects of group functioning. The correlational pattern suggests that all skills, with the exception of fostering positive peer interactions, are relevant for the emotional climate of the child care group, with sensitive responsiveness as the most important caregiver skill. This is not surprising, since all caregiver skills, except fostering positive peer interactions (that was not measured by De Schipper), have been shown to affect the well-being of the children in the group (De Schipper et al., 2006), and higher well-being of individual children will be reflected in a more positive emotional climate in the group. Caregiver sensitive responsiveness and positive affect were not only associated with the emotional climate of the group, but also with the second dimension of group functioning, namely cohesion. The broad affect of sensitive responsiveness on group functioning supports the notion of sensitive responsiveness as the most basic caregiver skill. It is generally recognized that children develop a sense of security in interactions with a sensitive caregiver. This 'secure base' promotes exploration of the environment (Ainsworth et al., 1978), and thus also interactions with peers. Fostering positive peer interactions, the caregiver skill focused directly on children's mutual interactions, was also related to cohesion and therefore seems to be effective: in groups with caregivers who promote peer contacts, more relationships among children were observed, and the children's behavior was also more coordinated and involved.

The regression analyses revealed that in three of the four significant models caregiver interactive skills were significant predictors of group functioning, which is consistent with the key role these caregiver skills are assumend to play in determining child care quality. 


\section{Program Structure and Group Functioning}

We expected program structure, in particular the opportunities for free play and play in small subgroups, to show a positive relation to group functioning. The results partly support this hypothesis, by showing that program structure was associated with emotional climate, but not with the second main dimension of group functioning, i.e., cohesion. Thus, opportunities for free play, measured by the item free play, and chances for play in small subgroups, measured by the item group time, were not related to more complex interactions and relationships among the children, in contrast to what was found in other studies (Booren et al., 2012; Kontos \& Keyes, 1999; Rimm-Kaufman et al., 2005). Evidently, the opportunities for free play and play in small subgroups are by themselves not sufficient to elicit involved and coordinated peer play. Our results suggest that challenging play areas and caregiver skills are also required to realize involved and coordinated peer play. In conclusion, the structure of the child care day, compared to the other contextual variables, plays a minor role with regard to group functioning.

\section{Physical Environment and Group Functioning}

As expected, space and furnishing of the classroom was positively related to group functioning, both to cohesion and to emotional climate. The most robust correlation pattern between space and furnishing and group functioning was found for the items room arrangement for play and child related display, which were both related to cohesion and emotional climate. The item room arrangement for play assesses the extent to which the classroom consists of varied and well-defined play areas with accessible play material, and child related display reflects the extent to which the classroom is decorated with material appropriate for the children's ages and interests. Both room arrangement and decoration of the classroom are in large part determined by the caregivers of the group. Generally, the management of the child care center decides about the building and classrooms and buys the furniture, the 'hardware' so to speak, but caregivers arrange the furniture, display the materials and decorate the classroom, in other words, they supply the 'software' of the physical environment. The items of the space and furniture subscale, which reflect physical aspects of the environment that are less influenced by the caregiver, showed no significant relation with any group functioning measure. This concerns the items indoor space, furniture for routine care, play and learning, and furnishings for relaxation and comfort (assessing e.g. classroom size, illumination possibilities, solidity and safety of the furniture, presence of carpets or a couch). Apparently, properties of the classroom directly affected by the caregiver are more relevant to group functioning than the purely physical characteristics of the classroom. 
The gross motor play equipment item of the ECERS-R subscale space and furnishing, only measured in groups where most children were 30 months or older, was also significantly related with group functioning. This points to the possible relevance of play activities in relation to functioning of child care groups, at least with older children. The item gross motor play equipment measures the availability of material and opportunities for gross motor play. Gross motor play seems to encompass characteristics that are associated with positive peer interaction. First, gross motor play mostly concerns situations in which children can do what they like and with whom they want to play. Compared to situations structured by the caregiver, these unstructured situations are found to promote more expressive, positive and complex peer interactions (Booren et al., 2012; Kontos \& Keyes, 1999; Rimm-Kaufman et al., 2005). Second, often the whole child care group or at least a large part of the group is involved in gross motor play, so children can choose among a lot of possible interaction partners. The assumption that gross motor play might promote positive and complex group functioning is confirmed by earlier findings of Fontaine (2005), who showed that materials for gross motor play promote social attention and exchange among toddlers. However, in the present study the relation between group functioning and different kinds of play activities was not examined so this remains an interesting topic for future research.

In conclusion, our results suggest that space and furnishing, especially the aspects determined by the caregiver, is relevant for group functioning. The regression analyses indicated that space and furnishing is a significant predictor for some aspects of cohesion, but - unlike caregiver interactive skills - does not significantly predict the emotional climate. It seems to primarlily affect the quality of the peer interactions and the number of relationships between children in the group.

Contrary to our expectation, we found crowdedness of the care group (reflected in square meters per child and number of children per play area) to be significantly related to only one of the six group functioning measures. This is not in agreement with earlier research that showed that children have more interactions and cooperation with peers in larger classrooms and classrooms with more play areas (Kantrowitz \& Evans, 2004). However, these earlier studies examined more crowded classrooms, with much higher physical density than observed in the present study. For instance, Maxwell (1996) observed classrooms where density varied from $2.46-4.71 \mathrm{~m}^{2} /$ child, and Loo \& Kennely (1979) compared children's behavior in situations with a density of 1.47 or $2.94 \mathrm{~m}^{2} /$ child. In the present study the average footage per child was much higher, over $5 \mathrm{~m}^{2}$ per child, which might have affected the association with group functioning. 


\section{Implications for Measuring Group Functioning}

The results of this study also shed some more light on the operationalization of group functioning. In an earlier study using the GFI-CC to assess group functioning in child care groups (Aarts et al., 2016b), the question was raised whether the cohesion constructs action coordination and involvement, which are highly correlated, can be distinguished with children this young, and whether both constructs are needed for a reliable assessment of cohesion in early child care groups. The present study shows that action coordination and involvement are associated with the contextual variables in a similar way, which further supports the idea that the two constructs cannot (yet) be distinguished with young children. So it may be sufficient to include only one of these two highly related constructs as a measure of group functioning for this young age group. Given that action coordination is somewhat more strongly related to most environmental variables, it seems the better choice. Accordingly, in future studies, it can be considered to simplify the instrument GFI-CC and assess cohesion solely by measuring network structure and action coordination.

\section{Limitations and Suggestions for Future Research}

This study is the first to examine the functioning of child care groups in relation to characteristics of the child care environment. As such, it has yielded novel and interesting information with possibly important implications for child care practice. But before addressing these practical implications, some limitations should be discussed as well.

First, in this study a correlational design was used, so no conclusions can be drawn about causal relations. Second, the sample was not representative for child care centers in the Netherlands, which limits generalizability of our findings to other Dutch child care centers. The outcomes may also not be generalized to other countries, given that the Dutch child care context differs in several important respects from the situation in other countries. In the Netherlands, for example, almost all children attend child care part-time, most groups are mixed aged, and parents are relatively highly educated (Veen et al., 2010). A third limitation is that the sample of child care groups was relatively small (44 groups), which limits the statistical power, so that, for example, the contribution of single items to the prediction of group functioning and interactive effects of different contextual variables could not be examined. Replication of this study in a larger sample and in other countries is needed. 


\section{Conclusions and Practical Implications}

The present study shows that some aspects of group functioning are more strongly related to characteristics of the context than others, and different aspects of group functioning are related to different environmental characteristics. Perhaps the most eye-catching finding is that the emotional climate of a child care group appears to be more context-dependent than the cohesion of a group. The emotional climate is reflected in the emotional tone of children's expressions and as such is an indicator of the well-being of the children in the group. The climate is best predicted by caregiver skills, in particular sensitive responsiveness.

To foster the number of relationships between children in a group (density) and decrease the risk of isolates in the group (inclusion), it seems necessary to focus both on caregiver skills (especially fostering positive peer interactions, sensitive responsiveness, and positive affect) and on space and furnishing. Furthermore, the results suggest that the quality and complexity of peer interactions, reflected in the group functioning variable action coordination, can be promoted by improving space and furnishings, in particular the room arrangement.

In conclusion, our results suggest that group functioning is affected by the direct environment of a child care group, especially by caregiver interactive skills and the way caregivers arrange the physical environment for the group. It is widely acknowledged that caregiver interactive skills play a central role in determining child care quality. This study shows that these skills are also relevant to promote positive group functioning, particularly the emotional climate of a group. Sensitive responsiveness and positive affect play a vital role, since these skills not only positively affect the emotional climate in a child care group, but also its cohesion, presumably by providing children with enough confidence to interact with their peers and by modeling sensitive and positive peer contacts. It also makes sense to encourage peer interactions in order to promote group functioning. Caregivers that foster positive peer interactions stimulate the number, quality, and complexity of the peer interactions in a child care group, especially if they at the same time provide a classroom with well-defined and varied play areas. Unfortunately, the low scores on the caregiver skill fostering peer interactions indicate that most observed caregivers had little eye for positive interactions among the children, nor did they promote positive interactions. Comparably low scores on fostering positive peer interactions were also observed by Helmerhorst, Riksen-Walraven, Gevers Deynoot-Schaub, Tavecchio, and Fukkink (2014) in a large and representative sample of 200 child care centers in the Netherlands. In most child care groups observed in the present study the room arrangement needed considerable improvement too. 
In child care, until now, it is not common to recognize, pay attention to, and stimulate interactions and relationships among children in the group, neither by relevant caregiver interactive behaviors, nor by the arrangement of the physical space of the group. Both need to be improved. In a recent study, Helmerhorst, Riksen-Walraven, Fukkink, Tavecchio, and Gevers Deynoot (2016) showed that a 6-week intervention program, consisting of a videofeedback training for caregivers and a consultancy program for center directors, was effective in improving relevant caregiver interactive skills (including fostering positive peer interactions and sensitive responsiveness) and relevant aspects of the physical environment (such as room arrangement for play). An important next step in the present research line would be to examine whether this program also improves group functioning in child care groups.

Children attending center-based child care are part of a child care group, with its specific group functioning. The functioning of a child care group affects the daily experiences of the children in the group, and thereby possibly their development. Hence, an important next step in research may also be to examine whether group functioning indeed affects children's development. The present study offers tentative guidelines to take advantage of the group situation in child care and to promote group functioning. 


\section{CHAPTER 5}

\section{The accuracy of caregivers' identification of peer affiliations in child care groups ${ }^{4}$}




\begin{abstract}
In this study, the accuracy of caregivers' identification of interaction preferences (affiliations) between children in 36 early child care groups was examined by comparing peer affiliations identified by observations in the group with affiliations as reported by one of the caregivers of the group. On average, one third of the observed and reported affiliations were identical. Most caregivers reported fewer affiliations than were actually observed, but there was large variation in accuracy among caregivers. Factors that might explain differences in the accuracy of caregivers were also examined. As expected, accuracy was positively related to the caregivers' ability to foster positive peer interactions, which by definition presumes having an eye for peer interactions. Caregivers who worked more days per week in a child care group were also more accurate in identifying interaction preferences, presumably because they had more opportunities to observe current peer interactions in the group.
\end{abstract}




\section{Introduction}

Nowadays, many young children are cared for in the group setting of a child care center, which offers them numerous opportunities for interacting with age mates. Early positive peer interactions are important because they contribute to the development of social competence (e.g. Fabes, Hanish, Martin, Moss, \& Reesing, 2012; Howes, Rubin, Ross, \& French, 1988; Mueller \& Brenner, 1977; Vaughn, et al., 2016 ). In child care groups, caregivers play a vital role in determining to what extent the children in the group have positive interactions with each other (Howes et al., 1994; Singer \& Hännikäinen, 2002; Tierney Williams et al., 2010). Promoting positive interactions between children is therefore an important skill for caregivers in child care groups. However, recent studies indicate that caregivers' attention for peer interactions in their child care group is limited. In two observational studies (Aarts, Burk, \& Riksen-Walraven, 2016a; Helmerhorst, Riksen-Walraven, Gevers Deynoot-Schaub et al., 2014), caregivers in child care centers were found to score remarkably low, on average, on a rating scale reflecting the extent to which they fostered positive peer interactions (i.e., mean ratings around 2 on a 7-point scale). A score in this low range is given if a caregiver hardly pays any attention to positive peer interactions and does not promote such interactions. A possible explanation for these low scores is that caregivers in child care centers are not aware of what happens between children in the group. In the present study, we explored this possibility by examining the extent to which caregivers are able to correctly identify interaction preferences among children in their care group, and factors that might explain differences between caregivers in the accuracy of their identification of interaction preferences.

\section{Early Peer Interactions and Affiliations}

Interactions between children can be observed already in the very first year of life. In infancy, interactions with age mates are characterized by looking, smiling, gesturing, vocalizing, touching, imitation, and complementary behavior like give and take (Markova, 2010; Selby \& Bradley, 2003; Zmyj et al., 2007). By the time children are preschoolers their social competence has improved enormously, reflected in the increased complexity of their peer interactions such as joint pretend play (Brenner \& Mueller, 1982; Camaioni et al., 1991; Eckerman et al., 1989; Endedijk et al., 2015; Schaefer et al., 2010; Singer \& de Haan, 2007). Although young children's playmate choices may still be influenced by situational factors (Ramsey, 1995), various studies have shown that toddlers and preschoolers display interaction preferences, also called affiliations, reflected in the interaction frequency between children (for an 
overview see Coplan \& Arbeau, 2009). Even infants have been found to show interaction preferences (Howes, 1983; Markova, 2010; Strayer \& Santos, 1996; Vandell \& Mueller, 1980, Whaley \& Rubenstein, 1994). Such preferences can carry on for months (Gershman \& Hayes, 1983) or even years (Howes et al., 1988), if children remain in the same child care group. In conclusion, in child care groups rather stable peer affiliations can be identified, reflected in a relatively high interaction frequency between certain children.

\section{Previous Research on Accuracy of Caregivers' Identification of Peer Affiliations}

To our best knowledge, there are only a few studies on the accuracy of caregivers' identification of children's affiliations in child care groups. Howes $(1983,1988)$ found that caregivers identified most of the observed peer affiliations in child care groups and preschool groups (79 \%, and 85\% respectively). In these studies children attended child care full-time and many of the children had been with the same peer group since infancy. In the Netherlands, where the present study was conducted, most children attend a child care group only a few days per week, which makes the group composition much less stable. This changing group composition makes it more difficult to perceive the interaction preferences between children accurately. In the present study we therefore expected only moderate accuracy of the caregivers' identification of peer affiliations in the group. Both in preschool and in elementary school classrooms, large variation in teachers' capability to identify children's affiliations has been shown (Gest, 2006; Gronlund, 1950; McCandless \& Marshall, 1957; Neal, Cappella, Wagner, \& Atkins, 2011). Therefore, in the present study we also expected distinct differences in caregivers' accuracy.

No one has yet examined what factors might explain the variation between caregivers in the accuracy of their identification of peer affiliations in child care. In the present study, theoretically relevant determinants of this variety were explored. These are discussed below.

\section{Caregiver Characteristics and Caregivers' Accuracy on Peer Affiliations}

Caregiver interactive skills. First, the caregivers' accuracy in perceiving interaction preferences among peers might be explained by what is generally considered as the most basic interactive skill for caregivers of young children, i.e., their sensitive responsiveness or the ability to recognize signals and needs of individual children and respond appropriately and promptly to their cues and signals (Ainsworth et al., 1978). It may be expected that a caregiver who is sensitive-responsive to a child's needs and signals will also have a keen eye for the child's behavior in interaction with peers. However, sensitive responsiveness has been defined in terms 
of caregivers' one-to-one interactions with individual children, and this does not necessarily imply that sensitive-responsive caregivers also are aware of interaction preferences among peers. In fact, sensitive-responsive caregivers have been found to not necessarily encourage positive peer interactions, possibly because some of them initiate adult-child interactions rather than facilitate peer interactions (Howes et al., 1994).

A caregiver skill that is more likely to be associated with a caregiver's awareness of peer affiliations is fostering positive peer interactions, which is defined as the caregivers' ability to create opportunities for positive peer interactions, to guide the interactions between children in the group, and to reinforce positive peer interactions (Helmerhorst, Riksen-Walraven, Vermeer, Fukkink, \& Tavecchio, 2014). Based on this definition, this skill implies having an eye for peer interactions. Consequently, even more than sensitive responsiveness, we expected caregivers' capability to foster positive peer interactions to be positively related to their accuracy in identifying peer affiliations in a child care group.

Caregiver work experience. The work experience a caregiver has with children in a group setting in general and with the children in her care group in particular, might also be an important predictor of how well she identifies interaction preferences between children. The more opportunities to observe peer interactions a caregiver has had in child care groups in general, the better her knowledge of peer interactions and consequently, the more accurate her identification of peer affiliations in her child care group will be. Furthermore, it might be expected that caregivers' opportunities to observe the peer interactions in their present group will also increase their accuracy of identifying who prefers to interact with whom in that group.

Previous Dutch research, however, provides only scarce support for the assumed relation between caregivers' years of work experience and their eye for peer interactions. In a recent study, Fukkink, Gevers Deynoot-Schaub, Helmerhorst, Bollen, and Riksen-Walraven (2013) found that caregivers with more work experience in child care were more competent in fostering positive peer interactions, but de Kruif et al. (2009) found no such relation. Also no association was found between caregivers' years of experience in the present group and the extent to which they fostered positive peer interactions (de Kruif et al., 2009; Fukkink et al., 2013).

In the present study we added a third measure of work experience, probably reflecting more closely the caregiver's current experience with the group of children, namely the number of days per week she is working in the present group. We expected a positive association between the number of working days per week 
of caregivers in the present group, and the accuracy of their perceptions of peer affiliations in the group.

\section{Group Characteristics and Caregivers' Accuracy on Peer Affiliations}

Age of the children in the group. The age of the children in the child care group may affect the accuracy of the caregivers' identification of peer affiliations, since affiliations among older children are more visible and observable than affiliations of younger children, for several reasons. First, the locomotor skills of baby's are still limited, which limits their their possibilities to actively seek the proximity of other children. Proximity is a characteristic of young children's peer affiliations (Howes, 2006; Whaley \& Rubenstein, 1994) that can be easily noticed. Older children with more sophisticated motor skills can seek the company of specific peers by crawling or walking. Consequently, their peer affiliations can be more easily perceived than those of the youngest children. Second, the expression of peer interactions becomes more complex and visible with age. For instance, the interaction among toddlers talking and laughing together is more easily noticed than infants merely looking at each other. Third, as children grow older, peer affiliations become stronger. Strayer and Santos (1996) noticed that 3-, 4- and 5-year-olds directed relatively more interactions towards peers they preferred to interact with than children aged 1 or 2. Given the above, it seems plausible that peer affiliations are more easily observed and can be more accurately identified in child care groups with older children. In elementary school classrooms, where the density and stability of the affiliation networks also increases with children's age, the accuracy of the teachers' identification of interaction preferences among peers has been shown to increase with grade level (Gest, 2006; Neal et al., 2011). In the present study, we expected the caregivers' reports of peer affiliations to be more accurate for groups with older children. In particular, given the fact that the 3-year-olds (i.e., the oldest children in Dutch child care groups) direct relatively more interactions towards preferred peers than 1- and 2-year-olds (Strayer \& Santos, 1996), we expected the caregivers to be more accurate in groups with relatively more 3-year-olds.

Group size. Group size is another group characteristic that can be expected to influence the accuracy of the caregiver's identification of peer affiliations of children in the group. In large groups it is more difficult to keep an eye on all children, which is reflected by the negative relation between group size and caregivers' sensitive responsiveness (NICHD, 1996, 2000). Furthermore, larger group size is associated with more restrictive and less socially stimulating behavior of the caregiver (Vandell \& Wolfe, 2000), perhaps because in large groups the caregiver has to spend more attention to the managing of the group of children. Based on 
these results, we expected caregivers' identification of peer affiliations to be more accurate in smaller groups.

\section{The Dutch Child Care Context}

Because the child care situation in the Netherlands may be relevant for the interpretation of the results of this study, a brief picture of the Dutch child care context is given. At present, $61 \%$ of the Dutch 0 - to 4 -year-old children attend formal child care (OECD, 2014). Children can attend child care from the age of 3 month until the age of 4 when they enter kindergarten. Because the parents' working hours define how many and on which day(s) their children attend child care, possibilities for flexible child care (e.g. care for half a day, extra hours care before or after the regular opening hours or switching days during the week) are common. As 73\% of the mothers work part-time, on average 26 hours per week (Merens et al., 2012), and many parents combine formal care with informal care, for instance by grandparents, Dutch children attend formal child care part-time as well, on average for 19 hours per week (OECD, 2014). As a result, the composition of child care groups varies over the days of the week, and is less stable over time than in most other countries.

\section{Summary and Research Aims}

The first goal of the present study was to document the accuracy of caregivers' identification of peer affiliations in child care groups. In general, we expected their accuracy to be moderate and to vary between caregivers. Next, we explored the association of the caregivers' accuracy with their interactive skills, with their experience with peer interactions, and with characteristics of the care group. We expected the accuracy of the caregivers' identification of interaction preferences among children in the group to be positively associated with the caregivers' ability to foster positive peer interactions and their sensitive responsiveness. We also expected the caregivers' accuracy to be higher with more years of experience in child care in general, more years of experience with the present group, and more working days per week in the present group. Finally, we expected the caregivers' accuracy in identifying peer affiliations to be higher in groups with more 3-yearolds and in smaller groups. 


\section{Method}

\section{Participating Groups and Caregivers}

The present study was part of a larger study on group functioning in child care groups, in which in total 160 Dutch child care centers were asked if they were willing to cooperate with one of their child care groups. A group participated in the present study if it was a mixed aged group (0-4 yrs) or preschool group (2-4 yrs), if the caregivers of the group and the parents of the children present on the observation day gave their written consent, when at least eight children were present on the observation day, and if at least one caregiver of the group had drawn a sociogram of peer affiliations in the group (see Procedure below). Fifty-three centers (33\%) agreed to cooperate, of which 17 groups did not meet the participation criteria, 6 because no sociogram was drawn. The final sample consisted of 36 groups. In these groups a total of 417 children ( $54 \%$ boys), varying between 21.1 and 43.3 months of age $(M=30.6, S D=6.1)$, and 86 caregivers were observed. The number of observed caregivers per group varied between 1 and $3(M=2.3 S D=.5)$. For groups in which multiple caregivers particpated, one caregiver was randomly selected for inclusion in the present study. The caregivers in the final sample did not differ significantly from caregivers that were not included on any of the study variables. The 36 caregivers in the sample were all female. The vast majority (92\%) was born in the Netherlands. On average, the caregivers were 36 years old (range 20-62 years). Most of them (89\%) had three years of vocational training; the remaining $11 \%$ had more extensive vocational education.

\section{Procedure}

Each group was visited once by the first author. The visit lasted from 9:00 a.m. until 5:00 p.m. The caregivers were asked to keep their usual daily schedule. At the beginning and half way on the day of the visit, the researcher recorded the names of the children and caregivers present. Each caregiver was asked to fill in a form with information about her individual background (e.g. age, education, working days, work experience), and to draw a sociogram representing peer affiliations between children that were present on the day of the visit.

The children present in the classroom during at least 4 hours on the day of the visit were regarded as 'the group'. The caregivers present in the classroom during at least 4 hours on the day of the visit were seen as the caregivers of the group. During the visit, the children were filmed by the researcher for later observation of their peer affiliations, and the caregivers were filmed to later observe their interactive skills; the filming procedure is described below. In addition to the video 
recordings, the researcher rated the quality of the child care environment (not used in the present study).

\section{Filming the group of children.}

Criteria for where, when and what to film. The children in the group were filmed inside, during free play and waiting situations. During free play most children can choose what, where and with whom they play. Waiting situations are transitional situations, during which the caregiver is busy with organizational tasks like setting the table. The filming took place when at least five children were present in the classroom.

With consideration for the previous conditions, every three minutes all children present in the classroom were filmed in random order. In most instances, multiple children were filmed at the same time. They were filmed long enough to get an impression of what each child was doing and with whom (depending on the number of children involved and the complexity of the situation this ranged from approximately 15 to $90 \mathrm{sec}$.). Each group of children was filmed as often and as long as possible on the day of the researcher's visit.

Preparation for the scoring of peer affiliations. To observe the peer affiliations in the group, the video recordings were divided afterwards into 3-minute intervals. Per group on average 22.4 intervals (67.2 minutes observation time) were obtained. The range was 15 to 24 intervals ( 45 to 72 minutes).

Filming the caregivers. Next to the group of children, the caregivers were filmed separately by the researcher during her visit to the child care group. These video recordings were used to rate the caregivers' interactive skills afterwards. Each caregiver was filmed in three or four different naturally occurring situations in which she interacted with children, namely diapering, guidance of a play activity, transition between different activities, and snack or lunch time. Per caregiver on average 3.9 situations were obtained; 29 caregivers were filmed in four situations, 7 caregivers in three different situations. On average a situation was filmed for 7.4 minutes (range 2.4 - 8 minutes).

\section{Instruments and Measures}

Observed peer affiliations. The identification of the peer affiliations in the group was based on time sampling of the videotaped interactions between the children in the group. An interaction was defined as a deliberate exchange of mutually or complementary verbal or non-verbal behavior of two or more children. For each possible dyad in the group, we coded whether or not an interaction occurred during each interval. If an interaction continued into the next interval, it was coded 
as an occurrence of an interaction in that interval too. The 3-minute intervals of 10 groups were initially scored together by the first author and a trained research assistant. Next, 10 groups (590 interactions) were scored separately by the first author and the research assistant. Inter-rater reliability was assessed with an intraclass correlation (ICC), which indicated almost perfect agreement (.97). The research assistant scored the interaction matrices for the remaining groups.

The time-sampling coding scheme resulted in the identification of 2704 interactions observed between dyads, ranging from 0-21 interactions per dyad across all groups. Based on the observed interactions, dyadic affiliations were identified. An affiliation was defined as a behavioral preference child A has for child B, which was inferred when the number of observed interactions one child had with another child was greater than expected by chance (Schaefer et al., 2010). The dyadic interaction scores were converted to dichotomous affiliation measures $(0=$ no affiliation and 1 = affiliation). Across all groups, a total of 890 affiliations were identified ( $M$ $=24.7 S D=9.8$ ).

Caregiver sociogram. Each caregiver present on the observation day was asked to draw a sociogram of the children present on the observation day. They were given a drawing with 18 empty circles, each circle representing a child. The caregivers were asked to write the names of the children that were present on the observation day in the circles and draw lines between 'children' that interacted regularly with each other. One child could have as many affiliation preferences as the caregiver thought represented the usual situation. In total, caregivers reported 451 peer affiliations $(M=12.5, S D=7.9)$ across all groups.

Jaccard index. For each caregiver a Jaccard index (as cited in Neal, 2011) was calculated. The Jaccard index is a measure for the similarity of the affiliation network reported by the caregiver and the actually observed affiliation network. It describes the number of specific affiliations identified both in the observed and in the caregiver networks. The Jaccard index is calculated using the formula: P / $\mathrm{P}+\mathrm{Q}+\mathrm{D}$ where $\mathrm{P}$ is the number of affiliations that are present for both networks; $\mathrm{Q}$ is the number of affiliations that are present in the observed networks, but not in the caregiver networks; and D is the number of affiliations that are present in the caregiver networks, but not in the observed networks.

Caregiver interactive skills were rated from the videotapes using two scales of the Caregiver Interaction Profile scales (CIP; Helmerhorst, Riksen-Walraven, Vermeer et al., 2014), namely fostering positive peer interactions and sensitive responsiveness. These scales were designed to assess caregiver interactive skills not only in interactions with individual children in the group, but also at group level. On these scales, the highest scores can only be obtained when the caregiver divides her at- 
tention across all children and shows high quality interactive behavior consistently toward all children in the group.

Each of the two interactive skills was rated on a single 7-point rating scale $(7=$ very high, 6 = high, $5=$ moderate/high, $4=$ moderate, $3=$ moderate $/$ low, $2=$ low, $1=$ very low). Each rating scale contains a definition of the corresponding construct, a broad description of the relevant behaviors, and a detailed behavioral description for each separate scale point.

The scale fostering positive peer interactions rates the extent to which the caregiver gives positive attention to spontaneous positive peer interactions and actively stimulates positive interactions between children, for instance by creating situations that promote positive interactions or by directing the children's attention to each other in a positive way. A high score on this scale reflects a situation in which the caregiver both reacts positively on positive interactions and actively promotes them. Caregivers with a low score on this scale do not pay attention to positive interactions between children, nor do they attempt to promote such interactions.

Sensitive responsiveness reflects the degree to which a caregiver reacts promptly and adequately on children's signals for emotional support. A high score is given to a caregiver who shows warm attention and emotional support when needed and therefore serves as a 'safe haven' for all the children. A caregiver with a low score on this scale hardly gives any emotional support at all. She fails to recognize the children's signals and cues, or reacts too late or inadequately.

For each of the four situations in which the caregiver was filmed (diapering, guidance of play activity, transition, and lunch or snack time) the two interactive behaviors were rated. Per caregiver a mean score across the four situations was calculated for each of the rating scales. The episodes were independently rated by two trained observers. Inter-rater reliability (ICC for consistency), computed on $20 \%$ of the caregivers was .78 for fostering positive peer interactions, and .64 for sensitive responsiveness, which is viewed as substantial inter-rater agreement (Landis \& Koch, 1977).

Caregivers' work experience was assessed in three ways. First, by the caregivers' work experience in child care (in years), second, by their work experience in the present group (in years), and third, by the caregivers' number of working days per week in the present group.

Group characteristics. The age composition of the group was measured by the proportion 3-year olds. Group size was the largest number of children present at the same time in the group during the observation day. 


\section{Results}

\section{Preliminary Analyses}

Table 1 presents the means, standard deviations, and ranges for the study variables. The average Jaccard index, which is moderate, as expected, indicates that approximately one third of the identified affiliations (both by observation in the child care groups and reported by the caregiver) was identical, while the other two thirds were identified only by observation or by the caregiver. In total 32 of the 36 caregivers $(89 \%)$ reported less affiliations than were observed in their groups, while four of them described more affiliations than were actually observed (not in Table 1). The large range of the Jaccard index shows that, as expected, caregivers varied in their awareness of affiliations between children in the child care group. The average score on the caregiver interactive skills sensitive responsiveness was moderate, but the average score on fostering positive peer interactions was low, indicating that in most groups the caregivers hardly paid any attention to positive interactions among the children. The majority of the caregivers were experienced: they had worked on average 10 years in child care and almost 5 years in the child care center, in the classroom where the child care group was observed. On average they worked 2.7 days per week in the observed child care group. The mean age of the children in the group was 30 months. On average there were 4.83 -year-olds (range 1 to 13 ) in a group. The mean group size shows that on average 11 children were present in a group on the observation day. Most variables were normally distributed, except for the Jaccard, the proportion 3-year olds, and group size, that were skewed (1.20, 1.00 and 1.10, respectively).

The correlations among the caregiver characteristics and group characteristics are also presented in Table 1. Fostering positive peer interactions and sensitive responsiveness were significantly and moderately intercorrelated. Both caregiver skills were positively and significantly related to the age of the children in the group: the higher the mean age of the children, the more sensitive-responsive the caregivers behaved toward the children and the more they fostered positive peer interactions. The correlation between caregiver skills and group size was, although not significant, negative, suggesting that larger groups make it more difficult for caregivers to show sensitive responsiveness and foster positive peer interactions. The observed caregiver skills were not related to the caregivers' work experience.

\section{Caregiver Characteristics and Caregivers' Accuracy in Peer Affiliations}

Table 1 shows that, as expected, the Jaccard index was significantly and positively related to the extent to which the caregivers fostered positive peer interactions. The 


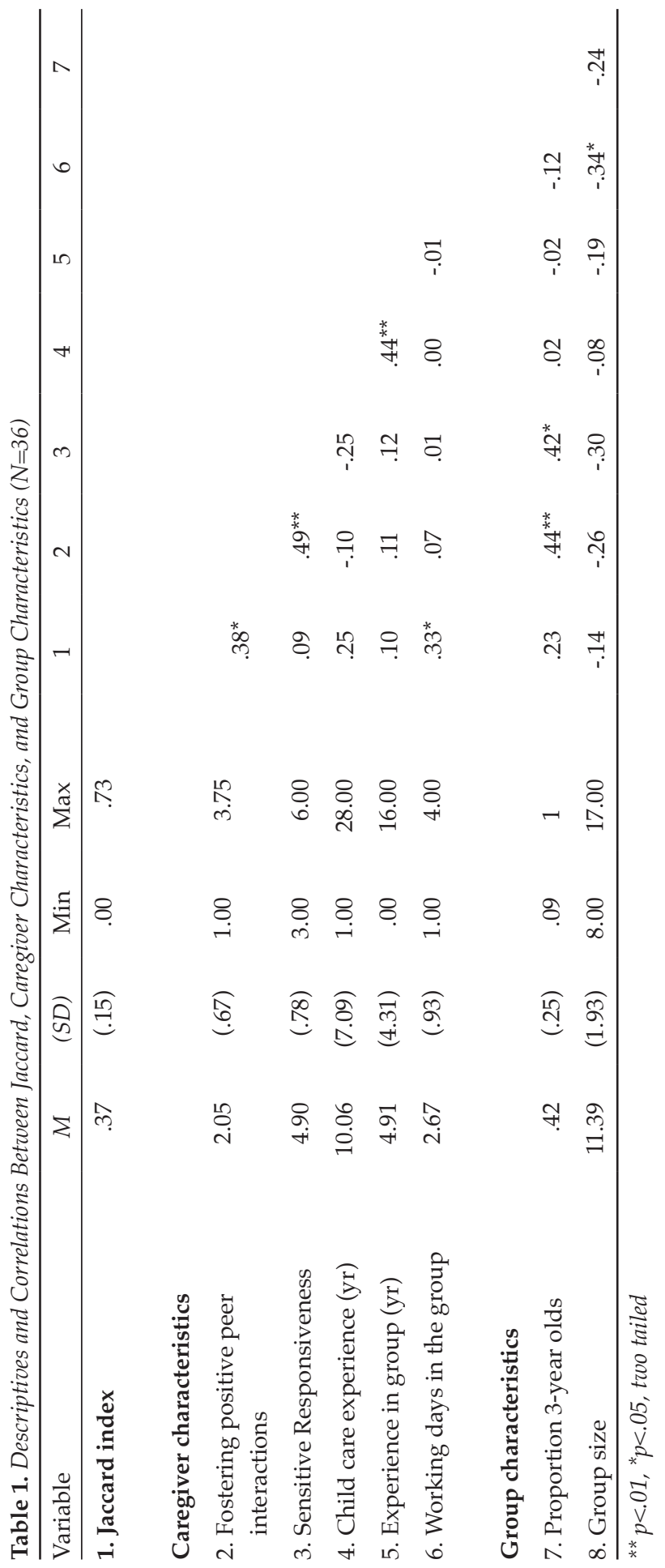


more accurate a caregiver's identification of peer affiliations in the group, the more she promoted positive peer interactions. However, sensitive responsiveness, the second observed caregiver interactive skill, was not related to the Jaccard index. Of the three variables that assessed work experience, only the number of working days per week in the present group was significantly and positively correlated with the accuracy of the caregivers' identification of peer affiliations in the group. The relation of the Jaccard index with the other two measures for work experience, i.e. child care experience and experience in the group, did not reach statistical significance.

\section{Group Characteristics and Caregivers' Accuracy on Peer Affiliations}

Unexpectedly, the proportion 3-year olds in a group was not significantly associated with the accuracy of the caregivers' identification of peer affiliations. The relation between group size and the Jaccard index was negative as expected, but did not reach statistical significance.

\section{Discussion}

In this study we examined the accuracy of caregivers' identification of peer affiliations in their child care group and caregiver and group characteristics that were assumed to be associated with this accuracy. Our results suggest that, in general, caregivers underestimate the number of peer affiliations in their group; about one third of the affiliations identified by observation and reported by caregivers is similar, while most of the caregivers report fewer affiliations than were actually observed. But our sample also contained caregivers who reported almost three quarters of the observed interaction preferences among children in the childcare group. So, as expected, we found a large variation in the extent to which caregivers have an eye for peer interactions. The results also confirm our expectation that a caregiver's accuracy is positively related to her ability to foster positive peer interactions and to the number of days per week she is working in the present group. In contrast to our expectation, caregivers' sensitive responsiveness and years of work experience in child care and in the present group were not significantly associated with their accuracy, nor was the age of the children in the group or the group size.

As expected, the caregiver skill fostering positive peer interactions was significantly related to the accuracy of the caregivers' report on peer affiliations, but sensitive responsiveness was not. This confirms our notion, described in the introduction, that the Jaccard index would be more likely associated with fostering 
positive peer interactions than with sensitive responsiveness. These results also confirm our assumption that fostering positive peer interactions, although associated with sensitive responsiveness, is a distinct skill related to the caregiver's eye for peer interactions. This conclusion has also an important practical implication: improvement of a caregiver's stimulation of peer interactions may require training that is not only focused on improvement of the caregiver's sensitive responsiveness in general, but specifically on her eye for peer interactions.

It is a remarkable finding that a caregiver's identification of peer affiliations in a care group is more accurate when she is working more days per week with this group, but not when she has more years of work experience in child care in general or in the present group. Probably working days per week in the present group is more relevant than years of experience in the present group for the opportunities a caregiver has to observe the current peer interactions of children in the group. In conclusion, more work experience in itself does not improve the caregivers' awareness of interaction preferences among children; it is the caregivers' chances to observe the current peer interactions in the group that matter. So, part-time work and/or spreading working days across multiple groups during the week may negatively affect the accuracy of the caregivers' identification of peer affiliations.

In contrast to our expectation, a caregiver's accuracy was not significantly higher as there were more 3-year olds in the group of children. This is surprising, especially because in groups with relatively more 3-year-olds caregivers scored higher on fostering positive peer interactions, a skill that per definition presumes attention for peer interactions. Thus, in groups with older children, caregivers pay more attention to positive peer interactions and more often promote them, but at the same time they do not seem to be better in identifying peer affiliations. These seemingly contradictory results may be caused by a ceiling effect in the relation between the number of 3-year-olds and the caregivers' accuracy of identification of peer affiliations in a group. The number of affiliations that a caregiver can perceive at the same time may be limited. In groups with many 3-year-olds, the caregivers may identify correctly more peer affiliations, but they cannot help but miss a part of the affiliations, which keeps the Jaccard index or the proportion identified affiliations at the same level as in groups with younger children.

The finding that the agreement between the peer affiliations identified by the caregivers and the identification based on observations was relatively low, suggests that most caregivers oversee peer interactions. But it is also possible that caregivers do perceive peer interactions accurately, but that the observations were not reliable. The behavioral identification of affiliations was based on observations from a single day, while the caregivers' reports were based on experience with the 
group of children for months or even years. So perhaps the caregivers' perceptions were more reliable and accurate than the observed peer affiliations. If this were the case, one would expect the caregivers to overestimate peer affiliations. But in fact, systematic underestimation was observed, which confirms the picture of most caregivers overseeing many peer interactions. Besides, the relatively low accuracy is in accordance with the low scores on the caregiver interactive skill fostering positive peer interactions, which were significantly interrelated. Furthermore, another study on the same child care groups (Aarts et al. 2016c) demonstrated that the observed peer affiliations on group level were stable over a two or three week period, underscoring the reliability of the observed interaction preferences.

\section{Limitations and Directions for Future Research}

Although the present study provides an interesting picture of the accuracy of caregivers' identification of interaction preferences among peers in child care groups, the results should be interpreted with caution given a number of limitations. First, the sample was relatively small, which limits the power of the statistical tests and precludes drawing robust conclusions. Second, we used a selective sample, which limits the generalizability of our findings to other child care centers in the Netherlands. Third, generalizability to other countries is also limited, given the typical characteristics of the Dutch child care context outlined in the introduction. And finally, the correlational design used in this study prevents conclusions about the causal direction of the relations found between characteristics of caregivers and groups, and the accuracy of the caregivers' accuracy in identifying peer affiliations.

Notwithstanding the limitations, the results of the present study suggest that most caregivers in Dutch child care centers have an incomplete picture of the peer affiliations in their group. However, the results also indicate that most caregivers are aware of at least some of the peer affiliations in their group. This raises the question what affiliations have a greater chance to be noticed by caregivers and what affiliations are easily overseen. Do characteristics of the children involved affect the visibility of the affiliation? For instance, are affiliations of extravert children more easily perceived than affiliations of children with less outgoing behavior? It is also possible that characteristics of the affiliation itself play a role. For instance, an affiliation that is marked by frequent rows, requesting regular intervention by the caregiver, will not easily be overlooked. These are interesting topics for future research with regard to the improvement of the caregivers' awareness of peer affiliations in child care groups. 
As peer interactions are relevant for children's development and an eye for peer interactions is required to foster positive peer interactions, the question arises how caregivers' awareness of peer interactions can be improved. The results in this study indicate that caregivers' attentiveness for peer interactions and peer affiliations is not related to their sensitivity in general and that this attentiveness does not improve 'automatically', simply by getting more years of work experience in child care. Obviously, more effort is needed. Caregivers have to be trained to become more aware of peer interactions and to foster them. Recently, Helmerhorst, Riksen-Walraven, Fukkink, et al. (2016) showed that a 6-week intervention program, consisting of a video feedback training for caregivers, improved relevant caregiver interactive skills including fostering positive peer interactions. It would be interesting to study whether this program also improves the accuracy of caregivers' identification of peer affiliations. Another factor that - according to our results - may promote caregivers' accuracy is the number of working days in the group. A caregiver who works more days in the group has more opportunities to observe the peer interactions among the children and consequently, has a better picture of the interaction preferences in the group. Therefore, it is advisable to thoughtfully plan part-time work of caregivers in child care, concentrating the working days of a caregiver as much as possible on one group and not spread her working days over multiple groups, as happens now frequently in the Netherlands. 

CHAPTER 6

Summary, conclusions, and general discussion 



\section{Summary of the Research in this Thesis}

This thesis arose from the experience of caregivers and pedagogues in Dutch child care who noticed that child care groups differ from each other with regard to their functioning, and who assumed that group functioning can affect the behavior of the children in the group. An extensive search in the scientific literature showed that empirical research with regard to the functioning of groups of children of this young age was lacking. Therefore, in this thesis we aimed to systematically examine group functioning in early child care groups and factors that are associated with differences in group functioning.

We defined child care groups as the children who attend child care together in the same classroom. Based on Hinde's theoretical model of personal relationships (1997), group functioning was defined as a relatively stable pattern of relationships, emotions, and cognitions, which develops as a result of repeated interactions among children in the group.

The thesis consists of four empirical studies. The studies made use of the same sample of 44 Dutch child care groups. A subsample was used in studies 2 and 4 .

Conceptualization and measurement of group functioning in child care and relation with structural group characteristics (study 1). In the first study, the measurement instrument that was developed to assess group functioning in child care (the Group Functioning Instrument for Child Care; GFI-CC), and the conceptual model underpinning this instrument were introduced. According to the model, group functioning in child care can be characterized by two main dimensions: cohesion and emotional climate. Emotional climate, or the affective atmosphere in the group, is viewed as a single construct. Cohesion refers to the mutual connection among children in the group and is seen as more complex. It is reflected by three complementary constructs, namely the network structure (the pattern of relationships between the children in the group), action coordination (the extent to which children spontaneously coordinate their behavior), and involvement (the degree to which children show positive interest in each other).

In this first study the GFI-CC was applied in 44 Dutch child care groups. During a one-day visit to the child care group, each group was filmed for 72 minutes during situations in which the children could choose what they did and with whom they interacted (free play and waiting situations). The assessment of group functioning of a child care group was based on observation of these video recordings. The network structure was assessed by time-sampling, coding the interactions between children in the group; two children that interacted more than expected by chance were identified as having a relationship. Action coordination, involvement, and emotional climate were rated on a 5-point scale. 
In general, the pattern of correlations between the dimensions and constructs reflecting group functioning provided initial support for the underlying model. Unexpectedly, the cohesion constructs action coordination and involvement were highly interrelated, and not distinct constructs, as was expected in the model.

In this study, we also examined the association between structural group characteristics and group functioning. As expected, group functioning scores were higher in smaller groups, in groups with older children, and in groups the children had been attending already for a longer period. Surprisingly, group constancy (the number of days the children were attending the child care group together during the week) was not related to group functioning.

Stability of group functioning in child care centers (study 2). As we defined group functioning as a relatively stable pattern of relationships and emotions, we examined the stability of group functioning in child care in the second study. In 36 Dutch child care groups, group functioning was measured with the GFI-CC twice with an intermediate period of two or three weeks. To insure that group composition on both observation days would be comparable, the second observation took place on the same day of the week as the first observation.

Various stability indicators demonstrated that group functioning in child care groups is stable, at least over a relatively short period of two or three weeks. The average group functioning scores across all groups remained the same (mean-level stability), and groups retained their relative position to each other with regard to group functioning scores (rank-order stability). The pattern of interrelations among the group functioning variables was also stable across assessments. Given the relatively unstable group composition in Dutch child care centers, the proportion of identical children present on both observation days was expectedly not very high (.76). Therefore, partial correlations that controlled for group composition were calculated for the rank-order stability. These partial correlations showed that a group's relative position was not affected by changes in the group composition, suggesting that group functioning of a child care group is shaped by factors that are more stable over time than group composition. It was concluded that the stability found in this study supports the test-retest reliability of the GFI-CC as well as the underlying definition of group functioning as a relatively stable pattern.

Caregiver and environmental characteristics as predictors of group functioning in child care (study 3 ). The third study examined the association between group functioning and characteristics of the child care environment, namely caregiver interactive skills (fostering positive peer interactions, sensitive responsiveness, respect for autonomy, positive affect, and negative regard), the program structure, the space and furnishings, and the crowdedness of the classroom. In this study the 
same 44 groups participated as in the first study. Group functioning was measured with the GFI-CC. The caregiver skills were rated on 7-point scales based on the observation of video-recordings that were filmed separately from the recordings of the children. For each caregiver skill, group scores were obtained by averaging the scores of the caregivers present in the group on the observation day. The quality of the program structure and of the space and furnishings of the classroom were assessed by subscales of the ITERS-R and ECERS-R, both well-known measurements of child care quality, complemented with measures for crowdedness of the classroom (number of children per square meter and per play area).

The results of this study indicate that group functioning is associated with characteristics of the child care environment. As predicted, the better the caregiver interactive skills, in particular sensitive responsiveness and positive affect, the higher the group functioning scores, especially for the emotional climate. Furthermore, in groups where caregivers were better at fostering positive peer interactions, children had more peer relationships and showed more action coordination and involvement. The space and furnishings of the classroom also explained differences in group functioning. The better the room arrangement (i.e. the number of play areas or the accessibility of play material for the children), the higher group functioning scores. The program structure (for instance opportunities for free play) and crowdedness of the classroom were not related to group functioning.

The accuracy of caregivers' identification of peer affiliations in child care groups (study 4). In the fourth study, in which 36 child care groups participated, we examined the accuracy by which caregivers identify interaction preferences (affliations) between children in their own child care group, and factors that might affect this accuracy. We used the interaction preferences of the children that had been observed in the first study to assess the network structure of the groups. In addition, all caregivers were asked to draw a sociogram of children in the group who interacted regularly with each other. Per group one randomly chosen caregiver was included in the statistical analysis. The observed peer affiliations of children were compared with affiliations of the same children reported by the caregiver of the group.

On average, approximately one third of the observed and reported affiliations were identical, but there were large differences between caregivers with regard to the accuracy of their reports. Most caregivers reported fewer interaction preferences than were observed, and some reported more preferences than observed. As expected, caregivers that were good at fostering positive peer interactions, presuming an eye for peer interactions, were better in identifying the affiliations of the children in their group. The same was true for caregivers that worked more days a 
week in the group, probably because this provides them with more opportunities to observe the peer interactions in their group.

\section{Conclusions}

Overall, the outcomes of the studies in this thesis can be summarized in the following main conclusions:

1. This thesis yields first empirical evidence for differences in group functioning between child care groups. There are relatively stable differences between child care groups with regard to the two main dimensions of group functioning in child care groups, namely cohesion (reflected in the network structure, action coordination and involvement among the children in the group) and emotional climate.

2. The Group Functioning Instrument for Child Care, the GFI-CC, is a reliable and valid instrument for assessing group functioning in early child care groups.

3. Group functioning is related to structural characteristics of the group. Group functioning scores are higher in smaller groups, in groups with a higher mean age, and in groups which the children have been attending for a longer time. Group functioning is not related to group constancy, i.e. the number of days during the week children attend the child care group together.

4. Group functioning, especially the emotional climate of a group, is related to characteristics of the child care environment. A positive emotional climate is associated with better caregiver interactive skills, particularly sensitive responsiveness. Cohesion scores are higher in groups where caregivers are good at fostering positive peer interactions, and in groups where the classroom is arranged in well-defined and varied play areas.

5. On average, caregivers are little aware of positive peer interactions, but there are large differences between caregivers. To improve this perceptiveness, training might be aimed at improving the caregivers' focus on the interactions between children in the group, and by increasing the caregivers' number of working days per week in the present child care group.

\section{General Discussion}

Next to the points addressed in the discussion sections of the separate studies, there are other, more general issues that are important to discuss. The following topics are addressed below: 1) the empirical support for the model of group functioning, 2) the possible simplification or extension of the model, 3) the definition of a child care group and related issues, 4) the question whether the CGI-CC can be seen as 
a measure of child care quality, 5) the assessment of group functioning in practice, and 6) limitations and suggestions for further research.

Empirical support for the conceptual model. A major question in this thesis concerns the extent to which the results support the model of group functioning in child care groups we introduced in the first study (chapter two). On the whole, the results of the relevant studies in this thesis show that the pattern of correlations among the dimensions and constructs of group functioning is in accordance with the conceptual model. The two-dimensional nature of the model is confirmed by the moderate correlation between cohesion and emotional climate, as reported in the first study, and by the different patterns of the correlations between the two dimensions and the contextual characteristics shown in the third study (chapter four). In the model, cohesion is reflected by five constructs, three of which concern the network structure of the group. The network constructs density, strength, and inclusion relate to the other group functioning constructs as expected, and therefore seem to fit in the model. The associations of the two other cohesion constructs, i.e., action coordination and involvement, with the other group functioning constructs are in the predicted positive direction, but the results indicate that action coordination and involvement are difficult to distinguish from each other. They are highly interrelated and display comparable correlation patterns with the structural and contextual characteristics, as was shown in the first and third study, respectively. As already discussed in earlier chapters, this suggests that action coordination and involvement are not as clearly differentiated in very young children as they are in older age groups. In conclusion, with the exception of the high correlation between action coordination and involvement, in general the results of the studies in this thesis offer initial support for our conceptual model.

Simplification of the model. Although the model describing group functioning in child care is generally supported by the results, the model is quite complex and simplification could be desirable. A proposal for simplification is elaborated below, based on the findings in this thesis. The two-dimensional nature of group functioning has to be maintained, because the dimensions cohesion and emotional climate are moderately correlated, indicating they represent unique aspects of group functioning. The single-construct dimension emotional climate cannot be simplified. The second dimension, cohesion, however, is reflected by five constructs, i.e. the three network structure constructs density, strength, and inclusion, and action coordination and involvement. Of the three network structure constructs, density seems to fit best in the model, because density has more significant relations with other cohesion constructs than strength and inclusion, as was shown in the first study, and also has more significant relations with characteristics of the child care 
environment, which was shown in the third study. So density might be retained as the only network structure measure. The remaining two cohesion constructs, action coordination and involvement, were closely interrelated. In a simplified model of group functioning, we suggest retaining action coordination, and omitting involvement, because of the slightly higher correlations of action coordination with the other group functioning constructs and with structural and contextual characteristics. Moreover, action coordination is meaningfully associated with the contextual characteristics, while involvement is not. In conclusion, our proposal for a simplified model of group functioning in child care would retain the two main dimensions, cohesion and emotional climate, and cohesion would be reflected by only two out of the five original cohesion constructs, namely network density and action coordination. The proposed simplification is supported by the association of group functioning with relevant characteristics of the environment; the dimensions and constructs that are recommended to be retained in the model (network density, action coordination, emotional climate) are more strongly associated with contextual characteristics than the constructs of group functioning that are proposed to be removed (network strength, inclusion, involvement). A simplified conceptual model would also lead to simplification of the instrument to measure group functioning in child care, the GFI-CC, which is desirable, given the fact that application of the present version of the GFI-CC is quite time-consuming.

Extension of the model. Above we speculated about a possible simplification of the model for group functioning in child care, but it is also possible that we have overlooked characteristics that are relevant for group functioning in our model. For instance, in the model the emotional climate is viewed as a single-construct dimension, varying across a positive-negative continuum, as for instance Howes (2000) did in preschools. However, some researchers studying adult groups distinguish two dimensions of emotional climate, namely 'positive climate' and 'negative climate'. For instance George (1996) argues that "these two dimensions of affective experience $[, \ldots]$ are caused by different factors, have different relationships with behaviors $[\ldots]$ and have different consequences for individuals and organizations" (p. 78). With regard to early school classrooms, the positive and negative climate are distinguished in the Classroom Assessment Scoring System (CLASS), a broadly used instrument to assess child care quality (e.g. La Paro et al., 2004; La Paro et al., 2014). Both dimensions were only moderately interrelated, and showed different patterns of correlations with the global quality of child care and with behavior problems of the children (La Paro et al., 2014), suggesting that positive and negative climate are distinct dimensions. However, in the CLASS the climate reflects primarily the teachers' behavior, while in the GFI-CC this dimension concerns the 
behavior of the children, so the conclusions of La Paro et al. (2014) may not apply to the emotional climate as operationalized in the GFI-CC. Therefore, until now we do not know whether the distinction between positive and negative climate makes sense with regard to child care groups and only future research can tell.

Another possible extension of the model worthwhile to discuss is the ease by which the child care group can be managed by the caregiver. Hoex and Schreuder (1997) consider this characteristic, which captures the degree to which children accept norms, rules and the program structure in the group, and the way they react to group activities initiated by the caregiver, as a relevant aspect of group functioning. This could be measured, for example, by the rating scale 'cooperation with caregiver', reflecting the compliance and willingness of children in the group to cooperate with the caregiver', used by De Schipper et al. (2006). However, cooperation of the group of children with the caregiver can only be observed in interaction with caregivers, while in the present research we choose to conceptualize the child care group as the peer group, as described below.

The definition of the child care group and related issues. In this thesis, we have applied the GFI-CC to child care groups, i.e. groups of children attending child care in the same classroom. This definition, in accordance with the structure and organization of most child care centers, is how child care groups are generally defined, both by caregivers in practice and by researchers studying early school classrooms. However, in theory, a broader definition could also be used, because in Dutch child care centers children not only meet the peers of their 'core' child care group in their 'own' classroom, but also regularly have opportunities to meet and play with children of other groups in the child care center (the 'broader' group so to speak), for instance outside or in the corridor, in aggregated groups, and during activities in which children of multiple groups participate. In the present study, for example, we decided not to film the observed groups on the playground outside, because often children of multiple groups were playing there together. Based on this practice, we could use a definition of a child care group in which children's experience with peers in the child care center outside the core group also is taken into account, and examine whether the development of children in child care is better predicted with this new definition of a child care group, compared to the use of the stricter, more conventional definition. However, measuring and discussing group functioning in a broader child care group will be much more complicated than with the traditional definition, and it is the question whether it is feasible at all. This difficulty is illustrated by the fact that, although most elementary school children also have peer relationships outside their own classroom, researchers 
studying social networks and peer acceptance in elementary school confine themselves to the peer context of the classroom too.

Another issue related to the definition of the child care group concerns the varying group composition of Dutch child care groups. According to our definition of a child care group - the group of children attending child care in the same classroom - it is the same group of children that is attending the same classroom on the different days in the week. However, because of the part-time attendance of child care in the Netherlands, a Dutch child care group is composed of different children on every day of the week. In this thesis, for practical reasons, group functioning was measured on a single day of the week. Future research is needed to ascertain whether such a one-day observation suffices to assess group functioning over all days of the week reliably, or if group functioning should better be measured on each day on the week separately. Given that in the Netherlands the composition of a child care group is often relatively comparable on two or three days of the week (because many children attend child care on for instance Tuesday ànd Thursday, or on Wednesday ànd Friday), it may even be possible that a child care group has two or three similar patterns of group functioning over the week.

The GFI-CC as a measure of child care quality? Can the GFI-CC be seen as a measure of the quality of the child care environment for individual children, given that child care quality measures aim to represent the degree to which the child care environment offers experiences to children that may promote their development (e.g. Layzer \& Goodson, 2006)? It might be, because the GFI-CC seems to represent important every day child care experiences for children. But it is too early to decide whether this instrument can be added to the 'well-established' quality measures that are now used in research and practice. An important question that should be answered first is whether group functioning contributes to children's wellbeing and development, and if so, whether it contributes beyond existing quality measures, to see if it makes sense to add the GFI-CC to the battery of child care quality measures. Although our third study showed that group functioning is related only moderately to two subscales of the ITERS-R and the ECERS-R, suggesting that group functioning is an aspect of the child care environment that is distinct from the components assessed by these subscales, the results of the studies in this thesis do not provide conclusions about the effect of group functioning on children's development. So it is too early to decide whether the GFI-CC can be used as a measure of child care quality.

A related question is whether maximum scores on group functioning indicate optimal group functioning. In this thesis high group functioning scores are described as desirable and it may seem as if the maximum scores on group functioning are 
the ultimate goal. Although this is obviously the case for inclusion and emotional climate, this does not apply for the other group functioning constructs. In a group with maximum scores on density, strength, and involvement all children have relationships with all other children in the group, and show involvement to many peers. In such a group there is no room for special relationships between certain children, that, for instance, offer children protection against the risk of peer aggression and rejection (Hay, Payne, \& Chadwick, 2004). Maximum scores of action coordination are also undesirable. They indicate that most children coordinate their behavior frequently to one or more other children in the group. This will be at the expense of solitary play, which, for example, is important for children's development of self reflection, regulation and autonomous functioning (Luckey \& Fabes, 2005), and is the most common type of play in groups of very young children (Urberg \& Kaplan, 1986). In conclusion, apart from inclusion and emotional climate, we do not know yet what group functioning scores are optimal for the wellbeing and development of children and only future research can tell.

Assessing group functioning in child care practice. This thesis arose from caregivers' needs to get more grip on group functioning in child care groups. Therefore, it would support caregivers if they or other child care professionals in their center or child care organization could rate the functioning of their own child care group themselves. Therefore, it is desirable to provide a simplified and possibly adapted version of the GFI-CC that can be used in practice, like the Netherlands Consortium of Child Care Research (NCKO) did with the 'quality monitor' (NCKO, 2009). This simplified version of the original measurement instruments that the NCKO uses in the assessment of Dutch child care quality identifies strong and weak features of the quality of the environment of a child care group and provides guidelines how to improve the quality. Accompanying training programs are offered, supporting child care directors and caregivers using the monitor and increasing the child care environment quality in their centers (Helmerhorst, Fukkink, Riksen-Walraven, Gevers Deynoot-Schaub, Tavecchio, 2016; Helmerhorst, Riksen-Walraven, et al., 2016). In conclusion, to support the caregivers, pedagogues, and directors of child care centers in assessing and improving group functioning, the development of an instrument for use in practice will be helpful.

\section{Limitations and future research}

As already mentioned in earlier chapters, it is necessary to replicate the studies on group functioning in child care centers in other countries, because the Dutch child care context differs from child care in other Western countries, for instance with regard to the part-time attendance and the relative unstable group composition. 
To our surprise, in the first study, we did not find any relation between group constancy (the number of days per week the children attend the child care group together) and group functioning. Based on the theoretical model of Hinde, we expected a relation, because in groups with higher constancy children have more opportunities to interact with each other and develop peer relationships. However, as described in chapter 2 , it is possible that the constancy measure we used was not detailed enough. The issue of group constancy raises a lot of discussion in the Netherlands, since increasing constancy in child care groups means decreasing parents' freedom to choose on what days of the week their child attends child care, which conflicts with the business interests of Dutch child care centers. Therefore, it is worthwhile to study the relation between constancy and group functioning more thoroughly in the future.

This is the first study on group functioning in child care centers focusing on the fundamental questions concerning the conceptualization and measurement of group functioning in child care groups and the relation between group functioning and the direct environment. Inevitably, a lot of important questions about group functioning in child care groups are left unanswered, and new relevant questions have arisen. Hopefully other researchers feel challenged to study this interesting, important, and relatively underdeveloped topic in the future. Notwithstanding the many remaining questions, the results provide a first impression of group functioning in Dutch child care centers and offer suggestions how to improve it. Therefore, we hope that managers, caregivers, and pedagogues in child care will use these insights to promote group functioning of child care groups in their daily practice. 
Nederlandse samenvatting

(Dutch summary) 



\section{Samenvatting van het onderzoek}

Aanleiding tot dit promotieonderzoek waren ervaringen van pedagogisch medewerkers en pedagogen werkzaam in de kinderopvang in Nederland. Zij merkten dat het functioneren van groepen in de kinderdagopvang van elkaar verschilt en zij veronderstelden dat dit 'groepsfunctioneren' het gedrag van de kinderen in de groep kan beïnvloeden. Een uitgebreide zoektocht in wetenschappelijke literatuur maakte duidelijk dat empirisch onderzoek naar het functioneren van groepen kinderen van deze jonge leeftijd ontbrak. Dit promotieonderzoek had daarom tot doel groepsfunctioneren van kinderdagverblijfgroepen en factoren die samenhangen met verschillen tussen groepsfunctioneren systematisch te onderzoeken.

Een kinderdagverblijfgroep hebben we gedefinieerd als de kinderen die samen gebruik maken van kinderdagopvang in dezelfde groepsruimte. Op basis van het theoretische model over persoonlijke relaties van Hinde (1997), werd groepsfunctioneren gedefinieerd als een relatief stabiel patroon van relaties, emoties en cognities dat ontstaat als gevolg van herhaalde interacties tussen kinderen in een kinderdagverblijfgroep.

Het onderzoek bestaat uit vier empirische studies. De studies maakten gebruik van dezelfde steekproef van 44 Nederlandse kinderdagverblijfgroepen. Voor sommige studies werd een deel van deze steekproef gebruikt.

Conceptualisering en meting van groepsfunctioneren in de kinderdagopvang en de relatie met structurele groepskenmerken (studie 1). De eerste studie introduceert het meetinstrument voor groepsfunctioneren in de kinderdagopvang (Group Functioning Instrument for Child Care; GFI-CC) en het conceptuele model dat hieraan ten grondslag ligt. Volgens dit model wordt het functioneren van groepen in de kinderdagopvang gekarakteriseerd door twee dimensies: cohesie en emotioneel klimaat. Het emotionele klimaat, of de affectieve sfeer in de groep, wordt gezien als een enkelvoudig construct. Cohesie verwijst naar de onderlinge verbinding tussen de kinderen in de groep en wordt beschouwd als meer complex. Het komt tot uiting in drie complementaire constructen, namelijk de netwerkstructuur (het patroon van de relaties tussen de kinderen in de groep), actiecoördinatie (de mate waarin kinderen spontaan hun gedrag op elkaar afstemmen) en betrokkenheid (de mate waarin kinderen positieve belangstelling voor elkaar vertonen).

In deze eerste studie werd de GFI-CC toegepast in 44 Nederlandse kinderdagverblijfgroepen. Iedere groep werd tijdens een eendaags bezoek gedurende 72 minuten gefilmd in situaties waarin de kinderen konden kiezen wat zij deden en met wie (vrij spel en wachtsituaties). Observatie van deze video-opnames vormde de basis voor de beoordeling van het groepsfunctioneren. De netwerkstructuur werd vastgesteld met behulp van time-sampling, het registereren van de interac- 
ties tussen kinderen in de groep; als twee kinderen meer met elkaar interacteerden dan verwacht op basis van toeval, werd dit geïdentificeerd als een relatie. Actiecoordinatie, betrokkenheid en emotioneel klimaat werden gescoord op een 5-punts schaal.

Het in dit onderzoek gevonden patroon van correlaties tussen de dimensies en constructen van groepsfunctioneren bood in het algemeen eerste voorlopige steun voor het conceptuele model. Echter, actiecoördinatie en betrokkenheid bleken onverwacht sterk met elkaar samen te hangen en niet zozeer verschillende constructen te zijn zoals werd verwacht op basis van het model.

In deze studie werd ook de relatie tussen structurele groepskenmerken en groepsfunctioneren onderzocht. Zoals verwacht waren de scores voor groepsfunctionen hoger in kleinere groepen, in groepen met oudere kinderen, en in groepen die door de kinderen al gedurende een langere periode bezocht werden. Het was verrassend dat groepsconstantie (het aantal dagen in de week dat de kinderen samen dezelfde groep bezoeken), niet gerelateerd bleek te zijn aan het functioneren van de groep.

Stabiliteit van groepsfunctioneren in kinderdagverblijven (studie 2). Aangezien groepsfunctioneren is omschreven als een relatief stabiel patroon van relaties en emoties, werd in de tweede studie de stabiliteit van groepsfunctioneren in de kinderdagopvang onderzocht. Het groepsfunctioneren werd met een tussenperiode van twee of drie weken tweemaal gemeten met behulp van de GFI-CC in 36 kinderdagverblijfgroepen. Om te waarborgen dat de groepssamenstelling op beide observatiedagen vergelijkbaar zou zijn, vond de tweede observatie plaats op dezelfde dag van de week als de eerste observatie.

Verschillende indicatoren voor stabiliteit duidden er op dat groepsfunctioneren stabiel is, althans over een relatief korte periode van twee of drie weken. De gemiddelde scores voor groepsfunctioneren bleven over alle groepen gelijk (mean-level stability) en groepen behielden hun relatieve positie ten opzichte van elkaar met betrekking tot de scores voor groepsfunctioneren (rank-order stability). Het patroon van de onderlinge relaties tussen de variabelen voor groepsfunctioneren was ook stabiel. Gezien de relatief onstabiele groepssamenstelling van Nederlandse kinderdagverbijven, was het aantal dezelfde kinderen dat aanwezig was op beide observatiedagen zoals verwacht niet heel hoog (76\%). Daarom werden partiële correlaties voor de rank-order stabiliteit berekend waarin gecontroleerd werd voor de groepssamenstelling. Deze lieten zien dat de relatieve positie van een groep niet werd beïnvloed door veranderingen in de groepssamenstelling, hetgeen suggereert dat het groepsfunctioneren van een kinderdagverblijfgroep wordt beïnvloed door factoren die stabieler zijn dan groepsamenstelling. Geconcludeerd werd dat de gevonden stabiliteit de onderliggende definitie van groepsfunctioneren als een 
relatief stabiel patroon en de test-hertest betrouwbaarheid van de GFI-CC ondersteunt.

Kenmerken van pedagogisch medewerkers en de omgeving als voorspellers van groepsfunctioneren in kinderdagverblijven (studie 3). De derde studie onderzocht de relatie tussen groepsfunctioneren en kenmerken van de directe omgeving van een kinderdagverblijfgroep, namelijk interactievaardigheden van pedagogisch medewerkers (het bevorderen van positieve interacties tussen kinderen, sensitieve responsiviteit, respect voor autonomie, expressie van positieve gevoelens naar de kinderen en het uiten van negatieve gevoelens jegens de kinderen), de programmastructuur, de groepsruimte en inrichting, en de relatieve drukte (crowdedness) in de groepsruimte. Aan deze studie namen dezelfde 44 groepen deel als in de eerste studie. Groepsfunctioneren werd gemeten met behulp van de GFI-CC. De interactievaardigheden van de pedagogisch medewerkers werden beoordeeld op 7-punts schalen, gebaseerd op observatie van video-opnames die afzonderlijk van de opnames van de kinderen waren gemaakt. Voor iedere interactievaardigheid werd een groepsscore verkregen door het gemiddelde te berekenen over de scores van de pedagogisch medewerkers die op de dag van de observatie in de groep werkten. De kwaliteit van de programmastructuur, van de groepsruimte en van de inrichting werden beoordeeld met behulp van subschalen van de ITERS-R en ECERS-R, veelgebruikte meetinstrumenten voor de kwaliteit van de kinderopvang, aangevuld met scores voor de relatieve drukte in de groepsruimte (het aantal kinderen per vierkante meter en per speelhoek).

De resultaten van deze studie tonen aan dat het groepsfunctioneren gerelateerd is aan kenmerken van de directe omgeving van de kinderdagverblijfgroep. Zoals voorspeld bleek dat hoe beter de interactievaardigheden van de pedagogisch medewerkers in een groep, vooral sensitieve responsiviteit en expressie van positieve gevoelens, hoe hoger de scores voor groepsfunctioneren, met name voor emotioneel klimaat. Bovendien hadden kinderen in groepen waar de pedagogisch medewerkers beter waren in het bevorderen van positieve contacten tussen kinderen, meer relaties met andere kinderen en vertoonden ze meer actiecoördinatie en betrokkenheid. De groepsruimte en de inrichting bleken ook verschillen in groepsfunctioneren te voorspellen. Hoe beter de kwaliteit van de inrichting (het aantal speelhoeken en de toegankelijkheid van het spelmateriaal voor de kinderen), des te hoger de scores voor groepsfunctioneren. De programmastructuur (bijvoorbeeld de gelegenheid voor vrijspel) en de relatieve drukte in de groepsruimte bleken niet samen te hangen met groepsfunctioneren. 
De identificatie van interactievoorkeuren tussen kinderen in kinderdagverblijfgroepen door pedagogisch medewerkers (studie 4). In de vierde studie, waaraan 36 kinderdagverblijfgroepen deelnamen, onderzochten we de accuraatheid waarmee pedagogisch medewerkers interactievoorkeuren tussen kinderen identificeren en factoren die hierop van invloed kunnen zijn. We gebruikten de interactievoorkeuren van de kinderen die in de eerste studie waren geobserveerd om de netwerkstructuur te bepalen. Hiernaast werden alle pedagogisch medewerkers gevraagd om met behulp van een sociogram aan te geven welke kinderen in de groep regelmatig met elkaar contact hadden. Per groep werd één willekeurig gekozen pedagogisch medewerker betrokken in de statistische analyse. De geobserveerde interactievoorkeuren van de kinderen werden vergeleken met de interactievoorkeuren van dezelfde kinderen volgens de pedagogisch medewerker van de groep. Gemiddeld was ongeveer eenderde van de geobserveerde en door de pedagogisch medewerkers genoemde interactie voorkeuren van de kinderen hetzelfde, maar er waren grote verschillen tussen pedagogisch medewerkers in de mate waarin hun beschrijving overeen kwam met de geobserveerde interactievoorkeuren van de kinderen. De meeste pedagogisch medewerkers meldden minder interactievoorkeuren dan er geobserveerd waren, een enkeling meldde meer interactievoorkeuren dan er waren waargenomen. Zoals verwacht waren pedagogisch medewerkers die goed waren in het bevorderen van positieve contacten tussen kinderen, een vaardigheid die oog voor contacten tussen kinderen veronderstelt, beter in het identificeren van de interactievoorkeuren van de kinderen in hun groep. Hetzelfde gold voor pedagogisch medewerkers die meer dagen per week in de groep werkten, waarschijnlijk omdat dit hen meer gelegenheid biedt om de actuele contacten tussen kinderen te observeren.

\section{Conclusies}

De resultaten van de studies in dit onderzoek kunnen worden samengevat in de volgende belangrijkste conclusies:

1. Deze thesis levert het eerste empirisch bewijs voor verschillen in groepsfunctioneren tussen kinderdagverblijfgroepen. Er zijn relatief stabiele verschillen tussen kinderdagverblijfgroepen met betrekking tot de twee belangrijkste dimensies van groepsfunctioneren in kinderdagverblijven, namelijk de cohesie (weerspiegeld in de netwerkstructuur, actiecoördinatie en betrokkenheid van de kinderen in de groep) en het emotionele klimaat.

2. Het Group Functioning Instrument for Child Care, de GFI-CC, is een betrouwbaar en valide instrument voor de beoordeling van groepsfunctioneren van kinderdagverblijfgroepen. 
3. Groepsfunctioneren is gerelateerd aan structurele kenmerken van de groep. Scores voor groepsfunctioneren zijn hoger in kleinere groepen, in groepen waar kinderen gemiddeld ouder zijn en in groepen waar de kinderen al gedurende een langere periode komen. Groepsfunctioneren hangt niet samen met groepsconstantie, d.w.z. het aantal dagen in de week dat kinderen samen in de groep zijn.

4. Groepsfunctioneren, met name het emotionele klimaat van een groep, houdt verband met kenmerken van de directe omgeving van de groep. Een positief emotioneel klimaat is gerelateerd aan betere interactievaardigheden van de pedagogisch medewerker, met name sensitieve responsiviteit. Scores voor cohesie zijn hoger in groepen waar pedagogisch medewerkers goed zijn in het bevorderen van positieve contacten tussen kinderen en in groepen waar de groepsruimte is ingedeeld in welomschreven en gevarieerde speelhoeken.

5. In het algemeen hebben pedagogisch medewerkers weinig oog voor contacten tussen kinderen, maar er zijn wat dit betreft grote verschillen tussen pedagogisch medewerkers. Deze vaardigheid kan verbeterd worden door training specifiek gericht op het herkennen van interacties tussen kinderen in de groep en door het verhogen van het aantal dagen dat een pedagogisch medewerker in dezelfde groep werkt. 



\section{References}



Aarts, M. C., Burk, W. J., \& Riksen-Walraven, J. M. (2016a). Caregiver and environmental characteristics as predictors of group functioning in child care centers. Manuscript submitted for publication.

Aarts, M. C., Burk, W. J., \& Riksen-Walraven, J. M. (2016b). Group functioning in child care centers: Conceptualization, measurement, and relation with structural characteristics. Small Group Research, 47(5), 483-509. doi:10.1177/1046496416658961

Aarts, M. C., Burk, W. J., \& Riksen-Walraven, J. M. (2016c). Short-time stability of group functioning in child care groups. Manuscript submitted for publication.

Ahnert, L., Pinquart, M., \& Lamb, M. E. (2006). Security of children's relationships with nonparental care providers: A meta-analysis. Child Development, 77(3), 664-679. doi:10.1111/j.14678624.2006.00896.x

Ainsworth, M. S., Blehar, M. C., Waters, E., \& Wall, S. (1978). Patterns of attachment: A psychological study of the Strange Situation. Hillsdale, NJ: Erlbaum.

Avant, T. S., Gazelle, H., \& Faldowski, R. (2011). Classroom emotional climate as a moderator of anxious solitary children's longitudinal risk for peer exclusion: A child x environment model. Developmental Psychology, 47, 1711-1727. doi:10.1037/a0024021

Balledux, M. (2001). Werken aan welbevinden [Working on wellbeing]. Utrecht, the Netherlands: Nederlands Instituut voor Zorg en Welzijn.

Barsade, S. G. (2002). The ripple effect: Emotional contagion and its influence on group behavior. Administrative Science Quarterly, 47, 644-675. doi:10.2307/3094912

Bollen, K. A., \& Hoyle, R. H. (1990). Perceived cohesion: A conceptual and empirical examination. Social Forces, 69, 479-504. doi:10.2307/2579670

Booren, L. M., Downer, J. T., \& Vitiello, V. E. (2012). Observations of children's interactions with teachers, peers, and tasks across preschool classroom activity settings. Early Education $\mathcal{E}$ Development, 23(4), 517-538. doi:10.1080/10409289.2010.548767

Bowlby, J. (1969). Attachment and loss: Vol. 1. Attachment. New York, NY: Basic Books.

Brenner, J., \& Mueller, E. (1982). Shared meaning in boy toddlers' peer relations. Child Development, 53(2), 380-391. doi:10.2307/1128980

Brown, R. (2000). Group processes dynamics within and between groups (2nd ed.). Oxford, England: Blackwell.

Brooks, J., \& Lewis, M. (1976). Infants' responses to strangers: Midget, adult and child. Child Development, 47, 323-332. doi:http:/ / www.jstor.org/stable/1128785

Camaioni, L., Baumgartner, E., \& Perucchini, P. (1991). Content and structure in toddlers' social competence with peers from 12 to 36 months of age. Early Child Development and Care, 67, 17-27. doi:10.1080/0300443910670102

Cairns, R. B., Leung, M.-C., Buchanan, L., \& Cairns, B. D. (1995). Friendships and social networks in childhood and adolescence: Fluidity, reliability, and interrelations. Child Development, 66, 1330-1345. doi:10.2307/1131650

Carless, S. A., \& De Paola, C. (2000). The measurement of cohesion in work teams. Small Group Research, 31, 71-88. doi:10.1177/104649640003100104

Carron, A., Brawley, L., Eys, M., Bray, S., Dorsch, K., Estabrooks, P., . . Terry, P. (2003). Do indivual perceptions of group cohesion reflect shared beliefs? An empirical analysis. Small Group Research, 34, 468-496. doi:10.1177/1046496403254274

Chang, A., \& Bordia, P. (2001). A multidimensional approach to the group cohesion-group performance relationship. Small Group Research, 32, 379-405. doi:10.1177/104649640103200401 
Coplan, R. J., \& Arbeau, K. A. (2009). Peer interactions and play in early chlildhood. In K. H. Rubin, K. W. Bukowski \& B. Laursen (Eds.), Handbook of peer interactions, relationships, and groups (pp. 143-161). New York: The Guidford Press.

Corsaro, W. A. (2005). The sociology of childhood (2nd ed.). Thousand Oaks, CA: Pine Forge Press.

Cummings, E. M., Davies, P. T., \& Campbell, S. B. (2000). Developmental psychopathology and family process: Theory, research, and clinical implications. New York: The Guilford Press.

de Kruif, R. E. L., Riksen-Walraven, J. M. A., Gevers Deynoot-Schaub, M. J. J. M., Helmerhorst, K. O. W., Tavecchio, L. W. C., \& Fukkink, R. G. (2009). Pedagogische kwaliteit van de opvang voor 0 - 4-jarigen in Nederlandse kinderdagverblijven in 2008 [Pedagogical quality of child care for 0 to 4 year olds in Dutch child care centers in 2008]. Amsterdam, the Netherlands: Nederlands Consortium Kinderopvang Onderzoek

de Kruif, R. E. L., Vermeer, H. J., Fukkink, R. G., Riksen-Walraven, J. M. A., Tavecchio, L. W. C., van IJzendoorn, H. H., \& van Zeijl, J. (2007). De nationale studie pedagogische kwaliteit kinderopvang eindrapport project 0 en 1 [The national study pedagogical quality child care final report project 0 and 1]. Amsterdam, the Netherlands: Nederlands Consortium Kinderopvang Onderzoek

De Rivera, J., Kurrien, R., \& Olsen, N. (2007). The emotional climate of nations and their culture of peace. Journal of Social Issues, 63(2), 255-271. doi:10.1111/j.1540-4560.2007.00507.x

DeRosier, M., Cillessen, A. H. N., Coie, J. D., \& Dodge, K. A. (1994). Group social context and children's aggressive behavior. Child Development, 65, 1068-1079. doi:10.2307/1131305

De Schipper, E. J., Riksen-Walraven, J. M. A., \& Geurts, S. A. E. (2006). Effects of child-caregiver ratio on the interactions between caregivers and children in child care centers: An experimental study. Child Development, 77(4), 861-874. doi:10.1111/j.1467-8624.2006.00907.x

Eckerman, C. O., Davis, C. C., \& Didow, S. M. (1989). Toddlers' emerging ways of achieving social coordinations with a peer. Child Development, 60, 440-453. doi:10.2307/1130988

Eisenberg, N., \& Strayer, J. (Eds.). (1987). Empathy and its development. Cambridge, England: Cambridge University Press.

Endedijk, H. M., Ramenzoni, V. C. O., Cox, R. F. A., Cillessen, A. H. N., Bekkering, H., \& Hunnius, S. (2015). Development of interpersonal coordination between peers during a drumming task. Developmental Psychology, 51(5), 714-721. doi:http:/ / dx.doi.org/10.1037/a003890

Erickson, M. F., Sroufe, L. A., \& Egeland, B. (1985). The relationship between the quality of attachment and behavior problems in preschool in a high-risk sample. In I. Bretherton \& E. Waters (Eds.), Growing points of attachment theory and research. Chicago: University of Chicago.

Estell, D. B., Cairns, R. B., Farmer, T. W., \& Cairns, B. D. (2002). Aggression in inner-city early elementary classrooms: Individual and peer-group configurations. Merrill-Palmer Quarterly, 48(1), 52-76. doi:10.1353/mpq.2002.0002

Fabes, R. A., Hanish, L. D., \& Martin, C. L. (2003). Children at play: the role of peers in understanding the effects of child care. Child Development, 74, 1039-1043. doi:10.1111/1467-8624.00586

Fabes, R. A., Hanish, L. D., Martin, C. L., Moss, A., \& Reesing, A. (2012). The effects of young children's affiliations with prosocial peers on subsequent emotionality in peer interactions. British Journal of Developmental Psychology, 30(4), 569-585. doi:10.1111/j.2044-835X.2011.02073.x

Fish, M., \& Dane, E. (2000). The Classroom Systems Observation Scale: Development of an instrument to assess classrooms using a systems perspective. Learning Environments Research, 3(1), 67-92. doi:10.1023/a:1009979122896 
Fontaine, A. M. (2005). Ëcologie développementale des première interactions entre enfants: effect des matériels de jeu [Developmental ecology of early peer interactions: the role of play materials]. Enfance, 57(2), 137-154. doi:10.3917/enf.572.0137

Fukkink, R. G., Gevers Deynoot-Schaub, M. J. J. M., Helmerhorst, K. O. W., Bollen, I., \& RiksenWalraven, J. M. A. (2013). Pedagogische kwaliteit van de kinderopvang voor 0- tot 4- jarigen in Nederlandse kinderdagverblijven in 2012 [Pedagogical quality of child care for 0 to 4 year olds in Dutch child care centers in 2012] Amsterdam, the Netherlands: Nederlands Consortium Kinderopvang Onderzoek.

Gazelle, H. (2006). Class climate moderates peer relations and emotional adjustment in children with an early history of anxious solitude: A child $\times$ environment model. Developmental Psychology, 42(6), 1179-1192. doi: 10.1037/0012-1649.42.6.1179

George, J. M. (1990). Personality, affect, and behavior in groups. Journal of Applied Psychology, 75(2), 107-116. doi:10.1037/0021-9010.75.2.107

George, J. M. (1996). Group Affective Tone. In M. A. West (Ed.), Handbook of Work Group Psychology (pp. 77-94). Chichester, England: John Wiley \& Sons.

Gershman, E. S., \& Hayes, D. S. (1983). Differential stability of reciprocal friendships and unilateral relationships among preschool children. Merrill-Palmer Quarterly, 29(2), 169-177. doi:digitalcommons.library.umaine.edu/psy_facpub/10

Gest, S. D. (2006). Teacher reports of children's friendships and social groups: Agreement with peer reports and implications for studying peer similarity. Social Development, 15(2), 248259. doi:10.1046/j.1467-9507.2006.00339.x

Gevers Deynoot-Schaub, M. J. J. M., \& Riksen-Walraven, J. M. (2006). Peer interaction in child care centres at 15 and 23 months: Stability and links with children's socio-emotional adjustment. Infant Behavior and Development, 29, 276-288. doi:10.1016/j.infbeh.2005.12.005

Gronlund, N. E. (1950). The accuracy of teachers' judgments concerning the sociometric status of sixth-grade pupils: Part I. Sociometry, 13(3), 197-225. doi: 10.2307/2785458

Harms, T., Clifford, R. M., \& Cryer, D. (2005). Early Childhood Environment Rating Scale, Revised Edition. New York. NY: Teachers College Press.

Harms, T., Cryer, D., \& Clifford, R. M. (2003). Infant-Toddler Environment Rating Scale, Revised edition. New York, NY: Teachers College Press.

Hay, D. F., Caplan, M., \& Nash, A. (2009). The beginnings of peer relations. In K. H. Rubin, W. M. Bukowski \& B. Laursen (Eds.), Handbook of peer interactions, relationships, and groups (pp. 121-142). New York, NY: Guildford Press.

Hay, D. F., Payne, A., \& Chadwick, A. (2004). Peer relations in childhood. Journal of Child Psychology and Psychiatry, 45(1), 84-108. doi: 10.1046/j.0021-9630.2003.00308.x

Hay, D. F., \& Ross, H. S. (1982). The social nature of early conflict. [Research Support, Non-U.S. Gov't]. Child Development, 53(1), 105-113. doi:http:/ / www.jstor.org/stable/1129642

Helmerhorst, K.O.W., Fukkink, R. G., Riksen-Walraven, J. M., Gevers Deynoot-Schaub, M. J. J. M., \& Tavecchio, L. W. C. (2016). Improving quality of the child care environment through a consultancy program for center directors. Manuscript submitted for publication.

Helmerhorst, K. O. W., Riksen-Walraven, J. M., Fukkink, R. G., Tavecchio, L. W. C., \& Gevers Deynoot-Schaub, M. J. J. M. (2016). Effects of the caregiver interaction profile training on caregiver-child interactions in dutch child care centers: A randomnized controlled trial. Child Youth Care Forum. doi: 10.1007/s10566-016-9383-9 
Helmerhorst, K. O. W., Riksen-Walraven, J. M., Gevers Deynoot-Schaub, M. J. J. M., Tavecchio, L. W. C., \& Fukkink, R. G. (2014). Child care quality in the Netherlands over the years: A closer look. Early Education and Development, 26(1), 89-105. doi:10.1080/10409289.2014.948784

Helmerhorst, K. O. W., Riksen-Walraven, J. M., Vermeer, H. J., Fukkink, R. G., \& Tavecchio, L. W. C. (2014). Measuring the interactive skills of caregivers in child care centers: Development and validation of the Caregiver Interaction Profile Scales. Early Education and Development, 25, 770-790. doi:10.1080/10409289.2014.840482

Hoex, J., \& Schreuder, E. T. (1997). Werken aan welbevinden. Een evaluatie-instrument voor de kinderopvang [Working on wellbeing. An instrument for evaluation in child care]. Utrecht, the Netherlands: Nederlands Instituut voor Zorg en Welzijn.

Hinde, R. A. (1997). Relationships: A dialectical perspective. Hove, United Kingdom: Psychology Press

Holloway, S. D., \& Reichhart-Erickson, M. (1988). The relationship of day care quality to children's free-play behavior and social problem-solving skills. Early Childhood Research Quarterly, 3(1), 39-53. doi:http: / / dx.doi.org/10.1016/0885-2006(88)90028-2

Howes, C. (1983). Patterns of friendship. Child Development, 54, 1041-1053. doi:10.2307/1129908

Howes, C. (1988). Peer interaction of young children. Monographs of the society for research in child development, 53(1, serial no.217). doi:http:/ / www.jstor.org/ stable/1166062

Howes, C. (2000). Social-emotional classroom climate in child care, child-teacher relationships and children's second grade peer relations. Social development, 9(2), 191-204. doi:10.1111/14679507.00119

Howes, C. (2006). Friendship in early childhood. In K. H. Rubin, W. M. Bukowski \& B. Laursen (Eds.), Handbook of peer interactions, relationships, and groups (pp. 180-194). New York: The Guildford Press.

Howes, C., Hamilton, C. E., \& Matheson, C. C. (1994). Children's relationships with peers: differential associations with aspects of the teacher - child relationship. Child Development, 65(1), 253 - 263. doi:http:/ / www.jstor.org/ stable/1131379

Howes, C., \& Matheson, C. C. (1992). Sequences in the development of competent play with peers: Social and social pretend play. Developmental Psychology, 28(5), 961 - 974. doi:10.1037/00121649.28.5.961

Howes, C., Phillips, D. A., \& Whitebook, M. (1992). Thresholds of quality: Implications for the social development of children in center-based child care. Child Development, 63(2), 449-460. doi:10.2307/1131491

Howes, C., \& Phillipsen, L. (1998). Continuity in childrens' relations with peers. Social Development, 7, 340 - 349. doi:10.1111/1467-9507.00071

Howes, C., Rubin, K. H., Ross, H. S., \& French, D. C. (1988). Peer interaction of young children. Monographs of the Society for Research in Child Development, 53(1), pp. i+iii+v+1-92. doi:10.2307/1166062

Howes, C., \& Stewart, P. (1987). Child's play with adults, toys and peers: an examination of family and child-care influences. Developmental Psychology, 23(3), 423 - 430. doi:10.1037/00121649.23.3.423

Inhoudelijk begeleidersoverleg Den Haag. (1999). De waardevolle groep [The valuable group]. Instituut Branche Belangen Kinderopvang Den Haag / Haaglanden Den Haag, the Netherlands

Ishikawa, F., \& Hay, D. F. (2006). Triadic interaction among newly acquainted 2-year-olds. Social Development, 15(1), 145-168. doi:10.1111/j.1467-9507.2006.00334.x 
Johnson, J. C., Ironsmith, M., Whitcher, A. L., Poteat, G. M., Snow, C. W., \& Mumford, S. (1997). The development of social networks in preschool children. Early Education and Development, 4, 389-405. doi:10.1207/s15566935eed0804_3

Kantrowitz, E. J., \& Evans, G. W. (2004). The relation between the ratio of children per activity area and off-task behavior and type of play in day care centers. Environment and behavior, 36(4), 541 - 557. doi:10.1177/ 0013916503255613

Kindermann, T. A. (1993). Natural peer groups as contexts for individual development: The case of children's motivation in school. Developmental Psychology, 29(6), 970-977. doi:10.1037/00121649.29.6.970

Kindermann, T. A. (2007). Effects of naturally existing peer groups on changes in academic engagement in a cohort of sixth graders. Child Development, 78(4), 1186-1203. doi: 10.1111/j.14678624.2007.01060.x

Kontos, S., \& Keyes, L. (1999). An ecobehavioral analysis of early childhood classrooms. Early Childhood Research Quarterly, 14(1), 35 - 50. doi:10.1016/S0885-2006(99)80003-9

La Freniere, P., \& Charlesworth, W. R. (1983). Dominance, attention, and affiliation in a preschool group: a nine-month longitudinal study. Ethology and Sociobiology 4(2), 55-67. doi:http:/ / dx.doi.org/10.1016/0162-3095(83)90030-4

Lamb, S., \& Zakhireh, B. (1997). Toddlers' attention to the distress of peers in a daycare setting. Early Education and Development, 8(2), 105-118. doi:10.1207/s15566935eed0802_1

Landis, J. R., \& Koch, G. G. (1977). The measurement of observer agreement for categorical data. Biometrics, 33(1), 159-174. doi:http:/ / www.jstor.org/stable/ 2529310

La Paro, K., Pianta, R. C., \& Stuhlman, M. (2004). The classroom assessment scoring system: findings from the prekindergarten year. The Elementary School Journal, 104, 409 - 426. doi: $10.1086 / 499760$

La Paro, K., Williamson, A. C., \& Hatfield, B. (2014). Assessing quality in toddler classrooms using the CLASS-Toddler and the ITERS-R. Early Education and Development, 25(6), 875-893. doi:1 $0.1080 / 10409289.2014 .883586$

Landis, J. R., \& Koch, G. G. (1977). The measurement of observer agreement for categorical data. Biometrics, 33(1), 159-174. doi:http:/ / www.jstor.org/ stable/2529310

Levine, J. M., \& Moreland, R. L. (1998). Small groups. In G. Lindzey, D. T. Gilbert \& S. T. Fiske (Eds.), The handbook of social psychology (Vols. 1 and 2, pp. 415 - 469). New York, NY: McGraw-Hill.

Li Grining, C., Raver, C. C., Champion, K., Sardin, L., Metzger, M., \& Jones, S. M. (2010). Understanding and improving classroom emotional climate and behavior management in the "real world": the role of head start teachers' psychosocial stressors. Early Education \& Development, 21(1), 65-94. doi:10.1080/10409280902783509

Liu, X.-Y., Härtel, C. E. J., \& Sun, J. J.-M. (2014). The workgroup emotional climate scale: Theoretical development, empirical validation, and relationship with workgroup effectiveness. Group \& Organization Management, 39, 626-663. doi:10.1177/1059601114554453

LoCasale-Crouch, J., Konold, J., Pianta, R., Howes, C., Burchinal, M., Bryant, D., . . Barbarin, O. (2007). Observed classroom quality profiles in state-funded pre-kindergarten programs and associations with teacher, program and classroom characteristics. Early Childhood Research Quarterly, 22, 3-17. doi:10.1016/j.ecresq.2006.05.001

Loo, C., \& Kennelly, D. (1979). Social density: Its effects on behaviors and perceptions of preschoolers. Environmental psychology and nonverbal behavior, 3(3), 131-146. doi:10.1007/bf01142588

Luckey, A. J., \& Fabes, R. A. (2005). Understanding non-social play in early childhood. Early Childhood Education Journal, 33(2), 67-72. doi:10.1007/s10643-006-0054-6 
Maccoby, E. E. (1990). Gender and relationships. A developmental account. American Psychologist, 45, 513-520. doi:00000487-199004000-00031

Markova, G. (2010). Interactions among infant peers: Examining individual differences in social competence [Abstract] Dissertation Abstracts International: Section B: The Sciences and Engineering, 70(9-B), 5869.

Martin, L. J., \& Carron, A. V. (2012). Development of a cohesion inventory for children's sport teams. Group Dynamics: Theory, Research, Practice, 16, 68-79. doi:10.1037/a0024691

Martin, C. L., Fabes, R. A., Hanish, L. D., \& Hollenstein, T. (2005). Social dynamics in the preschool. Developmental Review, 25(3-4), 299 - 327. doi:dx.doi.org/10.1016/j.dr.2005.10.001

Mashburn, A. J., Pianta, R. C., Hamre, B. K., Downer, J. T., Barbarin, O. A., Bryant, D., . . Howes, C. (2008). Measures of classroom quality in prekindergarten and children's development of academic, language, and social skills. Child Development, 79(3), 732-749. doi:10.1111/j.14678624.2008.01154.x

Maxwell, L. (1996). Multiple effects of home and day care crowding. Environment E Behavior, 28(4), 494-511. doi:10.1177/0013916596284004

McCandless, B. R., \& Marshall, H. R. (1957). A picture sociometric technique for preschool children and its relation to teacher judgments of friendship. Child Development, 28(2), 139-147. doi:10.2307/1125876

McMahon, S. D., \& Wernsman, J. (2009). The relation of classroom environment and school belonging to academic self-efficacy among urban fourth- and fifth-grade students. The Elementary School Journal, 109-, 267-281. doi:10.1086/592307

Meij, H., \& Schreuder, L. (2007). Welkom in de groep [Welcome to the group]

Amsterdam, the Netherlands: Uitgeverij SWP.

Merens, A., Hartgers, M., \& Van den Brakel, M. (2012). Emancipatiemonitor 2012 [Emancipation monitor 2012]. The Hague, The Netherlands: Sociaal en Cultureel Planbureau / Centraal Bureau voor de Statistiek.

Modry-Mandell, K. L., \& Gamble, W. C. (2007). Familiy emotional climate and sibling relationship quality: influences on behavioral problems and adaption in preschool-aged children. Journal Child Family Studies, 16, 61 - 73. doi:10.1007/ s10826-006-9068-3

Moore, G. T. (1986). Effects on the spatial definition of behavior settings on children's behavior: a quasi-experimental field study Journal of environmental psychology, 6, 205 - 231. doi:10.1016/ S0272-4944(86)80023-8

Mueller, E., \& Brenner, J. (1977). The origins of social skills and interaction among playgroup toddlers. Child Development, 48(3), 854-861. doi: 10.2307/1128334

Neckerman, H. J. (1996). The stability of social groups in childhood and adolescence: The role of the classroom social environment. Social Development, 5(2), 131-145. doi:10.1111/j.1467-9507.1996. tb00076.x

Newman, M. E. J. (2003). The structure and function of complex networks. SIAM Review, 45, 167256. doi:http:/ / epubs.siam.org/doi/pdf/10.1137/S003614450342480

Neal, J. W., Cappella, E., Wagner, C., \& Atkins, M. S. (2011). Seeing eye to eye: Predicting teacherstudent agreement on classroom social networks. Social Development, 20(2), 376-393. doi:10.1111/j.1467-9507.2010.00582.x

NICHD Early Child Care Research Network (1996). Characteristics of infant child care: factors contributing to positive caregiving. Early Childhood Research Quarterly, 11, 269 - 306. doi:10.1016/S0885-2006(96)90009-5 
NICHD Early Child Care Research Network (2000). Characteristics and quality of child care for toddlers and preschoolers. Applied Developmental Science 4(3), 116-135. doi:dx.doi. org / 10.1207/S1532480XADS0403_2

NICHD Early Child Care Research Network (2001). Child care and children's peer interaction at 24 and 36 months: The NICHD Study of Early Child Care. Child Development, 72(5), 1478 1500. doi:10.1111/1467-8624.00361

Organisation for Economic Co-operation and Development (OECD) (2011). Doing better for families, The Netherlands. Retrieved from http:/ / www.oecd.org/netherlands/47701063.pdf

Organisation for Economic Co-operation and Development (OECD) (2014). PF3.2: Enrolment in childcare and preschools. Retrieved from http://www.oecd.org/els/soc/PF3_2_Enrolment_in_childcare_and_preschools.pdf

Pennings, T., \& Meij, H. (2012). Stabiliteitsmeter, rekenhulp [Stability measurement, calculation tool] Utrecht, the Netherlands: Nederlands Jeugd Instituut.

Pianta, R. C., La Paro, K. M., Payne, C., Cox, M. J., \& Bradley, R. (2002). The relation of kindergarten classroom environment to teacher, family and school characteristics and child outcomes. The Elementary School Journal, 102(3), 225 - 238. doi:10.2307/1002217

Poole, M. S., \& Hollingshead, A. B. (Eds.). (2005). Theories of small groups: Interdisciplinary perspectives. London, England: Sage.

Rabaglietti, E., Vacirca, M., Zucchetti, G., \& Ciairano, S. (2012). Similarity, cohesion, and friendship networks among boys and girls: a one-year follow-up study among Italian children. Current Psychology, 31-, 246-262. doi:10.1007/s12144-012-9145-2

Ramani, G. B. (2012). Influence of a playful, child-directed context on preschool children's peer cooperation. Merrill-Palmer Quarterly, 58(2), 159-190. doi:10.1353/mpq.2012.0011

Ramsey, P. R. (1995). Changing social dynamics in early childhood classrooms. Child Development, 66(3), 764 - 773. doi:10.2307/1131949

Rayna, S. (2001). The very beginnings of togetherness in shared play among young children. International Journal of Early Years Education, 9(2), 109 - 115. doi:10.1080/713670685

Reijntjes, J. (2000). Kinderen in de groep, groepsgericht werken in kindercentra [Children in the group, a group oriented approach in child care]. Utrecht, the Netherlands: Nederlands Instituut voor Zorg en Welzijn.

Rimm-Kaufman, S., La Paro, K. M., Downer, J., \& Pianta, R. (2005). The contribution of classroom setting and quality of instruction to children's behavior in kindergarten classrooms. The Elementary School Journal, 105(4), 377 - 394. doi:10.1086/429948

Rivers, S., Brackett, M., Reyes, M., Elbertson, N., \& Salovey, P. (2013). Improving the social and emotional climate of classrooms: A clustered randomized controlled trial testing the RULER approach. Prevention Science, 14(1), 77-87. doi:10.1007/s11121-012-0305-2

Ross, H. S. (1982). Establishment of social games among toddlers. Developmental Psychology, 18-, 509-518. doi:10.1037/0012-1649.18.4.509

Ross, H. S., \& Lollis, S. P. (1989). A social relations analysis of toddler-peer relationships. Child Development, 60 (5), 1082-1091. doi:10.2307/1130782

Roorbach Jamison, K., Cabell, S. Q., LoCasale-Crouch, J., Hamre, B. K., \& Pianta, R. C. (2014). CLASS-Infant: An observational measure for assessing teacher-infant interactions in center based child care. Early Education and Development, 25, 553-572. doi:10.1080/10409289.2013 .822239 
Rubin, K. H., Bukowski, W., \& Parker, J. (2006). Peer interactions, relationships, and groups. In N. Eisenberg, W. Damon \& R. Lerner (Eds.), Handbook of child psychology: Social, emotional, and personality development (6th ed., Vol. 3, pp. 571-645). New York, NY: Wiley.

Sanefuji, W., Ohgami, H., \& Hashiya, K. (2006). Preference for peers in infancy. Infant Behavior and Development 29, 584-593. doi:10.1016/j.infbeh.2006.07.007

Schaefer, D. R., Light, J. M., Fabes, R. A., Hanish, L. D., \& Martin, C. L. (2010). Fundamental principles of network formation among preschool children. Social Networks, 32(1), 61-71. doi:10.1016/j.socnet.2009.04.003

Selby, J. M., \& Bradley, B. S. (2003). Infants in groups: A paradigm for the study of early social experience. Human Development, 46 (4), 197-221. doi:10.1159/000070370

Sheffield Morris, A. (2007). The role of the family context in the development of emotion regulation. Social Development, 16(2), 361 - 388. doi: 10.1111/j.1467-9507.2007.00389.x

Singer, E., \& de Haan, D. (2007). Social life of young children: Co-construction of shared meanings and togetherness, humor, and conflicts in child care centers. In O. N. Saracho \& B. Spodek (Eds.), Contemporary perspectives on social learning in early childhood education (pp. 279-302). Charlotte, NC: IAP.

Singer, E., \& Hännikäinen, M. (2002). The teacher's role in territorial conflicts of 2- to 3-year-old children. Journal of Research in Childhood Education, 17(1), 5-18. doi:10.1080/02568540209594994

Singer, E., Van Hoogdalem, A.-G., De Haan, D., \& Bekkema, N. (2011). Day care experiences and the development of conflict strategies in young children. Early Child Development and Care, 182(12), 1661-1672. doi:10.1080/03004430.2011.640753

Slomkowski, C., \& Dunn, J. (1996). Young children's understanding of other people's beliefs and feelings and their connected communications with friends. Developmental Psychology, 32(3), 442 - 447. doi:10.1037/0012-1649.32.3.442

Steiger, J. H. (1980). Tests for comparing elements of a correlation matrix. Psychological Bulletin, 87(2), 245-251. Retrieved from http://ww.w.statpower.net/Steiger\%20Biblio/Steiger80. pdf

Strayer, F. F., \& Santos, A. J. (1996). Affiliative structures in preschool peer groups. Social Development, 5(2), 117-130. doi:10.1111/j.1467-9507.1996.tb00075.x

Tierney Williams, S., Mastergeorge, A. M., \& Ontai, L. L. (2010). Caregiver involvement in infant peer interactions: scaffolding in a social context. Early Childhood Research Quarterly, 25, 251266. doi:10.1016/j.ecresq.2009.11.004

Tobin, K., Ritchie, S. M., Oakley, J. L., Mergard, V., \& Hudson, P. (2013). Relationships between emotional climate and the fluency of classroom interactions. Learning Environments Research, 16(1), 71-89. doi:10.1007/s10984-013-9125-y

Urberg, K. A., \& Kaplan, M. G. (1986). Effects of classroom age composition on the play and social behaviors of preschool children. Journal of Applied Developmental Psychology, 7, 403-415. doi:10.1016/0193-3973(86)90009-2

Vandell, D. L., \& Mueller, E. (1980). Peer play and friendship during the first two years. In H. Foot, T. Chapman \& J. Smith (Eds.), Friendship and social relations in children. (pp. 181-208). London, England: Wiley.

Vandell, D. L., Wilson, K. S., \& Buchanan, N. R. (1980). Peer interaction in the first year of life: An examination of its structure, content, and sensitivity to toys. Child Development, 51(2), 481-488. doi:10.2307/1129282 
Vandell, D. L., \& Wolfe, B. (2000). Child care quality: does it matter and does it need to be improved? (Special Report no.78). Institute for Research on Poverty. Retrieved from http:/ / www.irp. wisc.edu/publications/sr/pdfs/sr78.pdf

Vaugh, B. E., \& Santos, A. J. (2006). Structural descriptions of social transactions among young children: Affiliation and dominance in preschool groups. In K. H. Rubin, W. Bukowski \& B. Laursen (Eds.), Handbook of peer interactions, relationships, and groups (pp. 195-216). New Work: The Guilford Press.

Vaughn, B.E., Santos, A.J., Monteiro, L., Shin, N., Daniel, J.R., \& Krzysik, L. (2016). Social engagement and adaptive functioning during early childhood: Identifying and distinguishing among subgroups differing with regard to sociale engagement. Developmental Psychology, 52(9), 1422-1434. doi.org/10.1037/dev0000142

Veen, A., Roeleveldt, J., \& Heurter, A. (2010). Onderwijs en opvang voor jonge kinderen [Education and care for young children] Den Haag, the Netherlands: Onderwijsraad.

Verba, M. (1994). The beginnings of collaboration in peer interaction. Human Development, 37, 125139. doi: $10.1159 / 000278249$

Wasserman, S., \& Faust, K. (1994). Social network analysis, methods and applications. Cambridge, England: Cambridge University Press.

Watamura, S. E., Donzella, B., Alwin, J., \& Gunnar, M. R. (2003). Morning-to-afternoon increases in cortisol concentrations for infants and toddlers at child care: age differences and behavioral correlates. Child Development, 74, 1006-1020. doi:10.2307/3696199

Whaley, K. L., \& Rubenstein, T. S. (1994). How toddlers 'do' friendship: A descriptive analysis of naturally occurring friendships in a group child care setting. Journal of Social and Personal Relationships, 11, 383-400. doi:10.1177/0265407594113005

Wishard, A. G., Shivers, E. M., Howes, C., \& Ritchie, S. (2003). Child care program and teacher practices: associations with quality and children's experiences. Early Childhood Research Quarterly, 18(1), 65-103. doi:http:/ / dx.doi.org/10.1016/S0885-2006(03)00007-3

Yurtsever, G., \& de Rivera, J. (2010). Measuring the emotional climate of an organization. Perceptual and Motor Skills, 110, 501-516. doi:10.2466/ pms.110.2.501-516

Zmyj, N., Daum, M. M., Prinz, W., \& Aschersleben, G. (2007). Infants, older children or adults - Which age group is preferably perceived in infancy? Paper presented at the Society for Research in Child Development, Boston 

Dankwoord 

Hier is het dan: het dankwoord, het meest persoonlijke en misschien daarom ook wel het meest gelezen onderdeel van een proefschrift.

Toen ik startte met het onderzoek naar groepsfunctioneren had ik geen idee waaraan ik begon. Misschien maar goed ook. Het bleek namelijk een enorme klus te zijn die niet alleen plezier en bevrediging, maar ook frustratie opleverde en veel tijd en volharding heeft gevergd. Gelukkig heb ik bij het onderzoek veel hulp en steun gehad. Hiervoor wil ik in het bijzonder (en in willekeurige volgorde) de volgende personen bedanken:

Pedagogisch medewerkers in de kinderopvang: mijn contact met jullie vormt al meer dan 25 jaar de motor voor mijn motivatie, enthousiasme en inspiratie in mijn werk. We vinden elkaar in onze fascinatie voor (jonge) kinderen en hun ontwikkeling en in ons streven om zo goed mogelijk op hun behoeftes in te spelen. Mede dankzij jullie werk ik nog steeds met veel plezier in deze sector!

Marianne: Het is onmogelijk om jou als promotor voldoende te bedanken. Toen ik startte met het onderzoek was 'groepsfunctioneren' een vaag begrip dat alle kanten op waaierde. Het leek ons, mij en mijn collega's in de kinderopvang, relevant, maar wat we er precies mee bedoelden en hoe we het zouden kunnen beïnvloeden was vaag. Met behulp van je heldere analyses, vindingrijke suggesties en kritische vragen kreeg dit ongrijpbare begrip handen en voeten en is dit proefschrift een 'verhaal' met een kop en staart. Minstens zo belangrijk was je enthousiasme en betrokkenheid, zowel wat het onderzoek als mijzelf betreft. Eindeloos veel tijd moet je hebben besteed aan het doorlezen van de zoveelste versie en het zorgvuldig formuleren van je op- en aanmerkingen. Niet te spreken over de urenlange discussies op de achtste verdieping van het Spinozagebouw, waarbij trouwens ook veel gelachen werd. Zonder overdrijven kan ik stellen dat het tot een goed einde brengen van dit onderzoek zonder jou niet gelukt zou zijn.

Bill, ook jij hebt als copromotor nadrukkelijk je stempel op dit proefschrift gezet. Je bent niet alleen een kei op het gebied van statistiek en sociometrisch onderzoek, maar stelde ook fundamentele vragen en suggereerde nieuwe invalshoeken, vaak op cruciale momenten in het denkproces. Ik had al snel in de gaten dat ik veel van je kon leren, niet in het minst omdat je ingewikkelde kwesties duidelijk kunt uitleggen. Ik ben onder de indruk van je vriendelijkheid, je hulpvaardigheid en je eindeloze geduld.

Jolente Ruitenburg en Imke van Brink, jullie hebben als studentassistenten de videofragmenten van de groepen kinderen gescoord, een monnikenwerk. Dit deden jullie zorgvuldig, betrouwbaar en met een scherp oog voor gedrag van kinderen. Ik bewaar goede herinneringen aan de urenlange trainingssessies. Het was een waar genoegen om met jullie samen te werken. Dit geldt ook voor Charlotte Fokkinga 
en Brenda Servaas die de fragmenten van de pedagogisch medewerkers gescoord hebben. Dankjewel Katrien Helmerhorst, dat ik de door jou getrainde studentassistenten voor deze klus mocht 'lenen'.

KION en KINDwijzer: het is bijzonder dat jullie mij de gelegenheid hebben gegeven het groepsfunctioneren in kinderdagverblijven systematisch onder de loep te nemen en hiervoor tijd beschikbaar hebben gesteld. Ik hoop van harte dat de resultaten van dit onderzoek bijdragen aan het uitbuiten van de groepssituatie die kinderopvang per definitie met zich meebrengt.

Het Behavioural Science Institute (BSI) van de Faculteit der Sociale Wetenschappen: bij jullie kon ik als buitenpromovendus aan de slag. Dit betekende niet alleen dat ik fantastische begeleiding kreeg bij het onderzoek, maar ook dat ik gebruik kon maken van onontbeerlijke faciliteiten van de RU zoals wetenschappelijke zoeksystemen en abonnementen op ejournals. Mijn verbinding met jullie was gewaarborgd via mijn blauwe BSI-mok: als ik thuis aan het onderzoek werkte, dronk ik steevast hieruit mijn koffie.

(Ex-)collega's van binnen en buiten KION en familie: jullie bleven belangstelling tonen voor de voortgang van het onderzoek, ook al bleek snel dat dit een project was waarvoor ik een lange adem nodig had. Hoe vaak ik niet gedacht en gezegd heb dat ik "bijna klaar" was. Ik ben bang dat sommigen niet meer geloofden dat het ooit afkwam. Gelukkig is dit uiteindelijk toch gelukt!

Yolanda de Ridder: tien jaar geleden was je mijn leidinggevende en als zodanig zorgde je ervoor dat KION mij opdracht gaf tot het onderzoeken van groepsfunctioneren. Een win-win situatie waarin de kinderopvang meer te weten zou komen over het functioneren van groepen in de kinderopvang, KION zich zou kunnen profileren als kennisorganisatie en ik mezelf verder zou kunnen ontwikkelen. Wat jammer dat je dit moment niet meer hebt kunnen meemaken! Je zou zo trots geweest zijn, je had er alle vertrouwen in dat ik dit tot een goed einde zou brengen.

Ouders van kinderen, pedagogisch medewerkers en directies van kinderdagverblijfgroepen die deelnamen aan het onderzoek: ik vond het geweldig dat jullie mee wilden werken en dat ik gedurende twee dagen in jullie groep mocht komen kijken en filmen. Ik ben onder de indruk van jullie openheid. Met velen heb ik naar aanleiding van mijn bezoek waardevolle gesprekken gevoerd over het groepsfunctioneren en de kwaliteit van het pedagogisch aanbod op jullie groep. Bovenal, zonder jullie medewerking was er geen onderzoek geweest.

Igi, Ivo, Iris en Merit, mijn onmisbare thuisfront: jullie hebben mij zien ploeteren, jaar in jaar uit. Ik ben blij dat jullie mij de ruimte hebben gegeven om zoveel tijd aan dit onderzoek te besteden!

Allemaal hartelijk bedankt! 
Curriculum Vitae 

Mireille Aarts werd geboren op 10 maart 1961 in Nijmegen. In 1986 behaalde zij haar doctoraaldiploma Ontwikkelingspsychologie aan de Katholieke Universiteit Nijmegen. Al tijdens haar studie ging haar belangstelling uit naar de vroegkinderlijke ontwikkeling. Haar scriptieonderzoek betrof de kwaliteit van exploratie bij eenjarigen in relatie tot hechtingskwaliteit en responsiviteit van de opvoeder. Dit onderzoek werd begeleid door Marianne Riksen-Walraven.

$\mathrm{Na}$ als vrijwilliger gewerkt te hebben bij de Vereniging Kindercentra Nijmegen (VKN) waar zij trainingen verzorgde voor leidsters van peuterspeelzalen, kwam zij in 1990 als locatiemanager in dienst bij Stikon, een Nijmeegse organisatie voor kinderopvang. Vijf jaar later werd Mireille 'Mentor Groepshulpen' bij KION (een fusieorganisatie waarin Stikon opging). Ze zorgde ervoor dat de tot dan toe niet bestaande functie groepshulp werd ontwikkeld en ingevoerd binnen KION en dat de groepshulpen toegerust werden tot de uitvoering van hun taken. Van 1997 tot 2002 hield Mireille zich als Staffunctionaris Kwaliteit bezig met de opzet, implementatie en beheer van een kwaliteitssysteem bij KION. Hiernaast nam zij als inhoudsdeskundige deel aan kwaliteitsaudits die de KEMA uitvoerde bij kinderopvangorganisaties. Sinds 2002 heeft ze als Beleidsmedewerker Pedagogiek tot taak het pedagogisch beleid en de pedagogische aansturing binnen KION te ontwikkelen en te borgen. De laatste jaren houdt ze zich ook bezig met Voor- en Vroegschoolse Educatie (VVE). In dit kader onderhoudt ze contacten met het onderwijs in Nijmegen en de gemeente, adviseert het management van KION en ontwikkelt en geeft trainingen.

Naast haar werk als beleidsmedewerker voerde ze in opdracht van KION en KINDwijzer (landelijk samenwerkingsverband van organisaties voor kinderopvang) als buitenpromovendus aan de Radboud Universiteit onderzoek uit naar groepsfunctioneren op kinderdagverblijven.

Mireille was van 2003 tot 2008 lid van het Landelijk Pedagogenplatform Kindercentra dat een bijdrage levert aan visieontwikkeling, discussie en kwaliteitsverbetering in kindercentra in Nederland. Eén van de initiatieven van het Pedagogenplatform is het 'Pedagogisch kader kindercentra'. Mireille is auteur van publicaties van het platform over babyopvang, open deuren beleid en de relatie wetenschappelijk onderzoek en kinderopvang. In 2013 was ze betrokken bij de totstandkoming van de 'Bouwstenen voor een Pedagogisch Kwaliteitskader Kinderopvang'. 



\section{Sponsors}

Dit onderzoek is mede mogelijk gemaakt door KION en KINDwijzer. 



\section{KION: continu werken aan kwaliteit}

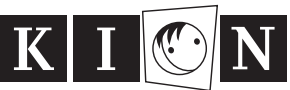

Het is voor KION een groot voorrecht om het promotieonderzoek van Mireille Aarts, beleidsmedewerker bij KION, te hebben mogen ondersteunen. Een onderzoek dat verschillen in het groepsfunctioneren systematisch onderzoekt en dat daarmee belangrijke inzichten oplevert. Inzichten die rechtstreeks verband houden met de manier waarop wij de opvang van jonge kinderen in kunnen richten in de circa 300 groepen die KION heeft.

Gedurende de bijna 25 jarige geschiedenis van KION zijn pedagogische kwaliteit, focus op de ontwikkeling van kinderen en vernieuwing de rode draad voor de organisatie geweest. KION heeft bewust geïnvesteerd in een systeem van continue kwaliteitsverbetering dat gebaseerd is op de vier basisdoelen zoals die door Riksen-Walraven voor de kinderopvang zijn geformuleerd.

Het promotieonderzoek van Mireille Aarts brengt KION als ambitieuze organisatie een stap verder in de opvang van wekelijks ruim 7.500 kinderen van nul tot twaalf jaar in Nijmegen en omgeving. We zien het bieden van een vertrouwde en uitdagende omgeving waarin kinderen zich kunnen ontplooien evenzeer als opdracht als het bieden van kansen aan medewerkers.

In haar kindbeeld beschrijft KION het kind als een ontdekkingsreiziger die voortdurend nieuwe ervaringen opdoet. Soms alleen, vaak samen met anderen. Het promotieonderzoek van Mireille Aarts geeft ons inspiratie en nieuw elan om als organisatie en branche hierin nog verder te professionaliseren.

Hiervoor danken we Mireille Aarts van harte.
A.E. Brunekreeft MPM
Bestuurder KION 



\section{KINDwijzer: Nu Goed Voor Later}

KINDwijzer heeft het promotieonderzoek van Mireille Aarts met veel enthousiasme en buitengewone interesse ondersteund. KINDwijzer is een landelijk netwerk van toonaangevende maatschappelijke kinderopvangorganisaties. KINDwijzerorganisaties stellen de optimale ontwikkeling van het kind en de pedagogische kwaliteit centraal in hun handelen. Daarbij zijn ze vooruitstrevend en beschikken ze over veel pedagogische kwaliteit, niet alleen via de pedagogisch medewerkers maar ook via pedagogische specialisten. Alles om te zorgen voor een complete en kwalitatief hoogwaardige dienstverlening.

Kinderopvang is veel meer dan 'opvang'. Het is een mini-samenleving, waar kinderen al jong leren dat niet iedereen hetzelfde is, dat je conflicten positief kunt oplossen, dat je in een groep met elkaar moet overleggen en dat je samen verantwoordelijk bent voor de groep. Kinderen 'oefenen' zo hun sociale en democratische vaardigheden op een ongedwongen manier. Jong geleerd is oud gedaan! Vanuit die gedachte hebben de KINDwijzer-organisaties ook met veel enthousiasme gewerkt aan het project Samen Goed Voor Later met als doel het maatschappelijk nut van de kinderopvang zichtbaar te maken. Het is uitgegroeid tot een pedagogische werkwijze voor 'burgerschapsvorming' waar 'de groep' een belangrijk aspect van is.

Groepsfunctioneren wordt door de KINDwijzer-organisaties dan ook als belangrijk onderdeel van de kwaliteit van kinderopvang gezien en de resultaten van het promotieonderzoek zijn daardoor belangrijk om die kwaliteit te bevorderen. Het geeft ons als kinderopvangorganisaties ruime inspiratie om onze kennis over pedagogische kwaliteit verder te vergroten en de deskundigheid van onze medewerkers te bevorderen. Daar zijn wij Mireille Aarts zeer erkentelijk voor.

\section{A.E. Brunekreeft MPM \\ Voorzitter KINDwijzer}

KINDwijzer wordt gevormd door: Impuls, KindeRdam, Kibeo, KION, Korein, Ludens, Sinne, SKA, SKBNM, Stichting Kinderopvang Den Helder, Stichting Kinderopvang Hoorn, Un1ek 